\title{
Avaliação dos limiares de deteç̧ão dos gostos doce, salgado, ácido e amargo em pré-escolares e escolares
}

\author{
Hellen Daniela de Sousa Coelho
}

Tese apresentada ao Programa de PósGraduação em Saúde Pública da Faculdade de Saúde Pública da Universidade de São Paulo para obtenção do título de Doutor em Saúde Pública.

Área de Concentração: Nutrição Orientador: Prof. Dr. Maria Elisabeth Machado Pinto e Silva

\section{São Paulo}

2005

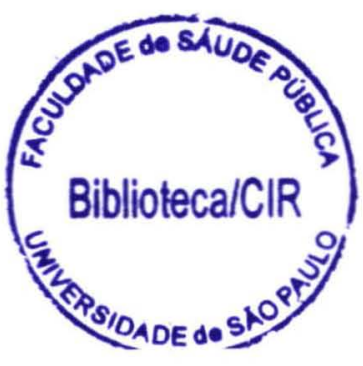


4636112005 doc

Autorizo exclusivamente para fins acadêmicos e científicos, a reprodução total ou parcial desta tese, por processos fotocopiadores. Ao usá-lo, cite a fonte. Assinatura:

Data: 
"Enquanto há porquês, há paixão de saber. Há prazer de estar acordado, de fazer parte da vida. Há desejo. E o desejo é como um menino persistente; não há respostas que o satisfaça. As crianças em geral são sábias. Continuam sempre a perguntar."

(Maria Laurinda R. de Souza, 2003) 


\section{Agradecimentos}

À Prof ${ }^{\mathrm{a}}$. $\mathrm{Dr}^{\mathrm{a}} \mathrm{M}$. Elisabeth M. Pinto e Silva, orientadora e amiga pelo incentivo permanente na realização deste trabalho acadêmico. E que me mostra o caminho a ser percorrido na área acadêmica desde de 1996.

À Profa . Assoc. Maria Aparecida P. da Silva e Helena Maria A. B. Cardello (FEA/UNICAMP) pelo auxílio e aprimoramento metodológico desta pesquisa.

Ao Prof. Dr. Wolney Conde Lisboa e Prof. Dr. Julio César Rodrigues Pereira (FSP/USP), ao Dr. Paulo Schiavom Duarte e ao Dr. Isac de Castro (FMUSP) pela paciência e apoio nas discussões estatísticas.

À Profa. Dra. Maria Tereza Sadek (FFLCH/USP) por todo incentivo à minha inserção no meio acadêmico.

À amiga Isa Maria Gouveia Jorge pelo auxilio na minha formação profissional.

Ao meu avô Antonio F. Sousa, aos meus pais Daniel P. Coelho e R. Celeste de S. Coelho e irmãos Denis A. de S. Coelho e Davi Guilherme de S. Coelho por todo carinho e paciência.

Ao Paulo, pelo equilíbrio emocional imprescindível para a conclusão deste projeto.

À toda equipe, crianças e seus respectivos pais das Creches da COSEAS/USP e Escola de Aplicação FE/USP por toda colaboração e paciência.

A todos amigos e pessoas que me ajudaram direta ou indiretamente. 


\section{RESUMO}

Avaliação dos Limiares de Deteç̧ão dos Gostos doce, salgado, ácido e amargo em Pré-escolares e Escolares. Coelho HDS. São Paulo; 2005.

[Tese de Doutorado - Faculdade de Saúde Pública da USP].

Introdução: O conhecimento dos fatores que interferem na capacidade das crianças detectarem os gostos básicos é pequeno, apesar da existência de vários testes de psicofísica padronizados. Objetivos: Avaliou-se o limiar de detecção dos gostos: doce, salgado, ácido e amargo em crianças, associando-o com estado nutricional, sexo e idade. Método: Foram estudadas 376 crianças, das Pré-escolas COSEAS/USP e da Escola de Aplicação FE/USP. Classificou-se o estado nutricional pelo indice de massa corpórea (IMC). As crianças foram motivadas por uma dinâmica. Utilizou-se teste de estímulo constante e verificou-se a concordância das respostas das crianças pelo método kappa. As associaçōes dos limiares de deteç̧ão e as demais variáveis foram analisadas por regressões logísticas no ponto estimado como o de maior poder discriminatório pela curva ROC (A). Resultados e Discussão: Houve concordância entre as repostas das crianças nos testes sensoriais. As variáveis que interferiram na detecção das soluções foram; a idade para o doce $(A=0,55)$, ácido $(A=0,73)$ e amargo $(A=0,62)$; ○ sexo $(A=0,58)$ e $\circ$ estado nutricional $(A=0,58)$ para $\circ$ ácido. Houve um maior risco de detectar a solução ácida $(0,16 \mathrm{mmol} / \mathrm{L})$ pelos escolares $(O R=5.9)$ e pelas meninas $(O R=1,8)$. E para $\circ$ amargo, notou-se que $o$ aumento da idade foi um fator de proteção $(0,26 \mathrm{mmol} / \mathrm{L})(O R=0,439)$. Conclusão: Evidenciou-se que as meninas foram mais sensiveis ao gosto ácido. Os escolares apresentaram uma maior probabilidade de detecção do gosto ácido e doce, o inverso ocorreu para o gosto amargo. A detecção do salgado não foi influenciada pelas variáveis do presente estudo.

Descritores: Criança, limiar, gosto, doce, salgado, ácido, amargo. 


\section{ABSTRACT \\ Evaluation of Thresholds for Detection of sweet, salty, sour and bitter}

Tastes in Preschool and Schoolchildren. Coelho HDS. São Paulo;

2005. Coelho HDS. São Paulo; 2005. [Tese de Doutorado - Faculdade de

Saúde Pública da USP].

Introduction: Despite the existence of some standardized psychophysical tests, not much is known about the factors that affect children's capacity to detect basic tastes. Objectives: The threshold of taste detection of sweet, salty, sour and bitter tastes in children was evaluated, associating it with nutritional condition, sex and age. Method: 376 children from COSEASIUSP preschool and from the elementary school of Escola de Aplicação/FE/USP were studied and their nutritional condition was classified according to the body mass index (BMI). The children were motivated by a group dynamics. Test of constant stimulation was carried out and children's responses were verified to be alongside the Kappa method. The association of the detection thresholds and further variables had been analyzed by logistic regression at the estimated point as being of greater discriminant power according to the resulted ROC curve (A). Results and Discussion: There was consensus among the children's responses to sensorial tests. The variables that had affected the detection of the solutions had been: age for the sweet $(A=0.55)$, sour $(A=0.73)$ and bitter $(A=0.62)$ tastes; sex $(A=0.58)$ and nutritional condition $(A=0.58)$ for the sour one. There was an increasing risk of detecting the sour solution $(0.16 \mathrm{mmol} / \mathrm{L})$ by the schoolchildren $(O R=5.9)$ and by the girls $(O R=1.8)$. And as for the bitter taste, it had been noticed that ageing was a protective factor $(0.26 \mathrm{mmol} / \mathrm{L})$ $(O R=0.439)$. Conclusion: It was proven that girls were more sensitive to the sour taste. Schoolchildren presented a bigger probability of detection of sour and sweet tastes while the opposite trend took place concerning the bitter taste. The detection of the salty taste had not been influenced by the variables of the present study.

Describers: Child; threshold; taste; sweet, salty, sour, bitter, taste. 


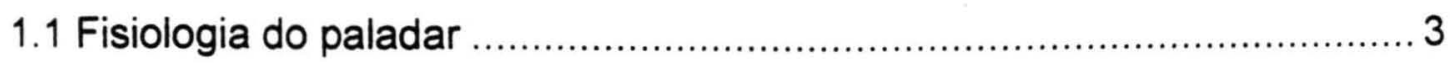

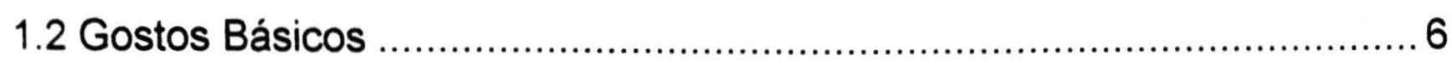

1.3 Regiões de deteç̧ão dos gostos básicos ............................................

1.4 Testes Sensoriais- Limiar de Detecção dos gostos .................................. 8

1.4.1 Estudos dos limiares de detecção dos gostos básicos........................11

1.5 Estado Nutricional da criança .......................................................... 17

1.5.1 Diagnóstico do estado nutricional na criança.................................... 19

1.5.2 Índice de massa corporal............................................................... 20

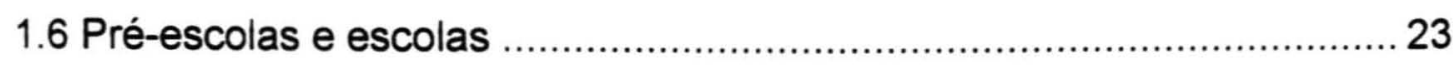

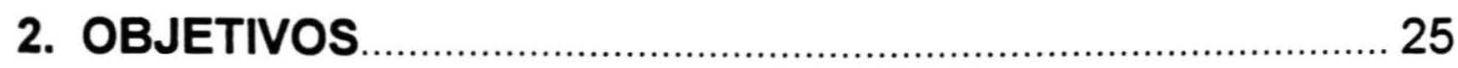

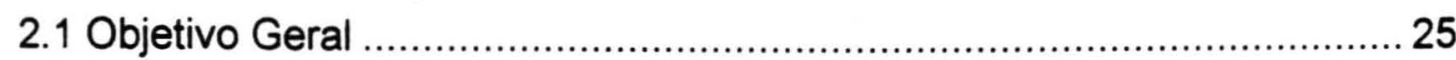

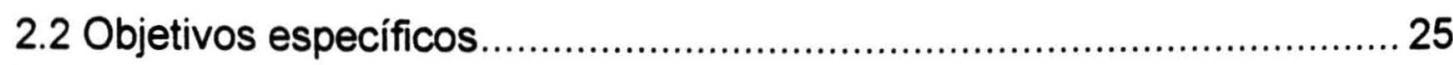

3. MATERIAIS E MÉTODOS .................................................. 27

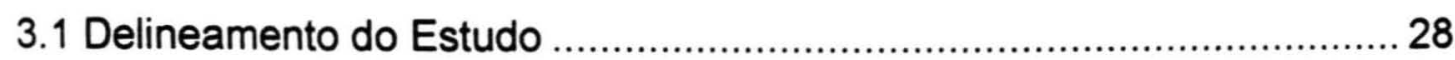

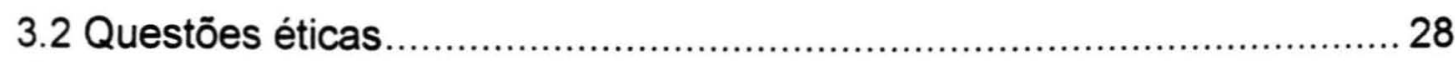

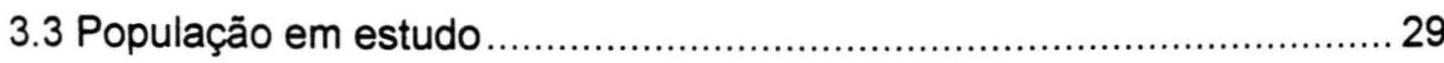

3.4 Critérios de seleção e exclusão das crianças ......................................... 29

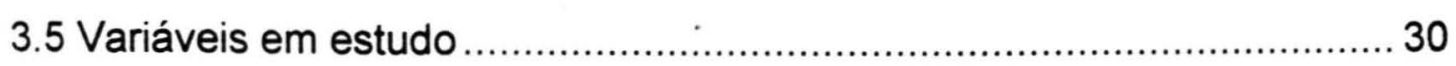

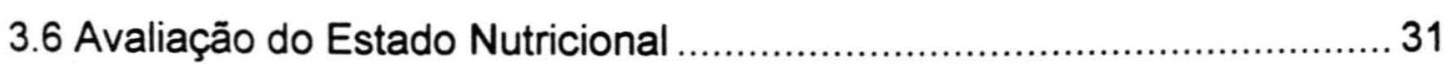

3.6.1 Treinamento e Padronização de Medidas Antropométricas ................. 31

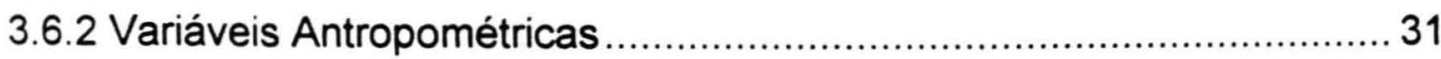

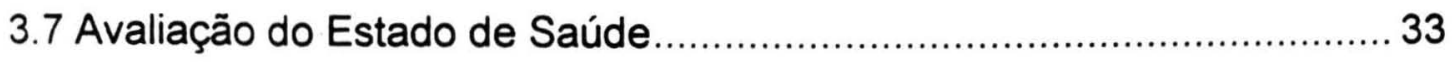

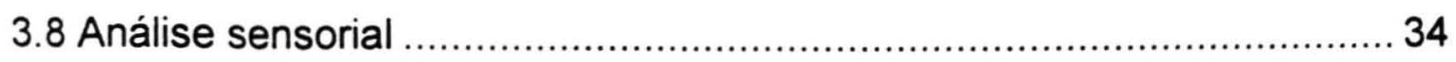

3.8.1 Familiarização dos pré-escolares com os Testes Sensoriais ............... 34 
3.8.2 Familiarização dos escolares com os Testes Sensoriais .................... 35

3.8.3 Local de realização dos testes sensoriais......................................... 36

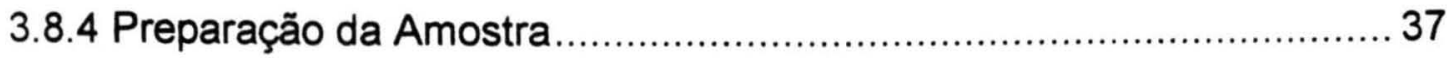

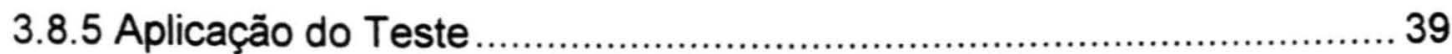

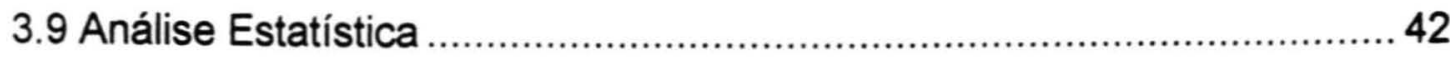

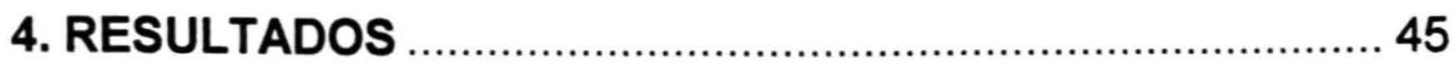

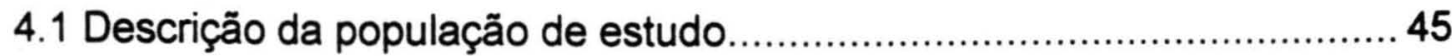

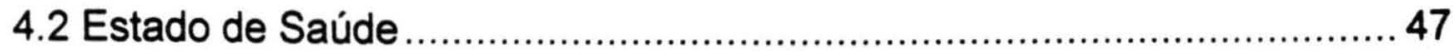

4.3 Caracterização do Estado nutricional das crianças ................................48

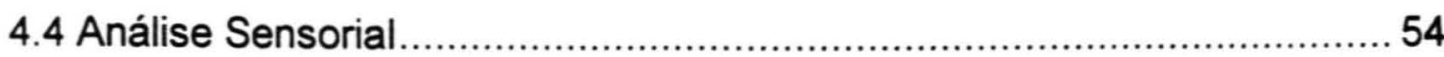

4.4.1 Avaliação da reprodutibilidade do teste .............................................5 54

4.4.2 Concentrações das soluções dos gostos básicos................................ 55

4.4.3 Análise da detecção dos gostos básicos no início das escalas .......... 57

4.5 Análise dos limiares de detecção dos gostos básicos nas escalas........ 58

4.6 Curvas ROC

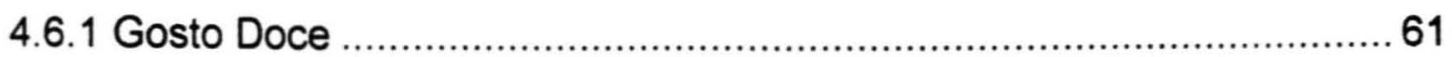

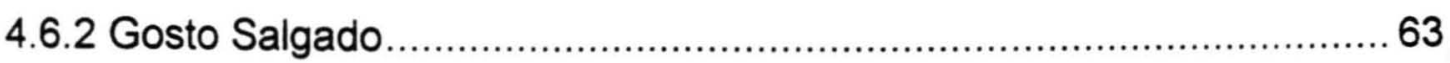

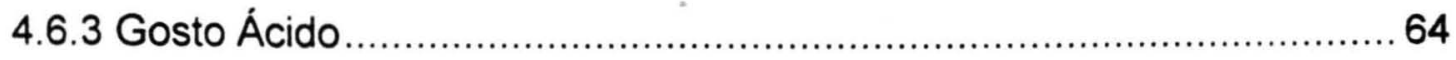

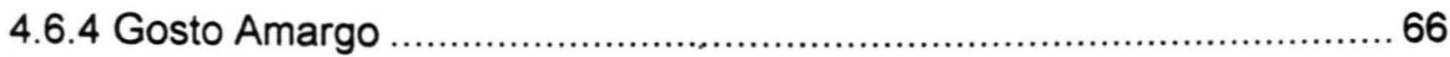

4.7 Análise da detecção dos gostos básicos ............................................68

4.8 Análise de regressão logística dos limiares de detecção .........................70

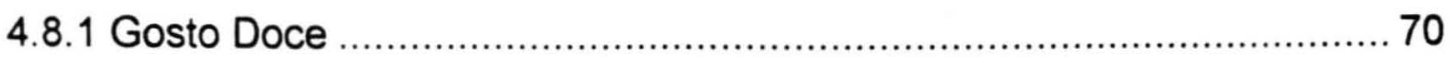

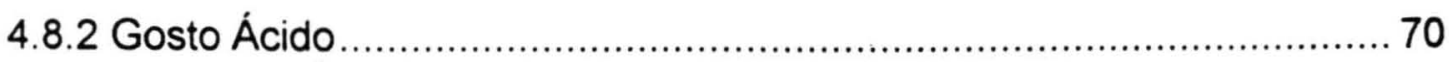

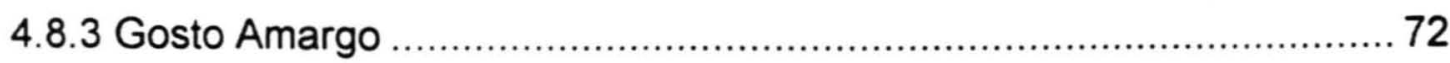

5. DISCUSSÃO 


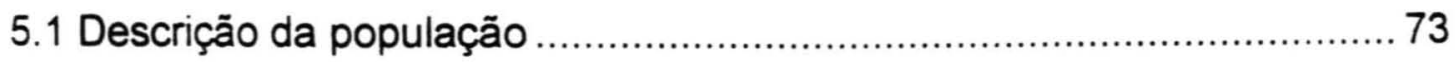

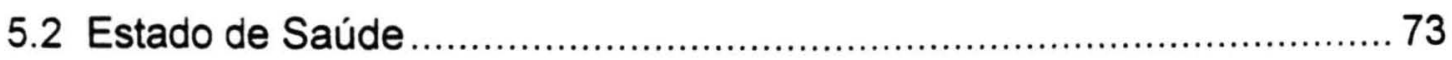

5.3 Caracterização do Estado Nutricional.................................................... 74

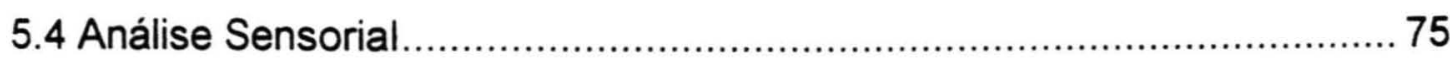

5.4.1 Avaliação da Reprodutibilidade do teste........................................... 77

5.4.2 Avaliação das Concentrações das soluções ...................................... 80

5.4.3 Análise dos limiares de deteç̧ão dos gostos básicos ………............ 82

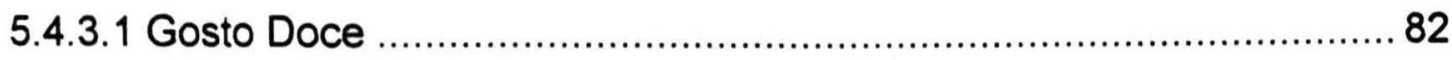

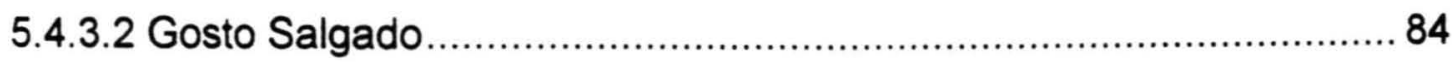

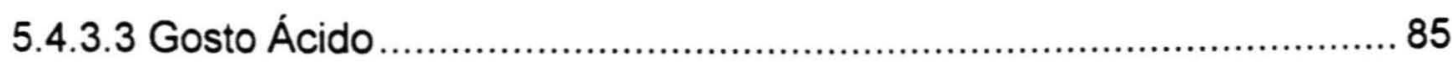

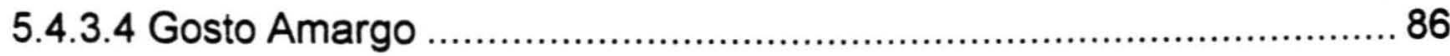

5.4.4.4 Aspectos gerais da sensibilidade aos gostos.................................. 88

6. CONCLUSÃO E CONSIDERAÇÕES FINAIS ....................... 92

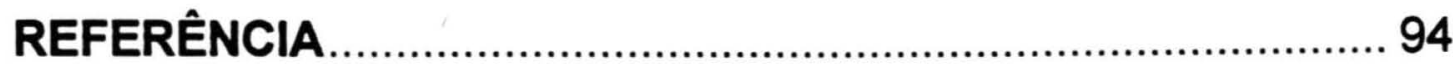

ANEXOS

Anexo 1 - Parecer do Cômite de Ética da FSP/USP ....................................A1

Anexo 2 - Termo de Consentimento esclarecido - Instituiçães.......................A2

Anexo 3 - Termo de Consentimento esclarecido - Responsável pelas crianças.A3

Anexo 4 - Formulário de Saúde e antropometria - Pré-escola/Creche..............A4

Anexo 5 - Formulário de antropometria e análise sensorial - Escola............A5

Anexo 6 - Formulário de Saúde - Escola ...................................................

Anexo 7 - Formulário de análise sensorial - Pré-escola/Creche......................A7 


\section{INTRODUÇÃO}

O paladar é essencial no desenvolvimento das preferências alimentares e conseqüentemente na composição da dieta (Drewnowski 1997, Lawless 1985). Afirma-se que diferenças individuais na capacidade de sentir a intensidade do gosto, em parte geneticamente determinadas, afetam as preferências alimentares e o consumo (Essick e col. 2003, Bartoshuk 2000). As sensações gustativas podem influenciar o consumo alimentar em face das necessidades metabólicas do organismo (Schiffman 1983).

Segundo Davidson e col. (1998) alguns aspectos estão relacionados com a variação na ingestão de alimentos, como: hipogeusias (sensibilidade diminuída do paladar), disgeusias (sensibilidade alterada do paladar) e ageusias (ausência de paladar).

A percepção alterada do sabor e/ou do olfato segundo diversos autores pode ser conseqüência de vários fatores como:

- Quadro clínico de desnutrição (Ohara e col. 1995), diabetes, doença de Cushing, hipertensão arterial, obesidade (Hess 1997, Obrebowski e col. 2000), adrenalectozemia (Phillips e Fuchs, 1989), câncer (Koops 1983, Hess 1997, Obrebowski e col. 2000, Kamath e col. 1983, Ovesen e col. 1991, Mulder e col. 1983, Gallagher e Tweedle 1983). 
- Consumo de alguns medicamentos, tratamentos (radioterapia) (Hess 1997), algumas intervenções cirúrgicas (Hetherington 1998),

- Processo de envelhecimento (Hetherington 1998, Kim e col. 2003), a idade, a composição da saliva (Meilgaard e col. 1991, Woods 1998),

- Hábito de fumar (Baker e col. 1983), hábito alimentar (Minohara e col. 1991),

- Humor e as sensações de fome ou de saciedade (Meilgaard e col. 1991, Woods 1998).

A deficiência na percepção do gosto relacionada à idade, apesar de não estar claramente elucidada, é considerada determinante na diminuição do prazer relacionado à alimentação, monotonia alimentar e redução de consumo no idoso (Drewnowski 1997).

Nota-se nos adultos que alterações na percepção dos gostos podem contribuir para o desenvolvimento da anorexia em pacientes com câncer (Kamath e col. 1983, Ovesen e col. 1991, Mulder e col. 1983, Gallagher e Tweedle 1983).

James e col. (1997) comentam que as divergências nas habilidades sensoriais de crianças e adultos podem refletir em distintos hábitos e preferências alimentares. Birch e Sullivan (1991) relatam que a aceitação de um alimento por uma criança está relacionada com o número de exposições a este e também à sensação imediata após o seu consumo, como, por 
exemplo, sinal de saciedade (aspecto positivo), episódio diarréico (aspecto negativo). Além disso, enfatiza a importância do ambiente para a ingestão da preparação alimentícia, o qual deve manter uma harmonia durante a refeição.

\subsection{Fisiologia do paladar}

As sensações gustativas são provenientes de estímulos de quimiorreceptores presentes na faringe, laringe (Phillips e Fuchs 1989), palato mole, amídalas e principalmente na língua (Woods 1998, Phillips e Fuchs 1989).

As papilas gustativas são estruturas sobressalentes que emergem da superficie da mucosa da cavidade oral, local no qual o contato com a saliva é grande, aumentando a probabilidade de dissolver as partículas dos alimentos a serem sentidos. Tais papilas adotam diferentes formas:

- Filiformes - aspectos de fibras ou fios que se estendem desde a superfície da língua em locais que os receptores gustativos são inexistentes.

- Fungiformes - apresentam forma de fungo e possuem uma grande superfície de contato, além de conterem receptores dos gostos na proporção de 8 a 10 corpúsculos gustativos por 
papila. Distribui-se na porção dorsal da língua, principalmente nas extremidades.

- Foliadas - apresentam forma de folhas e são encontradas na borda da língua, principalmente posterior e apresentam de 25 a 30 corpúsculos gustativos por papila. Às vezes apresentam na sua base uma pequena glândula de saliva, facilitando o acesso das substâncias gustativas.

- Circunvaladas - São as de maior tamanho (até $2,5 \mathrm{~mm}$ de diâmetro) e apresentam mais de 300 corpúsculos por papila, rodeadas por uma fenda na qual acumula-se saliva e são localizadas no dorso da língua, formando um " $v$ " de vértice posterior. Representam o tipo mais relevante de papila gustativa (Douglas 2002).

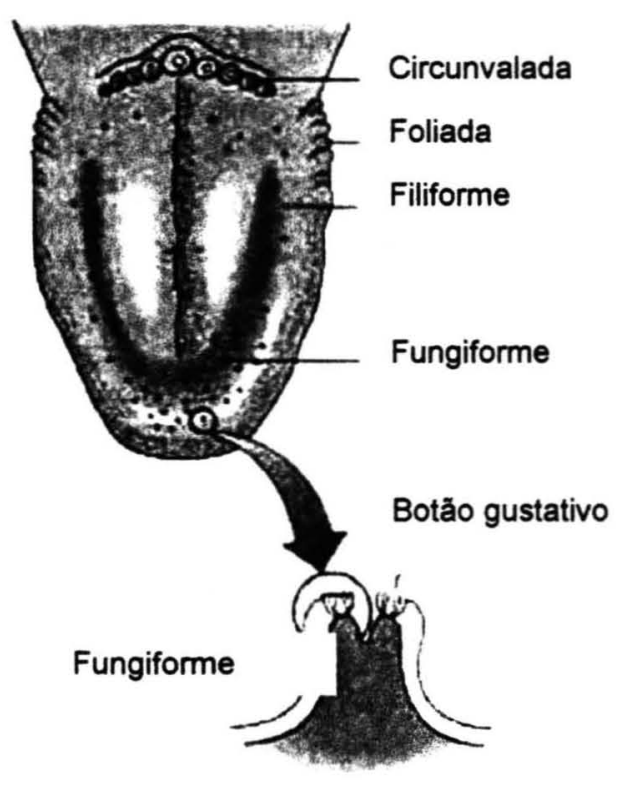

Figura 1- Esquema da Distribuição das papilas na superfície dorsal da língua. 
Entretanto, as papilas não representam os receptores gustativos propriamente ditos, onde se localizam os corpúsculos (agrupamentos celulares que reúnem os receptores presentes no interior da estrutura papilar). Excepcionalmente os receptores são encontrados fora dessa região (Douglas 2002).

Os botões gustativos também possuem diferentes tipos celulares, os quais fornecem sustentação às células receptoras e promovem sua contínua renovação (Baldo 1999). Estima-se que em média o número de células receptoras gustativas por botão gustativo seja de 5 a 100 unidades. E que estes apresentam um diâmetro de 40mm (Douglas 2002).

A sensibilidade química, genericamente, corresponde à capacidade de uma célula responder a uma substância química especifica (Baldo 1999). $\mathrm{Na}$ sensibilidade gustativa os receptores são células sensiveis a íons e moléculas que podem estar presentes nos alimentos ingeridos (Baldo 1999).

Embora, um determinado sabor seja uma complexa mistura de diversos elementos, é caracterizado pelo gosto do alimento ou bebida e pelo seu odor sentido pelas narinas, local onde os aromas também são detectados (Dúran e Costell 1999). Os estímulos responsáveis pela percepção do aroma são componentes voláteis, que não estão presentes nos estímulos dos gostos (Dúran e Costell 1999). 


\subsection{Gostos Básicos}

Vários pesquisadores citam que as sensações provenientes do gosto estavam limitadas a quatro propriedades básicas ou primárias: doce, azedo, salgado e amargo (Drewnowski 1997, Dúran e Costell 1999, Woods 1998, Lawless 1985, Nasser 2001, Schiffman e Erickson 1971). Atualmente houve a inclusão do umami como o quinto gosto básico. Este gosto também atua como realçador do sabor do alimento (Maga 1994 e Nasser 2001).

Os gostos primários, ou básicos, apresentam mecanismos específicos, porém seus receptores são estimulados por um conjunto de sinais químicos.

Os gostos secundários não apresentam receptores específicos, nem respondem a estímulos determinados, são resultantes da combinação dos estímulos dos gostos primários e do tempo, conseqüentemente carecem de especificidade. Entre eles destaca-se o gosto alcalino, determinado pela excitação quase simultânea de receptores salgado e azedo, o gosto metálico, determinado por metais além de outras substâncias inorgânicas e de reações simultâneas dos receptores do doce e salgado predominantemente e o gosto picante que ocorre devido a estimulações dos receptores gustativos (azedo, salgado ou doce) e de receptores orais de outra natureza (Douglas 2002). 


\subsection{Regiōes de deteç̧ão dos gostos básicos}

A identificação do local de deteç̧ão de gostos básicos é estudada por diversos pesquisadores.

Woods (1998) refere que o gosto doce é predominantemente reconhecido na ponta, azedo e salgado nas laterais e amargo na parte superior da língua. Kugino e col. (1997), em seu estudo mostrou que a parte da ponta da língua é sensível ao doce, ácido e salgado, na região da base ao amargo, enquanto a parte central é pouco sensivel aos gostos.

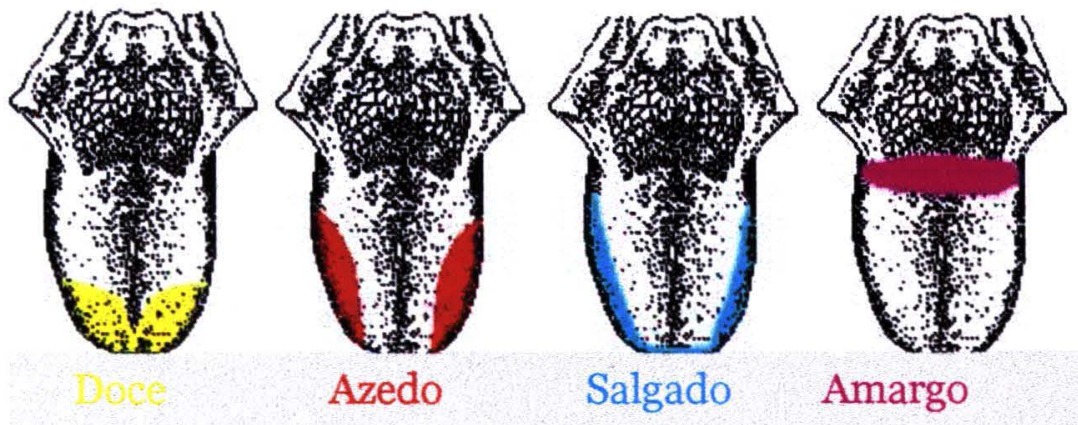

Figura 2. Distribuições das regiōes de reconhecimento dos gostos doce, azedo, salgado e amargo segundo Woods (1998).

Phillips e Fuchs (1989) demonstraram que em concentrações baixas das substâncias, responsáveis por caracterizar o gosto, cada botão gustativo específico da língua responde a um determinado estímulo. 0 doce e 0 salgado têm limiar de reconhecimento mais baixo nas margens anteriores da língua, o azedo nas laterais posteriores, o amargo na parte posterior central. Porém, em altas concentrações das soluções dos gostos, os botões 
gustativos respondem amplamente, ou seja, a sensibilidade para estímulos moderados a fortes diferiria entre si.

Smith e Margolskee (2001), referem que os gostos básicos podem ser detectados por todas as regiões da língua que contenham os botões gustativos.

Afirma-se que outros estudos devem ser realizados para o maior conhecimento da detecção dos gostos na língua (Kugino e col. 1997) e nas demais partes da cavidade oral (Phillips e Fuchs 1989), considerando a constituição da saliva como importante solvente para o alimento (Woods 1998, Smith e Margolskee 2001).

\subsection{Testes Sensoriais- Limiar de Detecção dos gostos}

A influência da idade na percepção dos gostos tem sido investigada em vários estudos, todavia há restrições quanto aos aspectos estudados como, por exemplo, muitos ignoram o sexo, a presença de doenças entre outras caracteristicas, além das diferenças nos procedimentos metodológicos. Por isso, é difícil comparar os diversos resultados observados nas diversas pesquisas e obter um consenso (Mojet e col. 2001).

Testes psicofísicos podem ser conduzidos com indivíduos para investigar as suas percepções sensoriais e preferências. Ao usar os 
consumidores como provadores não é necessário o treinamento dos mesmos em referência às características do produto alimentício a ser experimentado. Os participantes devem expressar seu grau de gostar, preferências, usando escalas como, por exemplo, a hedônica ou utilizando, testes comparativos de preferência (Guinard 2001).

O índice limiar (Threshold) é estudado pela psicofísica considerando a intensidade do estímulo, a concentração da solução e a resposta sensorial do provador. O threshold é o valor mínimo de um estímulo sensorial necessário para causar uma sensação, sendo possivel perceber a sensação e não identificá-la (ACTIA 2001).

Várias metodologias para o cálculo do limiar de detecção dos gostos básicos são descritas na literatura:

Segundo Hardy e col. (1981) deve-se aplicar o teste triangular para a apresentação das amostras, oferecendo três amostras para cada uma das séries, sendo uma a solução ( 8 concentrações distintas) a ser testada e as demais apenas com água destilada, cabendo ao provador analisar cada série e selecionar a diferente. Para isso os autores recomendam pingar com conta gotas as soluções na língua para evitar a adaptação gustativa. Entretanto, a não colocação da mesma quantidade de solução pode conduzir a resultados pouco confiáveis, pois o limiar de detecção é inversamente proporcional ao tamanho da área estimulada (Bartoshuck 1978, Mc Burney 1969). 
Chaves e Sproesser (1993) preconizam o mesmo teste triangular para apresentação das amostras, mas utilizando as soluções em maior quantidade. No caso de crianças essa metodologia poderia demandar um maior tempo para a execução do teste, o que diminuiria a confiabilidade dos resultados, já que estes estão associados diretamente ao cansaço do provador (Visser e col. 2000).

Moraes (1993) relata que as séries podem ser avaliadas conforme descrito anteriormente, por teste de estimulo constante, ou por análise de concentrações crescentes das soluções, apresentadas uma a uma, enfatizando que o teste deve ser repetido. Este último método foi preconizado pela Associação Brasileira de Normas Técnicas/NBR1372 (1994).

Nos testes de sensibilidade apresentam-se as amostras aos pares ou trios aos provadores para propiciar uma maior confiabilidade nos resultados quando comparados aos testes de limite, no qual o individuo só referiria se detectava ou não o estímulo (Bartoshuk 1978, Visser e col. 2000). Neste último método as pessoas conservadoras tendem a dizer que sentem o estímulo apenas quando têm certeza absoluta de sua opinião, e noutros tipos de personalidade tendem a dizer que detectaram o estímulo mesmo que isso não tenha ocorrido, havendo um maior viés na aferição do limiar de deteç̧ão (Bartoushuk 1978).

Marks e Wheeler (1998) citam que a detecção ou percepção dos estímulos dos gostos, ou de outro qualquer estímulo sensorial, constantemente envolve a combinação de diversos aspectos, como o 
procedimento sensorial aplicado e as decisões cognitivas de cada individuo. Os autores destacam a importância de manter atento o colaborador durante a coleta dos dados sensoriais, para obter resultados válidos. Os pesquisadores ressaltam ainda que quando $\circ$ indivíduo sabe qual $\circ$ gosto que será utilizado, os limiares de detecção tendem ser inferiores, o que afeta a acurácia da resposta.

1.4.1 Estudos dos limiares de deteç̧ão dos gostos básicos

Apesar de atualmente os testes sensoriais serem feitos com crianças (Guinard 2001), o conhecimento da função do gosto, por meio de aplicação de testes de limiares de detecção dos gostos, nesse grupo etário é pouco explorado na literatura (Visser e col. 2000). As crianças devem ser testadas utilizando métodos adequados, evitando procedimentos simplistas de classificar apenas os alimentos pelo nível de rejeição (Koivisto e Sjodén 1996). Alguns estudos mostram que as crianças rejeitam hortaliças (Pipes 1989), provavelmente devido à presença dos gostos azedo ou amargo nesses alimentos (Koivisto e Sjodén 1996). Há a preferência das crianças por alimentos com maior teores de doçura e sal quando comparados com os adultos (Desor e col. 1975, Desor e Beauchamp 1987).

No aspecto clínico, testes que avaliem a função da capacidade de sentir os gostos básicos em crianças são necessários, assim como os que 
associem as disfunções gustativas com os diferentes tipos de doenças (Visser e col. 2000).

As respostas das crianças aos alimentos são parcialmente influenciadas pela habilidade de perceber os gostos (James e col. 1997, Scott 2001). Caso a criança tenha melhor ou pior habilidade para a detecção dos gostos do que os adultos, possivelmente isso interferiria nas diferentes preferências alimentares (James e col. 1997).

Os estudos dos limiares de detecção dos gostos básicos apresentam resultados controversos (James e col. 1997, Mojet e col. 2001). Em algumas pesquisas há evidências que crianças apresentaram limiares de detecção similares aos adultos para alguns gostos básicos (Anliker e col. 1991, Hambridge e col. 1972). Por outro lado, James e col. (1997) referem que noutras pesquisas como as realizadas por Glanville e col. (1964), Hermel e col. (1970), Richter e Campbell (1940) e Yasaki (1976) as crianças apresentaram uma menor habilidade para detectar os gostos.

Os procedimentos dos testes sensoriais para a determinação dos limiares de detecção muitas vezes diferem entre si (James e col. 1997) e exercem influências diretamente na qualidade das respostas dos indivíduos (Cowart 1981). Nos estudos de Anlinker e col. (1991) e Hambridge e col. (1972) os valores dos limiares de detecção dos gostos foram comparados com dados reportados na literatura sem o esclarecimento dos procedimentos utilizados. 
Contudo, James e col. (1997) e Mojet e col. (2001) relataram que a variação da habilidade da determinação dos limiares de deteç̧ão dos gostos básicos não fora observada separadamente para meninos e meninas em várias pesquisas, como por exemplo, nos estudos de Anlinker e col. (1991), Hambridge e col. (1972).

Nos testes sensoriais conduzidos com adultos James e col. (1997) citam que em outros estudos (Cooper 1959, Hyde e Feller 1981, Jefferson 1970, Korslund 1967, Velle 1987, Weiffenbach e col. 1982) há conflitos entre os resultados obtidos quando consideradas as diferenças de gênero.

James e col. (1997) aplicaram o mesmo procedimento metodológico na execução dos testes sensoriais em crianças de 8 a 9 anos e adultos, e concluíram que os limiares médios de detecção para o doce, salgado, azedo e amargo não diferiram entre o grupo de mulheres e homens. Mas, os meninos apresentaram limiares de detecção superiores aos das mulheres e o mesmo ocorreu em comparação com o grupo de homens, exceto para o gosto amargo. Os limiares de detecção dos gostos doce e salgado foram menores entre as meninas do que nos meninos.

Apesar de existirem testes psicofísicos padronizados (Bartoshuk 1978), o conhecimento sobre a função dos gostos básicos em crianças é pequeno (Coelho e Pinto e Silva 2003, Visser e col. 2000). A revisão na literatura mostra que é possível realizar testes sensoriais com crianças caso seja considerado nos procedimentos as suas habilidades cognitivas e nivel de atenção (El-Chaar e col. 1996, Kimmel e col. 1994). 
Todavia, para manter o nível adequado de atenção das crianças durante os testes sensoriais estes devem ser realizados num curto espaço de tempo (Palisin 1986, Simonnds e Simonds 1982, Tzuriel e Klein 1985). Visser e col. (2000) ressaltam que as crianças se distraem facilmente e que um incentivo antes da aplicação do teste é essencial. As crianças devem ter contato com as soluçōes mais concentradas para distinguirem os gostos (Visser e col. 2000).

Menella e Beauchamp (1998), por meio da análise das expressões faciais de recém nascidos ao experimentarem as preparações alimentícias, avaliaram a capacidade de resposta dos bebês aos estímulos do paladar. Observaram que em relação ao doce, os bebês apresentaram um relaxamento facial, além de um movimento de sucção; ao azedo mostraram uma expressão de insatisfação, com contrações faciais, o mesmo observado com o amargo, porém também foi característico a este estímulo a protusão da língua e, quanto ao salgado, houve expressão de indiferença, já que nenhuma resposta facial foi observada.

Minohara e col. (1991) pesquisaram os limiares de detecção dos gostos básicos em pré-escolares japoneses, concluindo que a habilidade em discriminar os gostos estava relacionada ao crescimento e ao desenvolvimento, sendo fortemente afetada por fatores ambientais e pelo hábito alimentar.

Anliker e col. (1991) demonstraram que $88,23 \%$ de 34 crianças de 5 a 7 anos estavam aptas a participarem de um teste pareado para determinar 0 limiar de detecção para 6-n-propiltiouracil, composto amargo que tem a sua 
percepção aliada as características genéticas dos individuos. Dentre as 30 crianças que conseguiram participar do experimento com sucesso apenas duas foram classificadas como nontasters (não sensiveis). Utilizaram o teste de escolha forçada, ou seja, a pessoa tinha que selecionar uma amostra mesmo que não houvesse detectado o estímulo. As soluções foram apresentadas de forma crescente. Caso a criança acertasse qual era a solução, o teste era repetido nessa mesma concentração e se a resposta fosse positiva novamente apresentava-se a solução seguinte mais fraca, repetindo esse procedimento por 5 vezes. 0 limiar foi a média geométrica dos últimos 4 julgamentos. $O$ estudo ainda mostra que $\circ$ fato da criança ser sensivel ou não a essa substância interfere diretamente na sua escolha alimentar.

Visser e col. (2000) estudaram os limiares de detecção dos gostos doce e amargo de 45 crianças de 3 a 6 anos de idade. Para isso adaptou os procedimentos para a faixa etária, como por exemplo, com a introdução dos testes sensoriais através de uma história. A resposta foi "forçada", pois a criança tinha de dizer se o líquido tinha "gosto" ou era água e as amostras foram oferecidas aos pares. A criança tinha de acertar duas vezes consecutivamente qual era a solução e então era apresentada a outra mais diluída. O teste terminava quando duas respostas consecutivas eram incorretas. O limiar era a última concentração detectada. $\mathrm{O}$ grande número de amostras dificultou $\circ$ desenvolvimento do teste pelas crianças. Entretanto, os autores relataram que para aumentar a velocidade do experimento, as soluções foram apresentadas em ordem decrescente de 
diluição, mas sempre em duas concentrações menores da escala a ser apresentada e quando a solução não era detectada pela criança, apresentava-se a imediatamente superior.

James e col. (1997) utilizaram testes de estímulo constante nos seus estudos, para os gostos básicos em 61 adultos jovens e em 68 crianças de 8 a 9 anos, de ambos os sexos e não observaram diferença significativa entre os limiares de detecção de gostos entre homens e mulheres, ou entre meninas e adultos. Utilizou-se o teste de escolha forçada, sendo uma amostra a água destilada e a outra a solução. As soluções eram apresentadas de forma que houvesse um aumento das concentrações. Este teste foi realizado em duplicata. O limiar de detecção era a média geométrica entre a concentração mais alta com resposta incorreta e a concentração mais baixa da solução com duas respostas corretas. Utilizouse a média aritmética para calcular o limiar de detecção médio de cada grupo.

Lawless (1985) diz que as respostas para substâncias amargas em crianças e adultos são praticamente as mesmas, mas ressalta que vários estudos obtiveram resultados divergentes em decorrência da adoção de critérios metodológicos distintos, ou seja, os testes não estavam devidamente adaptados para a população infantil, pois trabalhavam apenas com respostas "sim ou não", facilmente influenciadas pela personalidade.

De Graaf e Zandstra (1999) investigaram a detecção do gosto doce em crianças de 9 a 10 anos $(n=30)$, adolescentes de 14 a 16 anos $(n=30)$ e adultos de 20 a 25 anos $(n=30)$. Nesse estudo perceberam que as crianças 
tinham uma menor capacidade de detectar o gosto doce que os adolescentes, os quais também percebiam em maiores concentrações que os adultos. A preferência pelo gosto doce era inversamente proporcional ao limiar de detecção, ou seja, quanto menos sensível era o grupo, maior necessidade de soluto na solução para se detectar o gosto, aumentava-se a preferência por produtos com maior nivel de doçura.

As diferenças na detecção dos gostos requerem uma atenção especial dos pesquisadores, pois além do sexo, idade, algumas diferenças genéticas, há as associadas com o tipo de personalidade e que, se ignoradas, podem invalidar os resultados, pois diminuem os poderes estatísticos dos testes e até anulam hipóteses (Stevens 1996). Além, das características do estado nutricional do indivíduo (Ohara e col. 1995, Hess 1997, Obrebowski e col. 2000).

\subsection{Estado Nutricional da criança}

Segundo Monteiro (1988), alterações mínimas do estado de saúde e nutrição decorrentes de deficiências na alimentação e/ou de infecções repetidas repercutem no crescimento infantil. Entretanto, os dados refletem que os problemas nutricionais, de crianças e adolescentes no Brasil, estão mudando de um déficit para um superávit de energia (Wang e col. 2002). 
O rápido crescimento em proporções epidêmicas, de excesso de peso e de obesidade na população de crianças e adultos (Seidell 1995, Flegal 1999), tem sido considerado um dos principais problemas de saúde pública nos países desenvolvidos e em desenvolvimento (American Academy of Pediatrics 2003).

Evidencia-se que a taxa da prevalência da obesidade na população brasileira aumentou nas últimas décadas. Os dados nacionais levantados referentes às crianças em 1989 pelo Instituto Nacional de Alimentação e Nutrição (INAN) e pelo Programa Nacional de Saúde e Nutrição (PNSN), apontavam que cerca de um milhão e meio de crianças eram obesas, com maior prevalência nas meninas e nas áreas de maior desenvolvimento (Brasil 1991). No entanto, esse perfil está mudando, e a obesidade vem aumentando no sexo masculino e nas classes menos favorecidas (Monteiro e Conde 1999).

A obesidade refere-se à deposição de gordura em excesso no organismo. É um distúrbio do estado nutricional traduzido por um aumento de tecido adiposo (Monteiro e Conde 2000, Monteiro e col. 2002), reflexo do balanço positivo de energia na relação do que é ingerido e gasto pelo organismo (Netto e Saito 2002). O excesso de peso durante a infância é considerado fator de risco para diversas doenças como por exemplo:

- hipertensão arterial (Dietz 1998, Kiess e col. 2001, Serdulla e col. 1993), 
- dislipidemias (Serdulla e col. 1993, Souza e Cardoso 2003, Kiess e col. 2001, Freedman e col. 1999)

- intolerância à glicose (Souza e Cardoso 2003), aumentando o risco para diabete tipo 2 (Ebbeling e col. 2002, Shinha e col.2002)

- doenças cardiovasculares (Souza e Cardoso 2003, Ebbeling e col.2002, Freedman e col. 1999).

Além da possibilidade do desenvolvimento de distúrbios psicológicos como depressão e angústia, baixa auto-estima e conseqüentemente 0 isolamento social (Souza e Cardoso 2003, Kiess e col. 2001, Strauss 2000, Coutinho 1999, Dietz 1998).

\subsubsection{Diagnóstico do estado nutricional na criança}

Vários critérios têm sido adotados para definir o diagnóstico de obesidade e conseqüentemente da eutrofia infantil, existindo, ainda, divergências na literatura (Neto e Saito 2002).

Geralmente os métodos antropométricos utilizados incluem medidas de peso e altura, pregas cutâneas e algumas circunferências (Escrivão e col. 2000). Estes dados podem ser utilizados em fórmulas que dão origem a 
índices relacionados à obesidade ou à massa corpórea, curvas pondoestaturais e tabelas de referências (Neto e Saito 2002).

Segundo Cole (1993), um padrão de crescimento (ou referência) é obtido através de um conjunto de dados que representa a distribuição de uma medida (peso, idade, IMC) antropométrica e sua modificação em função de alguma co-variável - usualmente a idade - para cada sexo.

A seleção de uma medida qualquer para traduzir o estado nutricional de um indivíduo deve ser realizada sob inúmeros cuidados e requisitos. A medida deve ser prática, de fácil e rápida execução, baixo custo e ainda propiciar a criação de indicadores que apresentem valores adequados de sensibilidade (capacidade de triagem) e especificidade (capacidade diagnóstica) (Conde 2004).

\subsection{2 Índice de massa corporal}

Em indivíduos adultos, o IMC há algum tempo é a medida selecionada para a avaliação do estado nutricional em função de sua praticidade e versatilidade, possibilitando a identificação tanto da deficiência nutricional quanto da obesidade. A finalização do processo de crescimento permite supor que, em condições populacionais típicas, todo acréscimo de massa obtido a partir desta idade é proveniente principalmente do acúmulo de 
massa gordurosa no corpo, fator associado a determinadas doenças crônicas e de risco para a mortalidade (Conde 2004).

A utilização do IMC na avaliação do estado nutricional de crianças e adolescente, por algum tempo, foi alvo de controvérsia. Seu significado e mesmo a propriedade de seu uso não se apresentavam claros ao longo do espectro etário envolvendo infância e adolescência. As modificações observadas na massa corporal ao longo do processo de crescimento não são de interpretação simples ou direta como em adultos (Conde 2004).

Freedman e col. (2004a) estudando a relação entre IMC e altura na infância e obesidade no adulto, concluíram que o IMC é o melhor índice peso-altura porque reflete uma associação positiva entre altura e adiposidade entre crianças. Esta classificação diferencial de excesso de peso é apropriada e reflete a associação entre altura e adiposidade entre crianças antes dos 12 anos de idade (Freedman e col. 2004b).

O índice de massa corpórea para a idade pode ser utilizado na avaliação nutricional, sendo mais eficiente do que a relação peso para a altura, já que está menos sujeito às variações étnicas (Cole 2000, NCHS 2000).

A partir da recomendação do IMC como critério principal para diagnóstico da obesidade em crianças e adolescentes (Bellizzi e Dietz 1999) e da publicação de estudos evidenciando aumentos exponenciais da obesidade infantil tanto em paises desenvolvidos quanto em desenvolvimento (Ebbeling e col. 2002, Wang e col. 2002), o debate em 
torno do emprego desse indicador para a avaliação do estado nutricional em crianças e adolescentes vem se dirigindo, para a seleção da curva de referência mais adequada e a definição dos valores críticos a serem empregados na classificação do estado nutricional (Conde 2004).

No Brasil entre os conjuntos de dados disponíveis aquele que melhor representa a condição saudável medida na população, segundo o indicador de massa corporal, é a base de Pesquisa Nacional sobre Saúde e Nutrição (PNSN) de 1989. Estes dados foram obtidos em período curto de tempo e com cobertura nacional e não devem ter sido modificados por fenômenos sazonais, como o clima, que reconhecidamente pode afetar a expressão do estado nutricional (Conde 2004).

A determinação dos valores críticos para classificação nutricional em cada idade foi realizada fixando-se o valor final desejado aos 20 anos: IMC igual a $25 \mathrm{~kg} / \mathrm{m}^{2}$ no caso do excesso de peso e IMC igual a $30 \mathrm{~kg} / \mathrm{m}^{2}$ no caso da obesidade, baseada em critérios epidemiológicos. Selecionou-se a curva correspondente ao IMC $17,5 \mathrm{~kg} / \mathrm{m}^{2}$ (aos vinte anos) como ponto de corte para definir baixo peso na população brasileira. Desta forma buscou-se conservar a prática utilizada na classificação do estado nutricional de adultos, que é o emprego de valor único em ambos os sexos também na classificação de baixo peso (Conde 2004).

Conde (2004) sugere a utilização da curva brasileira e a classificação do estado nutricional baseado na proposta da International Obesity Task Force (IOTF) (Bellizzi e Dietz 1999, Cole 2000) como referências na análise do estado nutricional dos brasileiros. Em seu estudo demonstrou que entre as 
curvas estrangeiras, a aplicação da norte-americana, seria a menos adequada. $\mathrm{O}$ autor ainda sugere cautela na utilização de curvas estrangeiras para a população brasileira. Dentre as curvas não brasileiras analisadas, a curva internacional (IOTF) mostrou-se mais próxima da curva brasileira e por extensão de seus resultados. Houve mesmo neste caso subestimação nos valores de prevalência do excesso de peso obtidos.

A importância da avaliação nutricional decorre da influência decisiva que o estado nutricional exerce sobre morbi-mortalidade, crescimento e desenvolvimento da criança (Monteiro e col. 1995). A avaliação do estado nutricional é uma etapa fundamental para se verificar se o crescimento está se afastando do padrão esperado por doença e/ou por condições sociais desfavoráveis. Não existe forma de diminuir os distúrbios nutricionais como a desnutrição e a obesidade se elas não forem diagnosticadas de maneira adequada (Mello e col. 2004).

Assim, o exame antropométrico é essencial no diagnóstico de saúde infantil (Barros e Victora 1991).

\subsection{Pré-escolares e escolares}

Atualmente com o aumento do número de mulheres no mercado de trabalho, houve uma valorização dos centros infantis de assistência ao préescolar (Oliveira e col. 1995). Estas. instituiçōes devem ter um cuidado 
especial com a alimentação das crianças, pois isto pode interferir na motivação e participação destas nas diferentes atividades (Lopez 1996).

As escolas e pré-escolas devem fornecer experiências às crianças para que possam ampliar seus conhecimentos, interferindo nos hábitos, atitudes e conseqüentemente na saúde (Schimitz e col. 1997).

As Pré-escolas e escolas são consideradas espaços ideais para o desenvolvimento deste projeto, o qual questiona se os limiares de detecção dos gostos: doce, amargo, salgado e azedo, variam de acordo com o estado nutricional, sexo e idade. 


\section{OBJETIVOS}

\subsection{Objetivo Geral}

Avaliar o limiar de detecção dos gostos básicos: azedo, doce, salgado e amargo em pré-escolares e escolares e verificar a associação com o estado nutricional e sexo.

\subsection{Objetivos específicos}

- Identificar o limiar de deteç̧ão dos gostos doce, salgado, azedo e amargo de cada criança e do grupo.

- Analisar a reprodutibilidade dos testes sensoriais

- Avaliar o estado nutricional das crianças

- Verificar a existência de associação entre estado nutricional (eutrofia e excesso de peso) e o limiar de detecção dos gostos básicos 
- Verificar a existência de associação entre idade e o limiar de detecção dos gostos básicos

- Verificar a existência de associação entre o sexo da criança e o limiar de detecção dos gostos básicos 


\section{MATERIAIS E MÉTODOS}

Este estudo compreende a análise dos limiares de detecção dos gostos doce, salgado, ácido e amargo em crianças, pré-escolares e escolares considerando o estado nutricional, o sexo e a idade. Os dados foram coletados nas Creches da Coordenadoria da Assistência Social da Universidade de São Paulo (COSEAS/USP) entre os meses de fevereiro e junho de 2001 e na Escola de Aplicação da Faculdade de Educação da Universidade de São Paulo entre os meses de fevereiro e junho de 2003.

A presente pesquisa utilizou os dados coletados para $\circ$ projeto temático do Departamento de Nutrição da Faculdade de Saúde Pública da Universidade de São Paulo, "Nutrição e Saúde: Uma abordagem integrada para a avaliação nutricional, desenvolvimento de alimentos para fins especiais e intervenção nutricional" - subprojeto "Avaliação dos limiares de detecção dos gostos básicos em crianças" (Coelho 2002) e do Projeto de "Análise dos limiares de detecção dos gostos básicos e sensibilidade ao 6-npropiltiouracil em crianças de 7 a 10 anos" (Caratin 2004) ambos com apoio financeiro da FAPESP. 


\subsection{Delineamento Do Estudo}

Trata-se de uma análise descritiva dos fatores ligados aos aspectos nutricionais em crianças por meio de um estudo transversal, com utilização de dados coletados em três creches/pré-escolas pertencentes a COSEAS/USP: Saúde, Oeste e Central e na Escola de Aplicação localizada no campus de São Paulo da Universidade de São Paulo.

\subsection{Questões éticas}

A pesquisa foi autorizada pelo Comitê de Ética da Faculdade de Saúde Pública da Universidade de São Paulo (USP), por meio dos documentos Of. COEP/063/00 e Of. COEP/267/02 (Anexo 1).

Este trabalho conta ainda com o beneplácito da Divisão de Creches COSEAS/USP e da Escola de Aplicação. (Anexo 2).

Os responsáveis pelas crianças foram argüidos sobre a disponibilidade delas em participar na pesquisa, após serem informados do objetivo do estudo e de seus procedimentos. Além de garantir o anonimato e a confidencialidade dos dados, bem como da possibilidade de desistirem do estudo a qualquer momento, sem apresentarem motivos ou sofrerem qualquer constrangimento. Foram, ainda, informados da plena liberdade 
para aceitarem ou não, ficando cientes de que as negativas de adesão não Ihes trariam nenhum prejuizo, e recebiam o termo de consentimento esclarecido. A participação da criança mesmo com a anuência dos responsáveis foi voluntária (Anexo 3 ).

\subsection{População em estudo}

A amostra de estudo foi constituída por 176 pré-escolares (4 a 6 anos e 11 meses) freqüentadores em período integral das Creches COSEAS/USP em 2001, e por 210 escolares ( 7 a 10 anos e 11 meses) matriculados na Escola de Aplicação FE/USP no ano de 2003 e que estavam presentes durante o periodo de coleta de dados.

\subsection{Critérios de seleção e exclusão das crianças}

Foram convidadas a participar do presente estudo todas as crianças das Creches COSEAS/USP e da Escola de Aplicação/USP pertencentes às faixas etárias selecionadas. 
Os fatores de exclusão dos dados das crianças nas análises foram: presença de alguma doença, como: febre, gripe, dor de garganta entre outras, assim como a utilização de medicamentos durante o período da coleta de dados, pois estas condições poderiam interferir na função de deteç̧ão dos gostos (Kim e col. 2003).

\subsection{Variáveis em estudo}

As variáveis coletadas para este estudo foram:

- Idade

- Sexo

- Peso

- Estatura

- Índice de Massa Corporal (IMC)

- Limiares de detecção para os gostos: doce, ácido, amargo e salgado.

As variáveis foram armazenadas no banco de dados elaborado no programa EpiData versão 1.5 (Lauritsen e Bruus. 2001), o qual foi validado para excluir possíveis falhas de interpretação, por meio de digitação em duplicata dos questionários. 


\subsection{Avaliação do Estado Nutricional}

\subsubsection{Treinamento e Padronização de Medidas Antropométricas}

Efetivou-se no Laboratório de Avaliação Nutricional de Populações do Departamento de Nutrição da Faculdade de Saúde Pública o treinamento para a mensuração da estatura e peso.

Os resultados do treinamento foram avaliados por meio do coeficiente de correlação (Lin 1989) e pela diferença das médias das medidas antropométricas (Bland e Altman 1986) entre o antropometrista, a pesquisadora e a colaboradora utilizando o pacote estatístico Stata (Statacorp 1999), mostrando que com $95 \%$ de confiabilidade não houve diferença significativa entre as medidas obtidas.

\subsubsection{Variáveis Antropométricas}

Os dados antropométricos foram mensurados conforme proposto por Lohman e col. (1988), ou seja, obtiveram-se em duplicata as medidas utilizando-se a média para os cálculos dos índices antropométricos, as quais foram registradas em formulário (Anexos 4 e 5). 
Para realizar as medidas antropométricas de peso e estatura foram adotados os seguintes procedimentos:
a) Peso

Para a mensuração do peso utilizou-se balança digital com bateria solar; marca Tanita $₫$, capacidade de 150 quilogramas, com precisão de 200g. Foi permitida apenas a utilização de peça íntima nos pré-escolares para a mensuração do peso. Os escolares foram instruídos a esvaziarem os bolsos e descalçarem.

\section{b) Estatura}

Para medir a estatura utilizou-se estadiômetro com precisão $0,1 \mathrm{~cm}$ desenvolvido pelo Núcleo de Pesquisa Epidemiológicas em Nutrição e Saúde (NUPENS/USP). Solicitou-se à criança que encostasse à parede os calcanhares, panturrilha, glúteos e ombros, além de que posicionasse a cabeça de acordo com o plano de Frankfurt (Lohman e col. 1988).

c) Idade

A idade em meses da criança foi obtida a partir do cálculo da diferença em meses da data de nascimento e da entrevista.

d) Indice de Massa Corporal

Para a análise do estado nutricional dos indivíduos foi calculado o Índice de Massa corpórea (IMC) ou Índice de Quetelet. Este índice foi obtido por meio da seguinte da fórmula:

$$
I M C=\text { Peso }(\mathrm{kg}) / \text { Estatura }^{2}(\mathrm{~m})
$$


A curva de referência nacional selecionada foi a proposta por Conde (2004), a qual usou um conjunto de dados obtidos pela Pesquisa Nacional de Saúde e Nutrição (PNSN) realizada pelo Instituto Brasileiro de Geografia e Estatística em 1989 (IBGE 1992). Dentre as diversas razões para a seleção dessa base de dados destacou-se: a representatividade nacional (excluindose área rural da Região Norte), o rigor na preparação para a mensuração das medidas antropométricas e o controle de qualidade realizado ao longo do estudo.

A determinação dos valores críticos para classificação nutricional em cada idade foi realizada fixando-se o valor final desejado aos 20 anos: IMC igual a $17,5 \mathrm{~kg} / \mathrm{m}^{2}$ para baixo peso, IMC igual a $25 \mathrm{~kg} / \mathrm{m}^{2}$ no caso do risco de obesidade e o IMC igual a $30 \mathrm{~kg} / \mathrm{m}^{2}$ no caso da obesidade, baseada em critérios epidemiológicos (Conde 2004). Esta proposição emergiu do grupo de trabalho da IOTF o qual propôs o uso de valores críticos de IMC equivalentes àqueles já empregados na classificação do estado nutricional de adultos (Bellizzi e Dietz 1999).

\subsection{Avaliação do Estado de Saúde}

Nas creches e pré-escolas a informação sobre a presença ou não de doenças foi obtida nos registros de saúde das crianças das creches, nos quais constam as intercorrências anotadas pela médica ou pelas auxiliares 
de enfermagem e transcritas no formulário de pesquisa de saúde da criança (Anexo 4).

$\mathrm{Na}$ escola a averiguação da presença de doenças e consumo de remédios ocorreu pelo preenchimento de um questionário pelos responsáveis pelas crianças (Anexo 6).

\subsection{Análise sensorial}

\subsubsection{Familiarização dos pré-escolares com os Testes Sensoriais}

Desenvolveu-se conforme proposto por Beauchamp e Cowart (1990) e Visser e col. (2000) uma história, a qual foi contada para as crianças pelo aplicador do teste sensorial. Essa dinâmica promove a familiarização entre as crianças e o adulto, além do incentivo de forma lúdica para a colaboração daquelas (Palisin 1986, Simonds e Simonds 1982, Tzuriel e Klein 1985).

A história teve o escopo de incitar a imaginação da criança, utilizandose de um pais chamado Glubelândia, no qual não havia "sabores", mas os personagens (glube-glubes) vão a procura deles. Os Glube-glubes viajam pelo espaço e, dentre várias aventuras, chegam na Saborlândia, onde eles conseguem os 4 "sabores" básicos, que são levados para a Glubelândia. 
Entretanto, no caminho de volta para casa, eles enfrentam uma grande chuva, e os sabores se misturam à água. Assim, a participação das crianças torna-se indispensável na tarefa de separar as garrafas de água da dos "sabores".

Os gostos básicos, doce, salgado, ácido e amargo foram experimentados pelas crianças logo após a dinâmica da história, explicandose que cada criança seria chamada posteriormente para auxiliar os personagens na busca dos gostos básicos. Este procedimento ocorreu para propiciar à criança um maior conhecimento sobre o teste a ser realizado (Visser e col. 2000).

As soluções apresentadas às crianças foram à base de água deionizada (água dos glube-glubes) com: ácido cítrico $(2,62 \mathrm{mmol} / \mathrm{L})$ para 0 gosto ácido, cafeina $(4,12 \mathrm{mmo} / \mathrm{L})$ para $\circ$ amargo, cloreto de sódio $(51,33 \mathrm{mmol} / \mathrm{L})$ para o salgado e sacarose $(46,74 \mathrm{mmol} / \mathrm{L})$ para o doce.

\subsubsection{Familiarização dos escolares com os Testes Sensoriais}

Foram realizadas dinâmicas com os grupos de crianças nas respectivas salas de aulas para ensinar os diferentes gostos básicos, por intermédio de degustações de alimentos como por exemplo: café, açúcar, limão e sal. 
Os gostos básicos (doce, salgado, ácido e amargo) foram experimentados pelas crianças logo após a dinâmica, explicando-se-lhes que seriam chamadas individualmente para os testes sensoriais posteriormente.

As soluções à base de água deionizada (água dos glube-glubes) com: ácido citrico $(2,62 \mathrm{mmol} / \mathrm{L})$ para o gosto ácido, cafeína $(4,12 \mathrm{mmol} / \mathrm{L})$ para o amargo, cloreto de sódio $(51,33 \mathrm{mmol} / \mathrm{L})$ para o salgado e sacarose $(46,74 \mathrm{mmol} / \mathrm{L})$ para o doce foram apresentadas aos escolares nas mesmas concentrações do que as oferecidas aos pré-escolares.

\subsubsection{Local de realização dos testes sensoriais}

Os testes foram realizados na biblioteca, sala da coordenação, ou corredor das salas de aulas conforme a disponibilidade do espaço e tempo da instituição. Os locais foram selecionados previamente para evitar a interferência de ruídos e odores, conforme preconizado pela ABNT/NBR 13172 - 1994, e para prevenir uma maior distração das crianças (Visser e col. 2000), utilizando um local familiar para elas (Liem e col. 2004, Guinard 2001). Segundo Butter e col. (1989) o estado de atenção influi na resposta dos individuos referentes aos aspectos do paladar. 


\subsubsection{Preparação da Amostra}

As amostras foram preparadas no Laboratório de Bromatologia do Departamento de Nutrição da Faculdade de Saúde Pública da Universidade de São Paulo. Utilizou-se água deionizada para o preparo das soluções e balança analítica para quantificar os solutos utilizados: sacarose, cloreto de sódio, cafeina, ácido cítrico (Woods 1998).

As concentrações de cada solução foram estabelecidas segundo uma série geométrica de diluições preconizada pela International Organization for Standartization (1985). Tal escala foi adaptada para os pré-escolares por meio de estudos preliminares com a população alvo e novas adaptações nas diluições das concentrações foram necessárias para a aplicação dos testes com escolares. 
Quadro 1 - Gostos básicos e concentrações das soluções utilizadas no testes de estímulo constante.

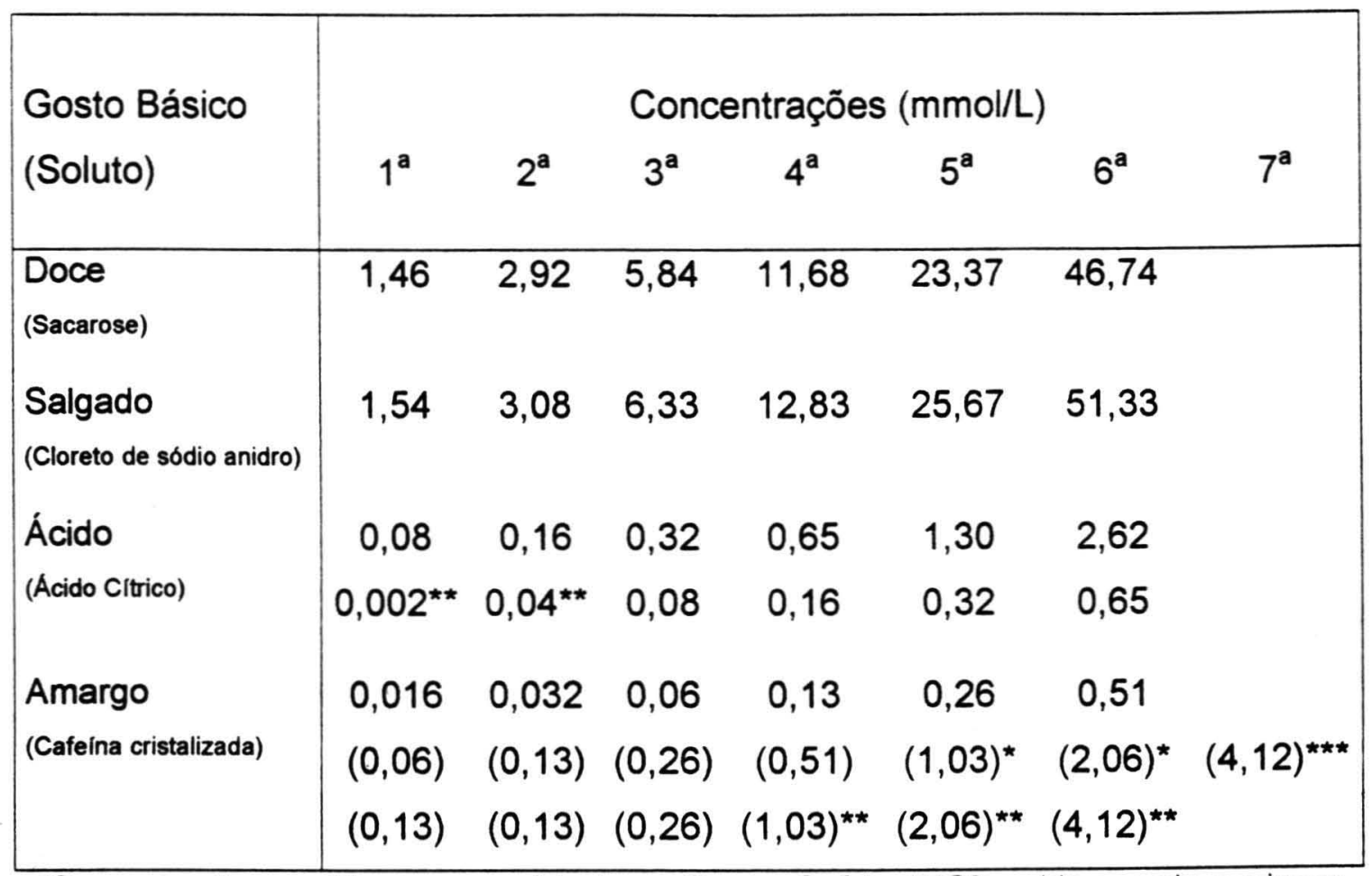

"Concentraçōes modificadas no pré-teste na Creche Saúde. "Oferecida quando a criança não foi capaz de detectar o gosto nas demais concentraçōes. "Concentrações modificadas no pré-teste na Escola de Aplicação.

Para a análise comparativa dos limiares de detecção de pré-escolares e escolares algumas categorias das escalas do gosto ácido e amargo foram agrupadas. Ou seja, a solução mais diluída de cafeína teve a concentração de $0,13 \mathrm{mmol} / \mathrm{L}$, aglutinando os pré-escolares que detectaram a solução na concentração $0,06 \mathrm{mmol} / \mathrm{L}$ com os que detectaram na solução de $0,13 \mathrm{mmo} / \mathrm{L}$. Para o gosto ácido a solução mais diluída foi de $0,08 \mathrm{mmol} / \mathrm{L}$, agrupando os escolares que detectaram a solução na concentração de 0,02 $\mathrm{mmmol} / \mathrm{L}$ e 0,04mmol/L (Quadro 2). 
Quadro 2 - Gostos ácido e amargo e concentrações das soluções utilizadas para a análise dos testes de estímulo constante.

\begin{tabular}{|l|cccccc|}
\hline $\begin{array}{l}\text { Gosto Básico } \\
\text { (Soluto) }\end{array}$ & \multicolumn{5}{|c|}{ Concentrações (mmol/L) } \\
\hline Ácido & 0,08 & 0,16 & 0,32 & 0,65 & 1,30 & 2,62 \\
(Ácido Cltrico) & $(0,02+0,04)$ & & & & & \\
Amargo & $0,13(+0,06)$ & 0,26 & 0,51 & 1,03 & 2,06 & 4,12 \\
(Cafeina cristalizada) & & & & & & \\
\hline
\end{tabular}

As soluções foram mantidas a temperatura ambiente, conforme preconizado por Arbisi e col (1999).

\subsubsection{Aplicação do Teste}

O teste de estímulo constante adaptado foi utilizado para identificação dos limiares de deteç̧ão dos gostos básicos das crianças. As amostras das soluções dos gostos doce, ácido, amargo e salgado devidamente codificadas foram apresentadas aos pares (solução e água deionizada 2AFC) conforme proposto por diversos pesquisadores (Weiffenbach e col. 1982, Cowart 1989, Stevens e col. 1991). A criança deveria indicar se algum estímulo era detectado entre as duas amostras. Cada solução apresentada à criança apresentava um volume aproximado de $10 \mathrm{~mL}$. Os indivíduos eram 
orientados a experimentarem as soluções oferecidas aos pares até decidirem qual apresentava o soluto (Liem e Menella 2003).

Após a avaliação da amostra, a criança recebia um copo com água deionizada (James e col. 1997) e aguardava-se 20 segundos para provar a próxima solução. Cada gosto foi testado em períodos distintos (manhã e vespertino) para evitar a adaptação do sistema sensorial (Zahar 1977). Segundo Mojet e col. (2001) são preferiveis várias sessões de testes sensoriais a uma extensa. A criança não foi informada sobre qual o gosto primário estava sendo determinado o limiar, conforme proposto por Marks e Wheeler (1998).

A apresentação das amostras aos pares seguiu uma ordem de apresentação às crianças previamente estabelecida, conforme proposto por Macfie e Bratchell (1989). E elas foram orientadas a provar das amostras da esquerda para a direita. As concentrações das soluçōes testadas foram oferecidas para as crianças em ordem crescente de concentração (Arbisi e col. 1999, James e col. 1997) tanto para os pré-escolares quanto para os escolares. Houve a apresentação das amostras até que o julgamento se repetisse sucessivamente duas vezes dentro da mesma série, isto é "detecção" da solução com soluto (Arbisi e col. 1999, James e col. 1997).

Para a primeira parte do estudo realizada com pré-escolares a escala das soluções também foi oferecida em ordem decrescente e neste caso as amostras foram testadas sucessivamente até duas respostas consecutivas de incapacidade de detectar o soluto na solução. Isto não ocorreu para o gosto amargo, que foi apresentado em duas séries crescentes das soluçōes 
em periodos distintos, devido à aversão das crianças ao gosto, que muitas vezes interrompiam a participação na experiência ao sentirem o amargor. Já na segunda parte do estudo com escolares a escala das soluções foi apresentada novamente em ordem crescente.

Partiu-se da premissa de que após duas respostas positivas na determinação da solução com o gosto na escala crescente de apresentação, as demais também seriam. E o contrário para a escala decrescente, ou seja, após dois erros consecutivos as demais soluções mais fracas também não seriam detectadas.

Tal fato foi indispensável metodologicamente, pois as crianças não conseguiam provar todas as soluções da escala, e a oferta dessas em blocos incompletos demandaria mais tempo nas instituições e paciência das crianças, aumentando possivelmente as desistências. Segundo Palisin (1986), Simonds e Simonds (1982), Tizuriel e Klein (1983), os testes não devem levar as crianças à exaustão.

Cada criança teve a resposta (limiar de detecção) anotada em ficha própria pelo aplicador do teste (Anexo 5 e 7 ).

Em nenhum momento a criança foi questionada a respeito de que gosto estava sendo experimentado, já que o objetivo deste estudo foi o limiar de detecção e não o limiar de reconhecimento. 


\subsection{Análise Estatistica}

Os dados contínuos foram primeiramente classificados em paramétricos e não paramétricos através do teste de Kolmogorov-Smirnov (Siegel 1981). Os dados foram representados através da média, mediana e desvio padrão.

Os dados categóricos como: estado nutricional (desnutrido, eutrófico categoria de referência-, excesso de peso e obeso), idade pré-escolares (4 a 7 anos incompletos - categoria de referência) e escolares (7 a 11 anos) segundo sexo (dicotômica, masculino -categoria de referência-) foram expressos em freqüência absoluta $(n)$ e freqüência relativa (\%).

A concordância das respostas das crianças obtidas nos testes sensoriais para cada gosto básico foi avaliada pelo método kappa. Desta forma, obtém-se uma medida que resulta em valores compreendidos entre 0 e +1 , sendo que +1 estabelece uma concordância perfeita; 0 (zero) quando a concordância obtida é a mesma esperada pelo acaso. Adotou-se o nivel de significância de 1\% (Landis e Koch 1977).

A verificação da adequação da escala utilizada para a população fundamentou-se na distribuição de freqüências da detecção dos gostos básicos e na associação entre a detecção na primeira concentração da solução de cada gosto básico com as demais variáveis de interesse por meio do teste de Qui-quadrado de Pearson, adotando-se o nível de significância de $5 \%$. 
A análise dos resultados foi feita a partir do limiar de detecção de cada criança, que é a concentração mais baixa da solução detectada (Arbisi e col. 1999).

Para a análise contra um desfecho primário (detecção do limiar) foi utilizado o teste de Mann-Whitney, comparando-se as medianas dos escores encontrados para as crianças que detectaram a solução segundo sexo, grupo etário e estado nutricional (eutrofia e excesso de peso), e estabelecendo-se o nivel de significância menor que $5 \%$.

Para verificar a performance global de cada solução testada como critério diagnóstico: grupo etário, sexo e estado nutricional, utilizou-se a Curva ROC (Receiver Operating Characteristics). Apesar de ter sido utilizada uma escala de seis pontos distintos de concentração há uma continuidade entre os valores. Esta curva foi construída colocando-se os valores da sensibilidade do método no eixo das ordenadas, e o complemento da especificidade, 1-especificidade, no eixo das abscissas. A sensibilidade seria a predição correta de deteç̧ão, e a especificidade a predição correta de não detecção, calculadas para cada valor da escala de diluição utilizada. Foi testado se a área sob a curva ROC era significativamente maior que a hipótese nula (área $=0,5$ ), no nível de significância de $5 \%$. Quanto mais próximo de 1,0 e mais distante de 0,5 for à área da curva, maior a performance do procedimento.

Foram realizados modelos de regressão logística não condicional. A deteç̧ão ou não de cada gosto, na concentração determinada pela Curva ROC com 0 maior valor de sensibilidade e especificidade 
concomitantemente, pelas crianças para cada gosto básico, estabelecido como variável dependente, e as demais como independentes. A análise da significância estatística foi feita por meio do teste de razão de verossimilhança (likelihood ratio test). Os cálculos estatísticos foram realizados com o auxílio do programa Stata 6.0 (STATACORP 1999) e SPSS for Windows 13.0 (2003). 


\section{RESULTADOS}

\subsection{Descrição da população de estudo}

A amostra final constituiu-se de 376 crianças de 4 a 11 anos de idade, sendo $47,87 \%$ meninos e $52,13 \%$ meninas. A distribuição das crianças por faixa etária e sexo é demonstrada na tabela 1. 
Tabela 1 - Distribuição em número e porcentagem de crianças segundo grupo, etário e sexo. Creche/ Pré-escolas COSEAS/USP e Escola de Aplicação- FE/ USP São Paulo, 2004.

\begin{tabular}{|c|c|c|c|c|c|c|c|}
\hline \multicolumn{2}{|c|}{ Grupo etário } & \multicolumn{4}{|c|}{ Sexo } & \multicolumn{2}{|c|}{ Total } \\
\hline & & \multicolumn{2}{|c|}{ Masculino } & \multicolumn{2}{|c|}{ Feminino } & \multirow[b]{2}{*}{$N$} & \multirow[b]{2}{*}{$\%$} \\
\hline & & $\mathrm{N}$ & $\%$ & $\mathrm{~N}$ & $\%$ & & \\
\hline \multirow{3}{*}{ Pré-escolares } & $41-5$ & 25 & 13,9 & 16 & 8,2 & 41 & 10,9 \\
\hline & $51-6$ & 24 & 13,3 & 24 & 12,2 & 48 & 12,8 \\
\hline & $61-7$ & 31 & 17,2 & 45 & 23,0 & 76 & 20,2 \\
\hline \multirow{4}{*}{ Escolares } & $71-8$ & 21 & 11,7 & 23 & 11,7 & 44 & 11,7 \\
\hline & $81-9$ & 19 & 10,6 & 33 & 16,8 & 52 & 13,8 \\
\hline & $91-10$ & 24 & 13,3 & 26 & 13,3 & 50 & 13,3 \\
\hline & $101-11$ & 36 & 20,0 & 29 & 14,8 & 65 & 17,3 \\
\hline \multicolumn{2}{|l|}{ Total } & 180 & 100,0 & 196 & 100,0 & 376 & 100,0 \\
\hline
\end{tabular}

A concentração de elementos é maior no grupo de escolares, e a faixa etária com maior número de indivíduos é a dos seis anos a seis anos e onze meses. Ressalva-se, entretanto, que entre os escolares de sete anos foi incluído um menino que pertencia à creche, prevalecendo o critério idade para a classificação da criança no grupo etário e não o local de estudo. 
A proporção de meninos e meninas não apresentou diferença estatisticamente significativa entre os grupos etários $(p=0,833)$, nem entre as diversas faixas etárias $(p=0,198)$.

\subsection{Estado de Saúde}

Identificou-se entre os pré-escolares 16 com doenças respiratórias crônicas, dentre estas apenas duas eram meninas. Tais crianças participaram do estudo, porque estavam assintomáticas e também não usavam medicamentos durante o período da coleta dos dados. Entretanto 8 pré-escolares foram excluídos da pesquisa, pois estavam doentes e/ou usavam medicamentos. As doenças manifestadas por estas crianças foram amidalite $(n=2)$, rinite $(n=1)$, síndrome de imunodeficiência adquirida $(n=1)$, anemia $(n=1)$ e desnutrição $(n=4)$, além de 3 crianças que usavam continuamente medicamentos, antialérgico $(n=2)$, e anticonvulsionante $(n=1)$.

Foram excluídos da amostra 29 escolares por terem alguma doença, como tosse $(n=7)$, bronquite $(n=3)$, sinusite $(n=2)$, anemia $(n=10)$ e desnutrição ( $n=1)$, e/ou utilizarem algum tipo de medicamento $(n=16)$. 


\subsection{Caracterização do Estado nutricional das crianças}

Os valores médios e medianos das variáveis: idade, altura, peso e IMC são próximos para cada grupo etário. Há uma dispersão maior dos valores referentes aos dados coletados de escolares.

Tabela 2- Distribuição das medidas de tendência central das características antropométricas segundo idade das crianças. Creche/ Pré-escolas COSEAS/ USP e Escola de Aplicação- FE/ USP São Paulo, 2004.

\begin{tabular}{lcccccc}
\hline & \multicolumn{3}{c}{ Pré- escolares } & \multicolumn{3}{c}{ Escolares } \\
\cline { 2 - 7 } & Média & DP & Mediana & Média & DP & Mediana \\
\hline Idade & 5,7 & 0,82 & 5,86 & 9,15 & 1,16 & 9,23 \\
Altura $(\mathrm{cm})$ & 114,9 & 6,99 & 114,95 & 135,03 & 9,62 & 134,85 \\
Peso $(\mathrm{kg})$ & 21,82 & 4,45 & 21,00 & 33,48 & 9,08 & 31,80 \\
IMC $\left(\mathrm{kg} / \mathrm{m}^{2}\right)$ & 16,39 & 1,99 & 16,11 & 18,10 & 3,19 & 17,37 \\
\hline
\end{tabular}

Ao avaliar o estado nutricional das crianças notou-se o predomínio da eutrofia $(66,5 \%)$. A prevalência de risco de obesidade e obesidade foi maior entre os escolares $(p=0,003)$. Observou-se que $24,2 \%$ dos pré-escolares e $40,7 \%$ dos escolares apresentaram excesso de peso (Tabela 3a). 
Destaca-se que não foi verificada associação do estado nutricional com o sexo da criança, tanto no grupo etário dos pré-escolares $(p=0,469)$, como no dos escolares $(p=0,141)$.

Tabela 3a- Distribuição em número e porcentagem de crianças segundo grupo, sexo e estado nutricional. Creche/ Pré-escolas COSEASI USP e Escola de Aplicação - FE/ USP São Paulo, 2004.

\begin{tabular}{|c|c|c|c|c|c|c|c|c|c|c|}
\hline \multirow{4}{*}{$\begin{array}{l}\text { Estado } \\
\text { Nutricional }\end{array}$} & \multicolumn{4}{|c|}{ Pré-escolares } & \multicolumn{4}{|c|}{ Escolares } & \multicolumn{2}{|c|}{ Total } \\
\hline & \multicolumn{8}{|c|}{ Sexo } & & \\
\hline & \multicolumn{2}{|c|}{ Masculino } & \multicolumn{2}{|c|}{ Feminino } & \multicolumn{2}{|c|}{ Masculino } & \multicolumn{2}{|c|}{ Feminino } & \multirow[b]{2}{*}{$n$} & \multirow[b]{2}{*}{$\%$} \\
\hline & $n$ & $\%$ & $\mathrm{n}$ & $\%$ & $\mathrm{n}$ & $\%$ & $n$ & $\%$ & & \\
\hline Eutrofia & 65 & 81,2 & 60 & 70,6 & 65 & 65,0 & 60 & 54,0 & 250 & 66,5 \\
\hline Risco de Obes. & 12 & 15,0 & 20 & 23,5 & 28 & 28,0 & 38 & 34,3 & 98 & 26,0 \\
\hline Obesidade & 3 & 3,8 & 5 & 5,9 & 7 & 7,0 & 13 & 11,7 & 28 & 7,5 \\
\hline Total & 80 & 100,0 & 85 & 100,0 & 100 & 100,0 & 111 & 100,0 & 376 & 100,0 \\
\hline
\end{tabular}

Por meio da análise de resíduo padronizado evidenciou-se uma falta de ocorrência de risco de obesidade e excesso de ocorrência do estado de eutrofia nos pré-escolares. Para os escolares houve uma falta de ocorrência de eutrofia e excesso na categoria de risco de obesidade (Tabela 3b). 
Tabela 3b - Resíduos padronizados no contingenciamento de estado nutricional e grupo etário a que a criança pertence. Creche/ Pré-escolas COSEAS/USP e Escola de Aplicação- FE/ USP São Paulo, 2004.

\begin{tabular}{lcccc}
\hline & \multicolumn{2}{c}{ Pré-escolares } & \multicolumn{2}{c}{ Escolares } \\
\cline { 2 - 5 } Estado Nutricional & $\mathrm{n}$ & $\begin{array}{c}\text { Resíduo } \\
\text { Padronizado }\end{array}$ & $\mathrm{n}$ & $\begin{array}{c}\text { Resíduo } \\
\text { Padronizado }\end{array}$ \\
\cline { 2 - 5 } & 125 & 3,0 & 125 & $-3,0$ \\
\hline Eutrofia & 32 & $-2,2$ & 66 & 2,2 \\
Risco de obesidade & 8 & $-1,7$ & 20 & 1,7 \\
Obesidade & 165 & & 211 & \\
\hline
\end{tabular}

O valor médio do índice de massa corporal dos escolares não diferiu entre os sexos no grupo de obesos $(p=0,063)$, tampouco no de eutróficos $(p=0,107)$. Em relação ao risco de obesidade, as meninas apresentaram valor mediano para o índice de massa corporal inferior ao dos meninos $(p=0,001)$.

$\mathrm{Na}$ comparação dos valores do indicador de massa corpórea dos escolares (Mediana=17,37, Média $=18,18 \mathrm{~kg} / \mathrm{m}^{2}$ e desvio padrão=3,28) e das escolares (Mediana=17,37, Média $=18,02 \mathrm{~kg} / \mathrm{m}^{2}$ e desvio padrão=3,12) não existiu diferença estatisticamente significante $(p=0,879)$. 
Destaca-se que o valor médio do índice de massa corpórea dos préescolares foi semelhante entre meninas e meninos nas diferentes categorias do estado nutricional; obesidade $(p=0,655)$, e eutrofia $(p=0,82)$, com exceção da categoria de risco de obesidade $(p=0,003)$ em que os meninos apresentaram valor mediano do IMC superior (Tabela 4). No geral o valor mediano do IMC das meninas foi de $15,84 \mathrm{~kg} / \mathrm{m}^{2}$ e dos meninos de 16,25 $\mathrm{kg} / \mathrm{m}^{2}(p=0,324)$.

Tabela 4 - Distribuição dos valores médios de IMC $\left(\mathrm{Kg} / \mathrm{m}^{2}\right)$ e desvio padrão segundo estado nutricional, sexo e grupo. Creche/ Pré-escolas COSEAS/ USP e Escola de Aplicação - FE/ USP São Paulo, 2004.

\begin{tabular}{|c|c|c|c|c|c|c|c|c|c|c|c|c|}
\hline \multirow{4}{*}{$\begin{array}{l}\text { Estado } \\
\text { Nutricional }\end{array}$} & \multicolumn{6}{|c|}{ Pré-escolares } & \multicolumn{6}{|c|}{ Escolares } \\
\hline & \multicolumn{12}{|c|}{ Sexo } \\
\hline & \multicolumn{3}{|c|}{ Masculino } & \multicolumn{3}{|c|}{ Feminino } & \multicolumn{3}{|c|}{ Masculino } & \multicolumn{3}{|c|}{ Feminino } \\
\hline & $M$ & DP & $\mathrm{Md}$ & $M$ & DP & $\mathrm{Md}$ & $M$ & DP & $\mathrm{Md}$ & $M$ & DP & Md \\
\hline Eutrofia & 15,54 & 1,04 & 15,37 & 15,54 & 1,00 & 15,59 & 16,25 & 1,36 & 16,45 & 15,88 & 1,09 & 15,87 \\
\hline $\begin{array}{l}\text { Risco de } \\
\text { obesidade }\end{array}$ & 18,72 & 0,76 & 18,40 & 17,85 & 0,64 & 17,63 & 20,72 & 1,79 & 20,07 & 19,37 & 1,24 & 19,06 \\
\hline Obesidade & 22,46 & 0,59 & 22,54 & 22,46 & 1,77 & 22,78 & 26,05 & 1,17 & 26,39 & 24,04 & 3,32 & 23,07 \\
\hline
\end{tabular}




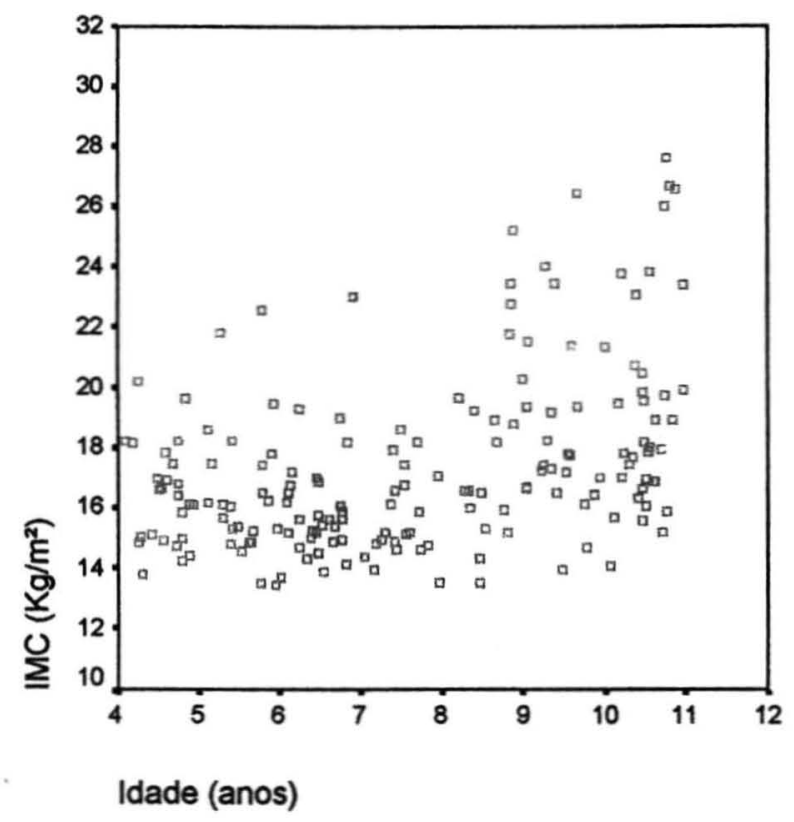

Figura 3 - Distribuição do IMC por idade em meninos

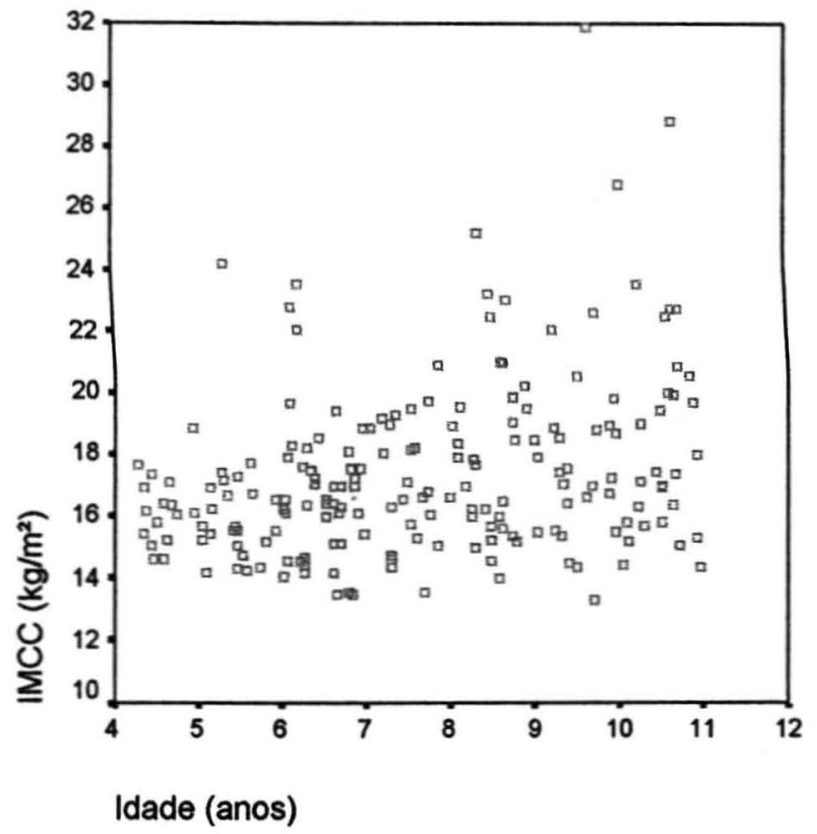

Figura 4 - Distribuição do IMC por idade em meninas 
Para a realização da regressão logística e outras análises estatísticas uniram-se as crianças que estavam classificadas como risco de obesidade e obesidade, a nova categoria recebeu o nome genérico de excesso de peso e constitui 33,5\% (n=126) da população de estudo. 


\subsection{Análise Sensorial}

\subsubsection{Avaliação da reprodutibilidade do teste}

Os limiares de detecção das crianças para cada gosto básico entre 0 primeiro teste e sua repetição (tabela 5) apresentaram concordância, ou seja, mantiveram-se praticamente inalterados $(p<0,001)$, e estas relações foram demonstradas a seguir: doce, $r=0,694$; salgado $r=0,606$, ácido $r=0,739$ e amargo $r=0,650$.

Tabela 5 - Concordância entre as respostas obtidas no primeiro e segundo teste sensorial para cada gosto básico segundo grupo etário. Creche/ Préescolas COSEAS/USP e Escola de Aplicação- FE/ USP São Paulo, 2004.

\begin{tabular}{cccccccc}
\hline Gosto & \multicolumn{3}{c}{ Pré-escolares } & & Escolares & Crianças \\
\hline & Menino & Menina & Total & Menino & Menina & Total & Total \\
Doce & 0,629 & 0,670 & 0,651 & 0,737 & 0,715 & 0,726 & 0,694 \\
Salgado & 0,448 & 0,567 & 0,515 & 0,694 & 0,658 & 0,676 & 0,606 \\
Ácido & 0,685 & 0,690 & 0,690 & 0,714 & 0,773 & 0744 & 0,739 \\
Amargo & 0,699 & 0,751 & 0,727 & 0,614 & 0,560 & 0,586 & 0,650 \\
\hline
\end{tabular}

método Kappa, "* todos os coeficientes apresentaram significância estatística $(p<0,0001)$. 
A concordância entre as respostas durante os testes sensoriais foi maior entre os escolares com exceção do gosto amargo. Entre os préescolares as meninas apresentaram uma concordância entre seus limiares de detecção nos testes sensoriais ligeiramente maiores do que os meninos com exceção do gosto ácido. Isso não foi observado no grupo dos escolares, os meninos apresentaram uma concordância entre os seus limiares de detecção para os gostos doce, salgado e amargo ligeiramente superior ao das meninas.

Optou-se por utilizar apenas as respostas obtidas na primeira seqüência de soluçōes oferecidas referente a cada gosto básico por criança, já que houve concordância entre os limiares de detecção de cada gosto básico nas duas aplicações dos testes sensoriais.

4.4.2 Concentrações das soluções dos gostos básicos

As prevalências de crianças aptas a detectarem as soluçöes testadas referentes aos gostos doce, salgado, ácido e amargo para pré-escolares e escolares na primeira concentração foram respectivamente: $17,6-21,3 \%$, $28,5 \%-29,4 \%, 26,1-64,9 \%$ e $49,1-24,6 \%$ das crianças. Todos os préescolares e escolares detectaram a presença do soluto testado para cada gosto básico até o fim da escala preconizada. 
Tabela 6 - Distribuição em porcentagem de crianças segundo grupo etário, que detectaram os gostos básicos por concentrações na primeira $\left(1^{\mathrm{a}}\right)$ e segunda $\left(2^{\mathrm{a}}\right)$ seqüências testadas. Creche/ Pré-escolas COSEAS/USP e Escola de Aplicação- FE/ USP São Paulo, 2004.

\begin{tabular}{|c|c|c|c|c|c|c|c|c|c|c|c|c|c|}
\hline \multirow{3}{*}{$\begin{array}{l}\text { Gostos } \\
\text { Básico } \\
\text { s }\end{array}$} & \multirow{3}{*}{$\begin{array}{c}{[]} \\
\mathrm{mmo} / \mathrm{L}\end{array}$} & \multicolumn{4}{|c|}{ Pré-escolares } & \multicolumn{4}{|c|}{ Escolares } & \multicolumn{4}{|c|}{ Crianças } \\
\hline & & \multicolumn{2}{|c|}{$1^{a}$} & \multicolumn{2}{|c|}{$2^{a}$} & \multicolumn{2}{|c|}{$1^{a}$} & \multicolumn{2}{|c|}{$2^{a}$} & \multicolumn{2}{|c|}{$1^{a}$} & \multicolumn{2}{|c|}{$2^{a}$} \\
\hline & & $\mathrm{n}$ & $\%$ & $\mathrm{n}$ & $\%$ & $\mathrm{n}$ & $\%$ & $\mathrm{n}$ & $\%$ & $\mathrm{n}$ & $\%$ & $\mathrm{n}$ & $\%$ \\
\hline \multirow[t]{6}{*}{ Doce } & 1,46 & 29 & 17,6 & 28 & 17,0 & 45 & 21,3 & 40 & 19,0 & 74 & 19,7 & 68 & 18,1 \\
\hline & 2,92 & 64 & 38,8 & 59 & 35,8 & 79 & 37,4 & 81 & 38,4 & 143 & 38 & 140 & 372 \\
\hline & 5,84 & 89 & 53,9 & 88 & 53,3 & 132 & 62,6 & 133 & 63,0 & 221 & 58,8 & 221 & 58,8 \\
\hline & 11,68 & 124 & 75,2 & 123 & 74,5 & 183 & 86,7 & 180 & 85,3 & 307 & 81,6 & 303 & 80,6 \\
\hline & 23,37 & 157 & 95,2 & 156 & 94,5 & 209 & 99,1 & 209 & 99,1 & 366 & 97,3 & 365 & 97,1 \\
\hline & 46,74 & 165 & 100,0 & 165 & 100,0 & 211 & 100,0 & 211 & 100,0 & 376 & 100,0 & 376 & 100,0 \\
\hline \multirow[t]{6}{*}{ Salgado } & 1,54 & 47 & 28,5 & 39 & 23,6 & 62 & 29,4 & 66 & 31,3 & 109 & 29,0 & 105 & 27,2 \\
\hline & 3,08 & 89 & 53,9 & 91 & 55,2 & 110 & 52,1 & 119 & 56,4 & 199 & 52,9 & 210 & 55,9 \\
\hline & 6,33 & 127 & 77,0 & 123 & 74,5 & 160 & 75,8 & 161 & 76,3 & 287 & 76,3 & 284 & 75,5 \\
\hline & 12,83 & 153 & 92,7 & 151 & 91,5 & 188 & 89,1 & 190 & 90,0 & 341 & 90,7 & 341 & 90,7 \\
\hline & 25,67 & 164 & 99,4 & 164 & 99,4 & 210 & 99,5 & 210 & 99,5 & 374 & 99,5 & 374 & 99,5 \\
\hline & 51,33 & 165 & 100,0 & 165 & 100,0 & 211 & 100,0 & 211 & 100,0 & 376 & 100,0 & 376 & 100,0 \\
\hline \multirow[t]{6}{*}{ Azedo } & 0,08 & 43 & 26,1 & 37 & 22,4 & 137 & 64,9 & 140 & 66,4 & 180 & 47,9 & 177 & 47,1 \\
\hline & 0,16 & 74 & 44,8 & 72 & 43,6 & 174 & 82,5 & 171 & 81,0 & 248 & 66,0 & 243 & 64,6 \\
\hline & 0,32 & 128 & 77,6 & 123 & 74,5 & 197 & 93,4 & 199 & 94,3 & 325 & 86,4 & 322 & 85,6 \\
\hline & 0,65 & 157 & 95,2 & 157 & 95,2 & 209 & 99,1 & 210 & 99,5 & 366 & 97,3 & 367 & 97,6 \\
\hline & 1,30 & 164 & 99,4 & 164 & 99,4 & 211 & 100,0 & 211 & 100,0 & 375 & 99,7 & 375 & 99,7 \\
\hline & 2,62 & 165 & 100,0 & 165 & 100,0 & 211 & 100,0 & 211 & 100,0 & 376 & 100,0 & 376 & 100,0 \\
\hline \multirow[t]{6}{*}{ Amargo } & 0,13 & 81 & 49,1 & 86 & 52,1 & 52 & 24,6 & 56 & 26,5 & 133 & 35,4 & 142 & 37,8 \\
\hline & 0,26 & 103 & 62,4 & 105 & 63,6 & 89 & 42,2 & 94 & 44,5 & 192 & 51,1 & 199 & 52,9 \\
\hline & 0,51 & 121 & 73,3 & 119 & 72,1 & 126 & 59,7 & 129 & 61,1 & 247 & 65,7 & 248 & 66,0 \\
\hline & 1,03 & 135 & 81,8 & 139 & 84,2 & 158 & 74,9 & 167 & 79,1 & 293 & 77,9 & 306 & 81,4 \\
\hline & 2,06 & 158 & 95,8 & 159 & 96,4 & 199 & 94,3 & 201 & 95,3 & 357 & 94,9 & 360 & 95,7 \\
\hline & 4,12 & 165 & 100,0 & 165 & 100,0 & 211 & 100,0 & 211 & 100,0 & 376 & 100,0 & 376 & 100,0 \\
\hline
\end{tabular}


4.4.3 Análise da detecção dos gostos básicos no início das escalas

Nos gostos doce $(1,46 \mathrm{mmol} / \mathrm{L})$ e salgado $(1,54 \mathrm{mmol} / \mathrm{L})$ não foram observadas associações da detecção dos solutos na primeira concentração com as variáveis de interesse (estado nutricional, sexo e grupo etário) (Tabela 7).

Porém, verificou-se associação entre o sexo e a detecção do gosto ácido $(0,08 \mathrm{mmol} / \mathrm{L})(p=0,021)$. Averiguou-se a associação entre o grupo etário e a detecção da solução de ácido cítrico, a qual foi detectada por uma proporção maior de escolares $(p=0,0001)$.

Para o gosto amargo $(0,13 \mathrm{mmol} / \mathrm{L})$ foi verificado uma proporção maior de pré-escolares capazes de detectar a solução mais diluída de cafeína também (Tabela 7). 
Tabela 7- Distribuição em porcentagem de crianças que detectaram os gostos básicos na primeira concentração segundo o sexo, grupo etário e estado nutricional. Crechel Pré-escolas COSEAS/USP e Escola de Aplicação- FE/ USP São Paulo, 2004.

\begin{tabular}{|c|c|c|c|c|c|c|c|c|c|}
\hline \multirow{2}{*}{$\begin{array}{l}\text { Gostos } \\
\text { Básicos }\end{array}$} & \multicolumn{3}{|c|}{ Sexo } & \multicolumn{3}{|c|}{ Grupo etário } & \multicolumn{3}{|c|}{ Estado Nutricional } \\
\hline & $M$ & $F$ & $p$ & $\begin{array}{c}\text { Pré- } \\
\text { escolares }\end{array}$ & Escolares & $p$ & Eutrofia & $\begin{array}{l}\text { Exc. de } \\
\text { Peso }\end{array}$ & $p$ \\
\hline Doce & 43,2 & 56,8 & 0,374 & 39,2 & 60,8 & 0,364 & 73,0 & 27,0 & 0,187 \\
\hline Salgado & 40,4 & 59,6 & 0,063 & 43,1 & 56,9 & 0,849 & 68,8 & 31,2 & 0,543 \\
\hline Ácido & 41,7 & 58,3 & 0,021 & 23,9 & 76,1 & 0,0001 & 61,7 & 38,3 & 0,058 \\
\hline Amargo & 51,1 & 48,9 & 0,350 & 60,9 & 39,1 & 0,0001 & 66,2 & 33,8 & 0,922 \\
\hline
\end{tabular}

${ }^{*}$ Qui-quadrado de Pearson

\subsection{Análise dos limiares de detecção dos gostos básicos nas escalas}

Os limiares de detecção para cada gosto básico foram demonstrados com seus valores médios, desvios-padrão, mediana segundo sexo, grupo etário e estado nutricional (Tabela 8). 
Tabela 8 - Distribuição das medidas de dispersão central e comparação dos valores medianos dos limiares de deteç̧ão dos gostos básicos das crianças segundo sexo, grupo etário, estado nutricional. Crechel Pré-escolas COSEAS/USP e Escola de Aplicação - FE/ USP São Paulo, 2004.

\begin{tabular}{|c|c|c|c|c|c|c|c|c|c|}
\hline \multirow{2}{*}{$\begin{array}{l}\text { Gostos } \\
\text { Básicos }\end{array}$} & \multicolumn{3}{|c|}{ Sexo } & \multicolumn{3}{|c|}{ Grupo etário } & \multicolumn{3}{|c|}{ Estado Nutricional } \\
\hline & M & $\mathrm{F}$ & $p$ & Pré-escolar & Escolar & $p$ & Eutrofia & $\begin{array}{l}\text { Excesso } \\
\text { de peso }\end{array}$ & $p$ \\
\hline \multicolumn{10}{|c|}{ Doce (mmol/L) } \\
\hline Média & 9,803 & 9,487 & 0,742 & 11,181 & 8,432 & 0,107 & 10,161 & 8,602 & 0,482 \\
\hline $\mathrm{DP}$ & 9,749 & 9,443 & & 11,281 & 7,819 & & 10,130 & 8,319 & \\
\hline Mediana & 5,843 & 5,843 & & 5,843 & 5,843 & & 5,843 & 5,843 & \\
\hline \multicolumn{10}{|c|}{ Salgado (mmol/L) } \\
\hline Média & 7,364 & 6,617 & 0,082 & 6,706 & 7,184 & 0,817 & 6,930 & 7,060 & 0,669 \\
\hline $\mathrm{DP}$ & 7,669 & 7,541 & & 7,303 & 7,838 & & 7,574 & 7,685 & \\
\hline Mediana & 6,331 & 3,080 & & 3,080 & 3,080 & & 3,080 & 3,080 & \\
\hline \multicolumn{10}{|c|}{ Ácido (mmol/L) } \\
\hline Média & 0,261 & 0,211 & 0,007 & 0,338 & 0,154 & 0,0001 & 0,257 & 0,191 & 0,010 \\
\hline DP & 0,254 & 0,273 & & 0,335 & 0,152 & & 0,286 & 0,212 & \\
\hline Mediana & 0,156 & 0,078 & & 0,323 & 0,078 & & 0,156 & 0,078 & \\
\hline \multicolumn{10}{|c|}{ Amargo (mmo/L) } \\
\hline Média & 0,853 & 0,838 & 0,965 & 0,703 & 0,957 & 0,0001 & 0,845 & 0,845 & 0,658 \\
\hline $\mathrm{DP}$ & 1,008 & 1,044 & & 0,980 & 1,050 & & 1,0 & 1,080 & \\
\hline Mediana & 0,387 & 0,259 & & 0,258 & 0,515 & & 0,258 & 0,258 & \\
\hline
\end{tabular}


Os limiares medianos do gosto doce, salgado e amargo não diferiram estatisticamente segundo o sexo da criança.

A idade foi um fator que interferiu nos limiares de detecção dos gostos ácido e amargo.

O grupo de escolares apresentou limiar de detecção para o gosto ácido inferior ao encontrado para o grupo de pré-escolares. O limiar mediano de detecção do gosto ácido das meninas foi inferior ao encontrado para os meninos $(p=0,021)$.

O limiar mediano de detecção do gosto amargo foi maior entre os escolares $(p=0,001)$.

\subsection{Curvas ROC}

O melhor ponto da diluição preconizada e experimentada pelos indivíduos considerando a sensibilidade e especificidade do resultado do teste como critério diagnóstico foi determinado por meio da Curva ROC. Este ponto foi selecionado como o corte que maximiza simultaneamente a sensibilidade como a especificidade na escala de diluições utilizadas para cada gosto básico. 
As figuras 5 a 8 demonstram os valores da área da curva ROC dos escores dos gostos básicos $(\mathrm{Az})$ e sua significância $(\mathrm{p})$ para as crianças segundo o sexo, grupo etário e estado nutricional.

\subsubsection{Gosto Doce}

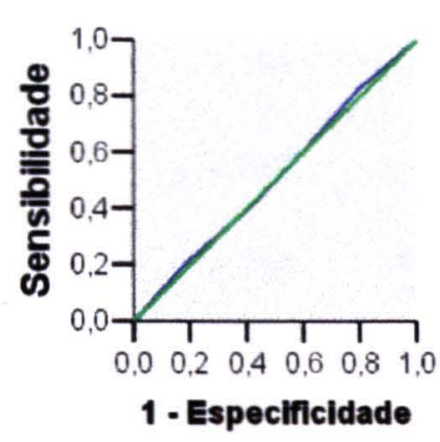

Figura 5A - Área sob a curva ROC dos escores de limiares de deteç̧ão do gosto doce segundo sexo. Área: 0,510, $p=0,747$

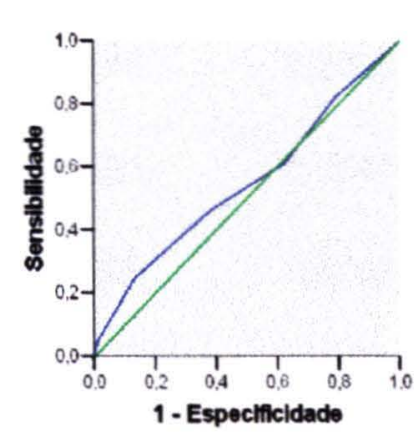

Figura 5B - Área sob a curva ROC dos escores de limiares de deteç̧ão do gosto doce segundo grupo etário. Área: $0,547, p=0,030$

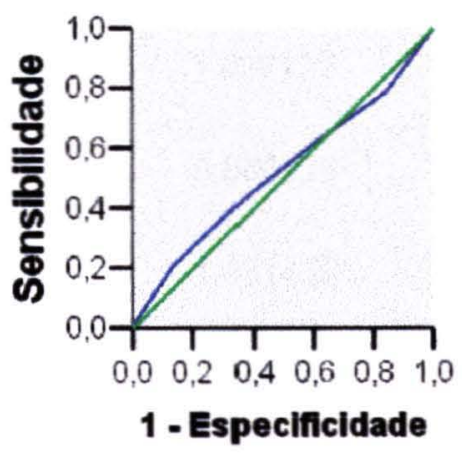

Figura 5C - Área sob a curve ROC dos escores de limiares de detecçăo do gosto doce segundo estado nutricional Área: $0,522, p=0,490$

As categorias básicas para obtenção dessas áreas da curva roc foram respectivamente: ser menino, pré-escolar e o estado nutricional de eutrofia.

Para o gosto doce estimou-se a concentração de $17,53 \mathrm{mmol} / \mathrm{L}$ com o poder de discriminação de 0,547 (IC95\%:0,488-0,607) como melhor ponto de corte para diagnosticar o grupo etário (Figura 5B). Selecionou-se a 
concentração de $23,371 \mathrm{mmo} / \mathrm{L}$ como ponto discriminatório da deteç̧ão da solução doce pelas crianças (Tabela 9).

Tabela 9 - Pontos estimados pela Curva ROC para o gosto doce segundo idade das crianças. Crechel Pré-escolas COSEASIUSP e Escola de Aplicação- FE/ USP São Paulo, 2004.

\begin{tabular}{cccc}
\hline $\begin{array}{c}\text { Pontos estimados } \\
(\mathrm{mmo} / \mathrm{L})\end{array}$ & Sensibilidade & Especificidade & $\begin{array}{c}\text { Sensibilidade }+ \\
\text { Especificidade }\end{array}$ \\
\hline 2,191 & 0,824242 & 0,208531 & 1,032773 \\
4,382 & 0,612121 & 0,374408 & 0,986529 \\
8,765 & 0,460606 & 0,620853 & 1,081459 \\
17,530 & 0,248485 & 0,867299 & 1,115783 \\
35,057 & 0,048485 & 0,990521 & 1,039006 \\
\hline
\end{tabular}




\subsubsection{Gosto Salgado}

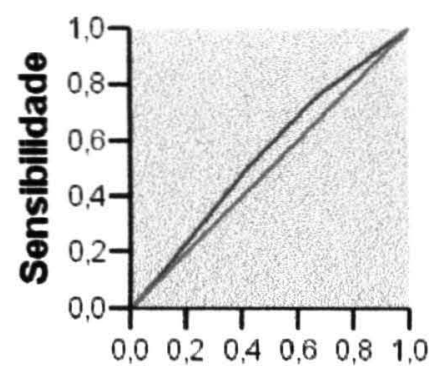

1 - Especificidade

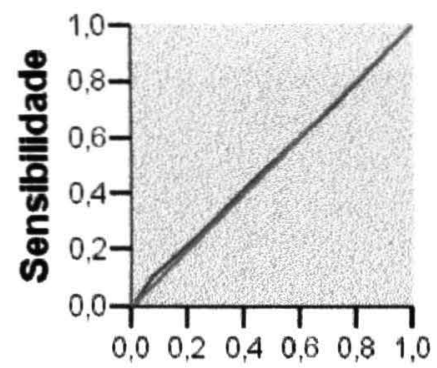

1 - Especificidade

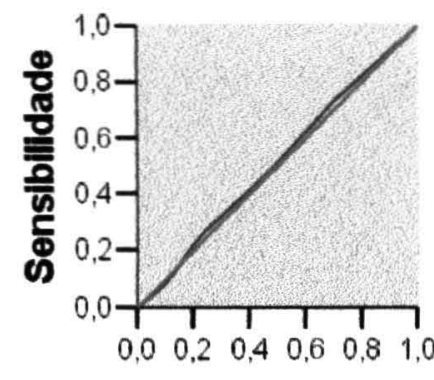

1 - Especificidade

Figura 6A - Área sob a

Figura 6B - Área sob a Figura 6C - Área sob a curva curva ROC dos escores de limiares de detecção curva ROC dos escores de limiares de deteç̧ão do gosto salgado segundo grupo etário. Área: 0,507, $p=0,822$

ROC dos escores de limiares de detecção do gosto salgado segundo estado nutricional. Área: 0,513 $p=0,677$

O valor da área estimada para cada curva dos limiares de detecção do gosto salgado pelas crianças para todas as variáveis de interesse foi próximo a 0,5 o que corresponde a uma performance ao acaso, impedindo a seleção de um possivel ponto de corte. As categorias bases para obtenção dessas áreas da curva roc foram: ser menino, grupo etário escolar e para o estado nutricional, o excesso de peso. 


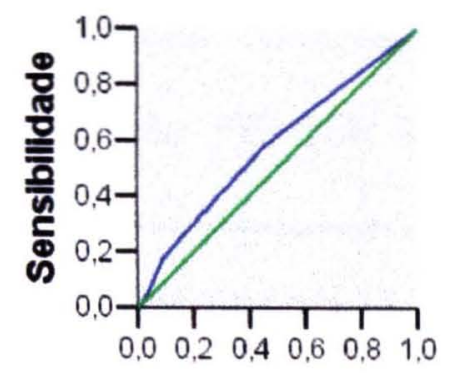

1 - Especificidade

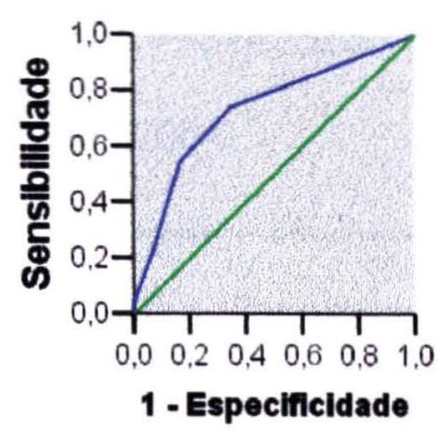

Figura 7B - Área sob a curva ROC dos escores de limiares de detecção do gosto ácido segundo grupo etário. Área: 0,731, $p=0,001$

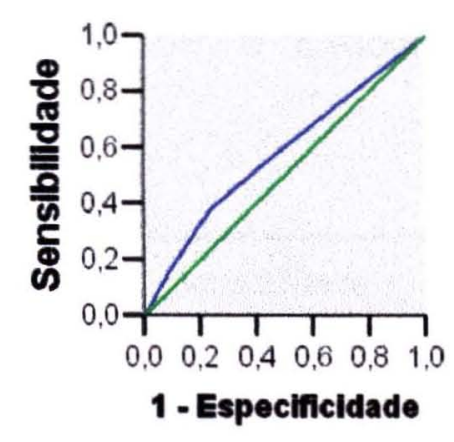

Figura 7C - Área sob a curva ROC dos escores de limiares de detecção do gosto doce segundo estado nutricional. Área: 0,576, $p=0,016$

As categorias de base para obtenção dessas áreas da curva roc foram: sexo masculino, grupo etário préescolar e estado nutricional de eutrofia.

O gosto ácido pôde ser utilizado como o melhor critério de diagnóstico para a idade com poder de discriminação de 0,731 (IC95\%:0,679-0,783) (Figura 7B) e para o sexo de 0,576 (IC95\%:0,518-0,634) (Figura 7A) no ponto de corte $0,117 \mathrm{mmol} / \mathrm{L}$ (Tabela 10 ), já para o estado nutricional o ponto de corte estimado é $0,2395 \mathrm{mmol} / \mathrm{L}$ com o poder discriminatório de 0,576 (IC95\%:0,516-0,636) (Figura 7C). Contudo optou-se como ponto ideal a 
concentração de $0,156 \mathrm{mmol} / \mathrm{L}$ da solução do gosto ácido para a análise logística.

Tabela 10 - Pontos estimados pela Curva ROC para o gosto ácido segundo idade das crianças. Crechel Pré-escolas COSEAS/USP e Escola de Aplicação- FE/ USP São Paulo, 2004.

\begin{tabular}{cccc}
\hline Pontos estimados (mol/L) & Sensibilidade & Especificidade & $\begin{array}{c}\text { Sensibilidade }+ \\
\text { especificidade }\end{array}$ \\
\hline 0,117 & 0,739394 & 0,654028 & 1,393422 \\
0,240 & 0,545455 & 0,834123 & 1,379578 \\
0,487 & 0,218182 & 0,933649 & 1,151831 \\
0,976 & 0,048485 & 1 & 1,048485 \\
1,961 & 0,006061 & 1 & 1,006061 \\
\hline
\end{tabular}




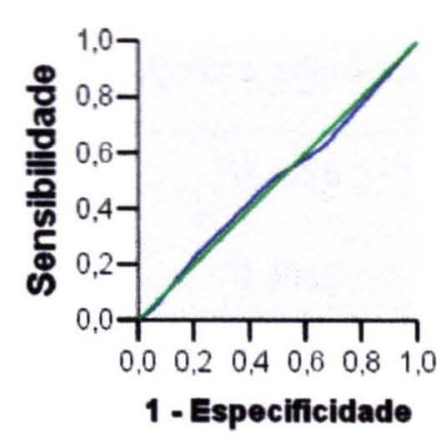

Figura 8A - Área sob a curva ROC dos escores de limiares de detecção do gosto amargo segundo sexo.

Área: $0,499, p=0,966$

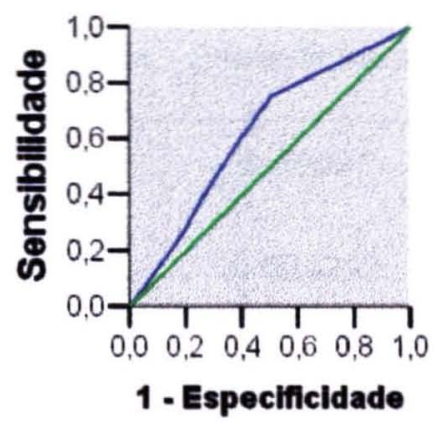

Figura 8B - Área sob a curva ROC dos escores de limiares de deteç̧ão do gosto amargo segundo grupo etário.

Área: $0,624, p=0,0001$

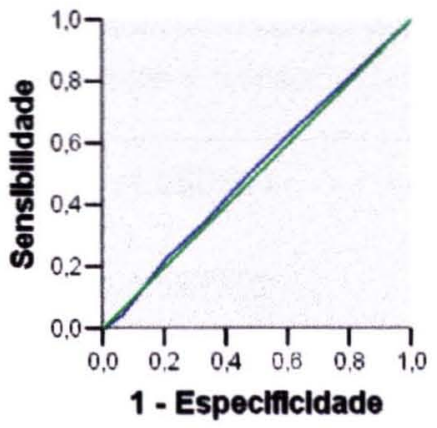

Figura $8 \mathrm{C}$ - Área sob a curva ROC dos escores de limiares de detecçăo do gosto amargo segundo estado nutricional. Área: $0,514, p=0,668$

As categorias básicas para obtenção dessas áreas da curva roc foram o sexo masculino, o grupo etário escolar e o estado nutricional de eutrofia.

Selecionou-se o ponto de corte para o diagnóstico do grupo etário pelo gosto amargo, o qual foi estimado na concentração de $0,1935 \mathrm{mmol} / \mathrm{L} \mathrm{com}$ poder de discriminação de 0,624 (IC95\%:0,566-0,682) (Figura 8B). Sugerese a concentração $0,258 \mathrm{mmol} / \mathrm{L}$ para as futuras análises. 
Tabela 11 - Pontos estimados pela Curva ROC para o gosto amargo segundo idade das crianças. Creche/ Pré-escolas COSEAS/USP e Escola de Aplicação- FE/ USP São Paulo, 2004.

\begin{tabular}{cccc}
\hline Pontos estimados & Sensibilidade & Especificidade & Sensibilidade + Especificidade \\
\hline 0,1935 & 0,753555 & 0,49697 & 1,250524 \\
0,3865 & 0,57346 & 0,624242 & 1,197702 \\
0,7725 & 0,402844 & 0,733333 & 1,136177 \\
1,545 & 0,251185 & 0,818182 & 1,069367 \\
3,09 & 0,056872 & 0,957576 & 1,014448 \\
\hline
\end{tabular}




\subsection{Análise da detecção dos gostos básicos}

A análise da associação entre as crianças que estavam aptas ou não a detectarem a presença do soluto nas soluçöes no valor estimado como o de maior poder discriminatório na população de estudo, na escala de concentração das soluções doce, ácida e amarga oferecidas, com exceção da salgada em que nenhuma variável estudada foi significante, foram mostradas abaixo segundo o grupo etário, sexo e estado nutricional para os gostos básicos na Tabela 12.

Tabela 12 - Distribuição em porcentagem de crianças que detectaram os gostos básicos no valor estimado como o de maior poder discriminatório (concentração) segundo sexo, grupo etário e estado nutricional. Creche/ Préescolas COSEAS/USP e Escola de Aplicação- FE U USP São Paulo, 2004.

\begin{tabular}{|c|c|c|c|c|c|c|c|c|c|}
\hline \multirow{2}{*}{$\begin{array}{l}\text { Gostos } \\
\text { Básicos }\end{array}$} & \multicolumn{3}{|c|}{ Sexo } & \multicolumn{3}{|c|}{ Grupo etário } & \multicolumn{3}{|c|}{ Estado Nutricional } \\
\hline & M & $F$ & $p$ & $\begin{array}{l}\text { Pré- } \\
\text { Escolar }\end{array}$ & Escolar & $p$ & Eutrofia & $\begin{array}{l}\text { Exc. de } \\
\text { Peso }\end{array}$ & $p$ \\
\hline $\begin{array}{l}\text { Doce } \\
\text { (23,37mmoVL) }\end{array}$ & 97,2 & 97,4 & 0,891 & 95,2 & 99,1 & 0,02 & 96,8 & 98,4 & 0,359 \\
\hline $\begin{array}{l}\text { Ácido } \\
(0,156 \mathrm{mmoVL})\end{array}$ & 60,0 & 71,4 & 0,019 & 44,8 & 82,5 & 0,0001 & 61,6 & 74,6 & 0,012 \\
\hline $\begin{array}{l}\text { Amargo } \\
(0,258 \mathrm{mmo} / \mathrm{L})\end{array}$ & 49,4 & 52,6 & 0,547 & 62,4 & 42,2 & 0,0001 & 50,4 & 52,4 & 0,717 \\
\hline
\end{tabular}

*Qui-quadrado de Pearson 
Para os gostos doce e amargo apenas uma variável de interesse, a idade, apresentou um valor de significância para ser inserida em um modelo de regressão logística. A regressão logística foi ajustada para um modelo de predição de detecção do gosto ácido com as variáveis, sexo e estado nutricional.

Tabela 13 - Resultados das analises univariadas de regressão logística para os gostos básicos. Creche/ Pré-escolas COSEAS/USP e Escola de Aplicação- FE/ USP São Paulo, 2004.

\begin{tabular}{lllll}
\hline Gosto & $\begin{array}{l}\text { Variaveis } \\
\text { independentes }\end{array}$ & OR & IC (95\%) & P \\
\hline Doce & $\begin{array}{l}\text { Grupo etário } \\
\text { (Pré-escolar X Escolar) }\end{array}$ & 5,325 & $1,115-25,423$ & 0,036 \\
Acido & $\begin{array}{l}\text { Grupo etário } \\
\text { (Pré-escolar X Escolar) }\end{array}$ & 5,783 & $3,617-9,244$ & 0,0001 \\
& $\begin{array}{l}\text { Sexo } \\
\text { (masculino X Feminino) }\end{array}$ & 1,667 & $1,084-2,562$ & 0,020 \\
& $\begin{array}{l}\text { Estado Nutricional } \\
\text { (eutrofico X excesso de peso) }\end{array}$ & 1,831 & $1,138-2,945$ & 0,013 \\
Amargo & $\begin{array}{l}\text { Grupo etário } \\
\text { (Pré-escolar X Escolar) }\end{array}$ & 0,439 & $0,289-0,666$ & 0,0001 \\
\hline
\end{tabular}




\subsection{Análise de regressão logistica dos limiares de deteç̧ão dos gostos básicos}

\subsubsection{Gosto doce}

A análise da detecção ou não do gosto doce foi realizada a partir da $5^{\text {a }}$ concentração da solução de sacarose $(23,37 \mathrm{mmol} / \mathrm{L})$, na qual $99,1 \%$ das crianças estavam aptas a detectar este gosto básico.

A probabilidade de detectar a presença do soluto na solução tendia a aumentar quanto maior a idade da criança, ou seja, caso a criança estivesse com mais de 7 anos a probabilidade dela detectar era 1,46 vezes maior do que a de uma criança pré-escolar (Tabela 13), considerando que nenhuma outra variável estudada interferiu no valor preditivo para o desfecho.

\subsubsection{Gosto Ácido}

A análise da deteç̧ão ou não do gosto ácido foi realizada a partir da $2^{\mathrm{a}}$ concentração da solução de ácido cítrico $(0,16 \mathrm{mmol} / \mathrm{L})$, na qual $82,5 \%$ das crianças estavam aptas a detectá-lo. Analisando separadamente cada variável independente observou-se uma alta chance de detectar a solução 
chance de detecção da solução entre as meninas é 1,67 vezes maior do que a dos meninos $(0 R=1,67, I C=1,08-2,56)$. As crianças com excesso de peso tiveram uma maior chance de detecção do soluto do que as eutróficas $(\mathrm{OR}=1,83, \mathrm{IC}=1,14-2,94)$ (Tabela 13).

Para essa solução oferecida referente ao gosto ácido foi realizada uma análise de regressão logística a fim de conhecer quais os fatores que estimularam ou inibiram a detecção da solução pelas crianças. Foram inseridas no modelo logístico as variáveis independentes que obtiveram $p<0,20$ na análise univariada. Iniciou-se a modelagem com a variável grupo etário, e posteriormente adicionou-se a variável estado nutricional, a qual não apresentou significância no modelo, nem o ajustou e optou-se por excluí-la. Adicionou-se a variável sexo.

O modelo multivariado logístico final foi significante (-2log likelihood=416,881). O resíduo não foi significante (Qui-quadrado tendendo a zero e $p=1,00$ ). Notou-se que a criança escolar tinha 5,9 mais chance de detectar a presença do soluto do que a pré-escolar (OR=5,93, IC=3,69-9,54, $p=0,0001$ ). Caso fosse menina, a chance de perceber o soluto era ainda maior $(O R=1.79, I C=1,12-2.87, p=0,015)$. Ou seja, as escolares constituiram o grupo mais sensível à solução testada de ácido cítrico na diluição de 0,156 mmol (Tabela 14). 
Tabela 14 - Resultados do modelo final de regressão logística para a $2^{\mathrm{a}}$ concentração do gosto ácido segundo sexo e idade. Crechel Pré-escolas COSEAS/USP e Escola de Aplicação- FE/ USP São Paulo, 2004.

\begin{tabular}{lccc}
\hline Variáveis independentes & OR & IC & p \\
\hline Grupo etário & 5,935 & $3,690-9,545$ & 0,0001 \\
Sexo & 1,795 & $1,122-2,875$ & 0,015 \\
\hline
\end{tabular}

\subsubsection{Gosto Amargo}

A análise da detecção ou não do gosto amargo foi realizada a partir da $2^{a}$ concentração da solução de cafeína $(0,26 \mathrm{mmol} / \mathrm{L})$, na qual $42,2 \%$ das crianças estavam aptas a detectar o gosto. Evidenciou-se que o aumento da idade (ser escolar) foi um fator de proteção quanto à sensibilidade ao gosto amargo na concentração testada (OR=0,439 IC $=0,289-0,666, p=0,0001)$ (Tabela 13). 


\section{DISCUSSÃO}

\subsection{Descrição da população}

A distribuição conforme o sexo na população de pré-escolares e escolares foi homogênea, assim como o observado em diversos estudos (Giugliano e Melo 2004, Giugliano e Carneiro 2004, Conde 2004).

\subsection{Estado de Saúde}

Houve uma maior prevalência de crianças com problemas respiratórios no grupo de pré-escolares, porém uma minoria apresentou sintomas durante a coleta de dados. A faixa etária que a criança pertencia revelou-se um importante condicionador da presença de doenças respiratórias. Segundo Monteiro e Benício (1987) as crianças mais novas são as mais atingidas pelas doenças do trato respiratório.

A taxa excessiva de morbidade respiratória em crianças observada em São Paulo pode ser atribuída a elementos adversos como, por exemplo: fatores ambientais, não necessariamente dependentes do nivel socioeconômico da população; fatores relacionados a instabilidades 
climáticas, à poluição atmosférica e à concentração demográfica (Monteiro e Benício 1987).

\subsection{Caracterização do Estado Nutricional}

A desnutrição na infância foi controlada na cidade de São Paulo, tornando-se relativamente rara mesmo entre as famílias mais pobres. Mudanças positivas em determinantes distais (renda familiar e escolaridade materna) e intermediários (saneamento do meio, acesso a serviços de saúde e antecedentes reprodutivos) do estado nutricional justificaram parte substancial do declínio da desnutrição observado entre meados das décadas de 80 e 90 (Monteiro e Conde 2000), tais dados condizem com o baixo número diagnosticado de crianças com desnutrição no processo de seleção da amostra desta pesquisa.

$\mathrm{Na}$ população de pré-escolares e escolares freqüentadores dos Centros de Ensino da Universidade de São Paulo, Campi Cidade Universitária e Faculdade de Saúde Pública, a prevalência de excesso de peso entre pré-escolares, crianças de 4 a 6 anos, foi de $24,2 \%$, sendo $18,8 \%$ entre meninos e $29,4 \%$ nas meninas. Conde (2004) mostrou que a taxa de prevalência do excesso de peso segundo o inquérito de 1996/97 foi de 19\% para meninos e $23,2 \%$ para meninas considerando a faixa etária de 5 a 6 anos, similares a deste estudo. 
Quanto aos escolares a taxa de excesso de peso foi de $40,7 \%$ neste estudo, 35\% meninos e 38,11\% meninas (Tabela 3a). Conde (2004) verificou uma prevalência inferior de excesso de peso, utilizando o mesmo indicador antropométrico, apresentando os valores de $21,3 \%$ e $16,1 \%$ nos meninos e $17,6 \% 23,7 \%$ nas meninas respectivamente para crianças de 7 a 8 anos e de 9 a 11 anos. Mas, a base de dados do pesquisador é anterior, o que também pode estar subestimando as taxas de excesso de peso na população atual.

A transição nutricional no Brasil acarreta diferentes respostas ao estado nutricional das crianças. Com fulcro dos dados obtidos de IMC de crianças de 10 a 17 anos em 1989, evidenciou-se a tendência de correção do estado nutricional e a indicação do aumento da obesidade (Monteiro e col. 2002).

\subsection{Análise Sensorial}

Notou-se que a utilização de uma história e dinâmica, previamente desenvolvidas, para as crianças foi essencial para estimular a sua participação e compreensão dos testes sensoriais (Coelho 2002, Coelho e Pinto e Silva 2003, Caratin 2004).

A apresentação da solução mais concentrada de cada gosto básico no mesmo momento em que foi contada a história, possibilitou a compreensão da metodologia a ser aplicada, além da familiarização com 0 
entrevistador, evitando-se, destarte, reações posteriores de aversão coincidindo com os dados de outros estudos (Coelho e Pinto e Silva 2003, Visser e col. 2000).

Evidenciou-se a participação efetiva das crianças selecionadas para a pesquisa, e ressalva-se que foi respeitada a limitação das expressões verbais dos grupos etários (Coelho e Pinto e Silva 2003, Guinard 2001, Kimmel e col. 1994). Ainda, controlou-se a dificuldade das crianças permanecerem concentradas nas atividades por um espaço de tempo, conforme proposto por Guinard (2001).

As crianças compreenderam as suas funções nos testes, contudo houve a necessidade de se respeitar o momento em que os pré-escolares queriam executar os testes, ou seja, às vezes eles preferiam brincar, dormir ou até mesmo simplesmente adiar o teste. Este procedimento pode ter favorecido a atual pesquisa em relação a outros estudos (Visser e col. 2000) na mesma faixa etária apresentando uma menor taxa de desistência.

A familiaridade das crianças com os pesquisadores na aplicação dos testes foi essencial para o estudo. As crianças na pré-escola praticamente não dominam a escrita e a leitura, exigindo um entrevistador (Kroll 1990), encarecendo os tradicionais testes sensoriais e demandando mais tempo para a coleta dos dados (Guinard 2001). Através da entrevista com o adulto foi assegurado que todas as crianças experimentassem as soluções na ordem correta e oferecessem respostas para cada fase do teste, ou seja, a cada prova de solução aos pares. 
Enfatizou-se a necessidade do entrevistador ser treinado, para que não influenciasse a resposta da criança com gestos e fala, pois segundo Guinard (2001), a criança tenderia a apresentar o julgamento do adulto. Não houve dificuldade entre a criança e o pesquisador ficarem a sós durante os testes, devido à familiarização anterior.

\subsubsection{Avaliação da Reprodutibilidade do teste}

A oscilação verificada entre as respostas das crianças foi pequena nas duas seqüências de testes sensoriais aplicados, coincidindo com o observado por outros pesquisadores na detecção dos gostos básicos em testes que exigiam escolhas forçadas (James e col.1997, Stevens e col.1991, Visser e col. 2000).

Segundo Visser e col. (2000) caso houvesse um aprendizado entre as diversas aplicações dos testes sensoriais, seria evidenciado uma redução no limiar médio de detecção dos gostos básicos nas sucessivas aplicações, 0 que não foi evidenciado na presente pesquisa.

Visser e col. (2000), mostraram, ainda, uma perda na estabilidade das respostas em triplicatas dos testes sensoriais com pré-escolares, discutindo que o aumento do tempo necessário de dedicação da criança é um fator limitante. Notou-se também uma maior resistência das crianças na 
participação deste estudo de acordo com o aumento de número de sessões sensoriais aplicadas, tanto nos pré-escolares como nos escolares.

Segundo Marks e Wheeler (1998), a atenção do provador ao teste está diretamente ligada a modificações nos limiares de detecção dos gostos. Isto foi evidenciado na última sessão de teste sensorial. Existiu uma maior dificuldade de levar as crianças ao local do teste, independentemente da idade delas, já que estavam totalmente familiarizadas com a situação e nada mais era novidade, o que também foi relatado por Visser e col. (2000).

Neste caso para os pré-escolares a importância das respostas das crianças para os "glube-glubes" foi retomada, por meio de bilhetes e desenhos destes, contudo, a motivação excessiva das crianças aumentou a distração de algumas, às vezes o teste tinha que ser interrompido e postergado para outro periodo, tal problema também foi citado por Guinard (2001).

Os escolares foram informados da importância de suas respostas para a pesquisa e que era a última fase dos testes não havendo a necessidade de repeti-los em outro momento.

Ressalta-se que apesar do amargo ter sido sempre o último gosto a ser apresentado à população, provavelmente não houve interferência na confiabilidade das respostas obtidas para os pré-escolares, que apresentaram uma boa concordância entre os limiares de detecção obtidos na primeira e segunda seqüência, diferindo dos dados obtidos por Visser e 
col. (2000), em que $8,8 \%$ das crianças não quiseram participar do último teste sensorial, e 6,6\% recusaram-se a degustar o estímulo amargo.

Para os escolares o coeficiente de concordância das respostas da primeira e segunda seqüência testada para a solução amarga foi o mais baixo dentre os gostos básicos estudados tanto nos meninos quanto nas meninas. A maior parte das crianças ao detectar o gosto amargo demonstrou uma aversão e não queriam mais participar do teste, fator que pode ter diminuído a confiança da resposta da criança no segundo teste da solução, já que não havia a mesma colaboração e conseqüentemente maior nivel de atenção.

O método de estímulo constante utilizado permitiu inclusive a participação das crianças mais novas (quatro anos de idade), confirmando as constatações de diversos pesquisadores (Guinard 2001, Kimmel e col. 1994, Liem e col. 2004) referentes à capacidade de pré-escolares participarem de testes sensoriais por meio de comparação de pares de amostras. Contudo, quando a criança estava distraída ou irritada, fatores que interfeririam na sua resposta, houve a possibilidade de realizar o teste em outro momento, controlando a falta de concentração da criança na execução do teste sensorial. 


\subsubsection{Avaliação das Concentrações das soluções}

A variação nos limiares de detecção foi grande, porquanto algumas crianças estavam aptas a perceber o estímulo na primeira concentração, enquanto outras só detectaram a presença do soluto na solução mais concentrada, fato igualmente relatado no estudo de Visser e col. (2000).

Os gostos que apresentaram uma maior proporção de crianças sensíveis logo no início da escala foram: o amargo, detectado por praticamente metade do grupo de pré-escolares $(49,1 \%)$ e o ácido detectado por $64,9 \%$ dos escolares na solução mais diluída. O aumento da escala mostrou-se desejável para diferenciar as características das crianças mais sensiveis aos estímulos sensoriais das demais. Todavia, isso originaria um número grande de soluções a serem provadas pelas crianças, dificultando a pesquisa devido à possibilidade de maior número de desitências, conforme já referido por Visser e col. (2000), quanto maior o tempo de duração do teste, maior a chance de distração, fadiga e de diminuição da motivação da criança.

Soma-se a isto a possibilidade de testes contínuos ocasionarem adaptações ao sistema gustativo (Hahn, 1934 citado por Visser e col. 2000) da criança. A adaptação ao gosto representaria um declínio na intensidade do gosto por uma prolongada estimulação, e que geralmente ocorre em estudos laboratoriais (Theunissen e col. 2000). Portanto, houve um cuidado metodológico, dividindo-se os testes dos gostos em diferentes dias ou período e também se tentou controlar essa possível interferência pela ingestão da água deionizada entre uma solução e outra, dando intervalo de 
tempo entre a degustação de cada solução, conforme preconizado por Bartoshuk (1978).

Não houve preocupação com possiveis interferências que a constituição da saliva pudesse ocasionar, modificando o reconhecimento dos gostos básicos por cada criança, já que tal fator não foi de interesse no presente estudo.

Várias crianças reclamaram do gosto da água deionizada, o que coincide com as experiências de Visser e col. (2000). A água deionizada pode ser amarga com a adapatação à saliva (Bartoshuk 1978), outro fato é que o gosto desse tipo de água é diferente da consumida habitualmente podendo induzir reações negativas (Visser e col. 2000).

No teste de estímulo constante foi possivel conferir se a criança acertou com maior segurança qual era a amostra que tinha o soluto, apesar da probabilidade de acerto ao acaso ser de $50 \%$ a cada par, tendo diminuído para $25 \%$ quando se exigiu duas respostas consecutivas positivas, aumentando a veracidade do experimento (Coelho 2002, Coelho e Pinto e Silva 2003).

Visser e col. (2000) e Radil e Wysocki (1997) pronunciaram que a possibilidade da criança não responder ao acaso determinaria uma desvantagem quanto aos resultados do limiar médio do grupo infantil em relação ao de adultos. Várias crianças se negaram a escolher uma das soluções mesmo o teste exigindo resposta forçada. Elas apenas manifestavam a sua opção por uma solução quando detectavam um 
estímulo diferente, diminuíndo o acerto ao acaso, coincidindo com os resultados de outras pesquisas com o mesmo público alvo (Visser e col. 2000, Coelho e Pinto e Silva 2003).

\subsubsection{Análise dos limiares de detecção dos gostos básicos}

A escala das soluções oferecidas às crianças, averiguada no pré teste como adequada, deveria ter um maior intervalo de concentrações, para garantir que todas não detectassem a solução no primeiro par de amostras oferecidas. Caso isto houvesse ocorrido permitiria uma maior diferenciação entre as extremamentes sensíveis aos gostos testados (Visser e col. 2000). Enfatiza-se que neste estudo os limiares médios de detecção dos gostos para as crianças mostrados podem ser superiores aos valores reais.

\subsubsection{Gosto Doce}

No gosto doce observou-se que a chance de detectar a presença da solução foi maior para os escolares, apesar do poder discriminatório do teste ser muito baixo $(0,547)$. 
Visser e col. (2000) não encontraram uma relação entre o aumento da idade das crianças de 3 a 6 anos e a variação no limiar médio para a solução de sacarose. Porém, as mais velhas mostraram-se mais sensiveis à sacarose, ou mais atentas ao teste $\left(r_{\text {sperman }}=-0,37, p<0,05\right)$. Os pesquisadores relataram que as crianças de três anos de idade eram mais dispersas, o que pode ter interferido nos limiares de detecção.

A concentração do limiar médio do gosto doce foi de $11,18 \mathrm{mmol} / \mathrm{L}$ para pré-escolares e de $8,43 \mathrm{mmol} / \mathrm{L}$ para escolares, ambas próximas ao encontrado por Pfaffman e col. (1971), 10mmol/L, porém inferiores ao mostrado por Visser e col. (2000) de $30,8 \mathrm{mmol} / \mathrm{L}$.

James e col. (1997) identificaram uma diferença significativa $(p<0,003)$ entre os limiares médios de detecção do gosto doce entre meninas $(7,2 \mathrm{mmol} / \mathrm{L})$ e meninos $(17,0 \mathrm{mmol} / \mathrm{L})$ de 8 a 9 anos. Tal aspecto não foi demonstrado neste estudo para nenhuma das faixas etárias. O grupo das meninas de 4 a 11 anos incompletos apresentaram o limiar médio de 9,5 $\mathrm{mmol} / \mathrm{L}$ e dos meninos de $9,8 \mathrm{mmol} / \mathrm{L}$ (Tabela 8 ) .

James e col. (1999) comparando as respostas produzidas por adultos ( $n=95)$ e crianças de 8 a 9 anos $(n=66)$ por meio do teste de magnitude para o gosto doce, com solução de sacarose em água, não obtiveram diferenças nos limiares médios de detecção dos dois grupos. Entretanto, quando realizou-se o teste com o suco de laranja para averiguar a intensidade de açúcar, as crianças apresentaram maiores limiares de detecção do que os 
Acredita-se que as crianças são menos hábeis do que os adultos para ignorarem irrelevantes características sensoriais do alimento (Berman e Freidman 1995). Isto poderia prejudicar a qualidade da resposta de uma criança referente a intensidade de um atributo como por exemplo, doçura na presença de aromas, texturas, ou outros sabores (James e col. 1999).

\subsubsection{Gosto Salgado}

O limiar de detecção do gosto salgado não foi associado ao estado nutricional da criança, sexo nem grupo etário desta.

James e col. (1997) obtiveram limiares médios para o gosto salgado diferente entre meninos $(6,1 \mathrm{mmol} / \mathrm{l})$ e meninas $(2,7 \mathrm{mmol} / \mathrm{l})$. Além disso, esses valores médios foram inferiores ao verificado neste estudo para meninos $(7,4 \mathrm{mmol} / \mathrm{l})$ e para meninas $(6,6 \mathrm{mmol} / \mathrm{l})$ de 4 a 10 anos (Tabela 8$)$. Na comparação dos valores medianos dos limiares de detecção do gosto em questão, os quais não estariam influenciados pelas crianças mais sensíveis, as que detectaram a solução na primeira concentração, evidenciou-se que apesar do limiar mediano das meninas ser inferior ao dos meninos, não houve diferença significativa estatisticamente entre os gêneros (Tabela 8). 


\subsubsection{Gosto ácido}

Os dados desta pesquisa corroboraram a idade como fator essencial à sensibilidade ao gosto ácido em baixas concentrações.

Glanville e col. (1964) mostraram que indiferentemente do sexo na faixa etária de 16 a 20 anos há uma maior sensibilidade ao gosto ácido, mas acompanhado por um exponencial declínio nas idades posteriores.

Os limiares de deteç̧ão do gosto ácido, principalmente os obtidos pelas meninas e escolares, com a aplicação da escala de diluição da solução de ácido cítrico, poderia ser inferior ao relatado neste estudo, pois uma grande maioria estava apta a detectar o estímulo na primeira concentração testada. Houve uma correlação negativa $r_{\text {sperman }}=-0,340$ ( $p<0,01)$, ou seja, quanto maior a idade maior a sensibilidade ao gosto ácido.

Segundo James e col. (1997) o limiar médio de detecção da solução de ácido cítrico diferiu entre meninas $(0,5 \mathrm{mmol} / \mathrm{L})$ e meninos $(1,4 \mathrm{mmol} / \mathrm{L})$ assim como neste estudo. Entretanto, os limiares encontrados nesta pesquisa para crianças de 4 a 10 anos foram inferiores, respectivamente de $0,21 \mathrm{mmol} / \mathrm{L}$ e $0,26 \mathrm{mmol} / \mathrm{L}$ para meninas e meninos (Tabela 8 ). Porém, 0 limiar médio de detecção do gosto ácido dos escolares $(0,154 \mathrm{mmol} / \mathrm{L})$ foi menor do que o dos pré-escolares $(0,338 \mathrm{mmol} / \mathrm{L})$ (Tabela 8$)$ e, inferior ao verificado para mulheres e homens, 0,2mmol/L, por James e col. (1997).

Weinffenbach e col. (1982), estudaram os limiares de detecção entre adultos e idosos e verificaram que os homens eram menos sensíveis do que 
as mulheres. Nesta pesquisa a hipótese de que a capacidade de detectar a solução de ácido cítrico estaria relacionada ao sexo foi confirmada, com poder de discriminatório baixo de 0,576 (Figura 5A) pois houve a chance de identificar se a criança era menina pela habilidade de sentir o gosto em questão em uma pequena concentração. Todavia, a idade teve um poder discriminatório maior de 0,731 na capacidade de detecção do gosto ácido, ou seja se uma criança estava apta a detectar uma solução de $0,117 \mathrm{mmol} / \mathrm{L}$ de ácido citrico, provavelmente pertenceria ao grupo de escolares.

O estado nutricional apresentou um baixo poder discriminatório de 0,576 (Figura 5C). Verificou-se que na análise univariada na concentração de $0,16 \mathrm{mmol} / \mathrm{L}$ de ácido citrico, a criança com excesso de peso apresentava uma maior probabilidade de detectar a solução. Porém no modelo multivariado, ao se acrescentar a idade, o estado nutricional não apresentou nenhum poder de ajuste. Tal aspecto pôde ser explicado pelos dados demonstrados na tabela $3 A$, que evidenciou a relação do excesso de peso com a maior idade da criança.

\subsubsection{Gosto Amargo}

A escala de diluição aplicada para o estudo do gosto amargo deveria ser mais diluida principalmente para os pré-escolares que detectaram mais facilmente a presença da cafeína. Houve uma correlação positiva entre 
aumento de idade e limiar de detecção do gosto amargo, $r_{\text {sperman }}=0,163$ $(p<0,01)$. Tal aspecto leva à hipótese que com o passar do tempo as crianças ficam menos sensíveis ao gosto amargo.

Visser e col. (2000) avaliou os limiares de detecção de crianças de 3 a 6 anos de idade, e Okoro e col. (1998) os limiares de reconhecimento do gosto amargo em crianças 9 a 17 anos de idade, ambos estudos não identificaram diferenças entre o sexo da criança e os limiares de detecção do gosto amargo. Além disso, não verificaram uma relação entre a idade e a tendência de detectar a presença do gosto conforme obtido nesta pesquisa. Porém tais pesquisadores utilizaram um soluto diferente, a uréia.

Por meio da aplicação de uma escala de diluições a base de cafeína James e col. (1997) não identificaram diferenças entre os limiares médios de detecção de meninos $(2 \mathrm{mmol} / \mathrm{L})$ e meninas $(1,1 \mathrm{mmol} / \mathrm{L})$. No presente estudo - limiar médio de detecção das meninas $(0,853 \mathrm{mmol} / \mathrm{L})$ e dos meninos $(0,838 \mathrm{mmol} / \mathrm{L})$ foram inferiores ao relatado na literatura para crianças $\mathrm{e}$ homens $(1,8 \mathrm{mmol} / \mathrm{L})$ e semelhantes ao encontrado para mulheres $(0,8$ $\mathrm{mmol} / \mathrm{L})$. Os pré-escolares apresentaram o limiar de detecção $(0,703 \mathrm{mmol} / \mathrm{L})$ mais baixo (Tabela 8 ).

A capacidade de detecção do gosto amargo poderia ser utilizada para saber o grupo etário que a criança pertence, apresentando uma alta sensibilidade e especificidade do resultado. Há uma maior probabilidade da criança ser pré-escolar detectando logo a solução, o melhor ponto estimado na escala para essa afirmação seria a segunda concentração $(0,26 \mathrm{mmol} / \mathrm{L})$ (Tabela 10). 


\subsubsection{Aspectos gerais da sensibilidade aos gostos}

Averiguou-se na literatura diferenças entre os limiares médios de detecção dos gostos doce, salgado, ácido e amargo entre meninos e mulheres. Entre meninas e mulheres nenhuma diferença foi notada nos limiares de detecção, nem entre homens e mulheres (James e col. 1997).

Guinard (2001) afirmou que o desenvolvimento da capacidade de sentir $\circ$ gosto ocorre durante toda a infância. $O$ feto humano parece ter células gustativas especializadas a partir da sétima ou oitava semana de gestação. A maturação dos botões gustativos passa a ser visivel da décima terceira à décima quinta semana (Bradley e Sterm, 1967 apud Guinard 2001). Crianças de zero a 18 meses apresentam mais botões gustativos do que os adultos (10.000 versus 2.000 ), e a papila foliada da criança é mais larga e abundante, entretanto isto não significa uma maior sensibilidade das crianças, pois a inervação dessas papilas não está desenvolvida e consequentemente não apresentam o papel funcional como nos adultos (Plattig 1984).

Hardy e col. (1981) aplicaram os testes sensoriais, com a apresentação das amostras aos trios, aplicando pequenas dosagens na língua, em jovens de 9 a 15 anos $(n=100, n=100)$, e adultos $(n=22, n=41)$ com diabetes tipo 1 e saudáveis, respectivamente. Em tal estudo, obtiveram resultados interessantes; o aumento da idade é capaz de alterar a habilidade individual da detecção do gosto salgado, doce, e amargo nas soluções. 
Quando os autores compararam os limiares de detecção dos jovens e adultos encontraram maiores valores para o último grupo com exceção do gosto ácido. Os diabéticos apresentaram menor acuidades sensoriais, apresentaram maiores limiares de detecção aos gostos básicos estudados, com exceção do ácido. Tais dados diferem deste estudo feito com crianças em que se notou a idade como fator determinante na capacidade de detectar ○ gosto ácido e amargo.

Há a hipótese que haja uma modificação na capacidade de sentir o gosto durante toda a fase da vida, e com diferentes comportamentos para gosto básico, evidenciando a necessidade de mais pesquisas utilizando a mesma escala de concentrações de solução e método para posteriores comparaçōes.

Determinou-se diferenças à sensibilidade ao gosto básico segundo a idade, enquanto para $\circ$ gosto ácido o aumento da idade estava relacionada à maior sensibilidade das crianças, para o gosto amargo ocorreu $\circ$ inverso. O que evidencia que além da inervação das papilas e do número de botões gustativos outros aspectos devem estar relacionados com o limiar de detecção dos gostos básicos.

Alguns estudos demonstram que crianças de 5 a 7 anos apresentam os mesmos limiares de detecção dos gostos que adultos (Anliker e col. 1991), mas a maioria acredita que as crianças apresentam uma sensibilidade menor do que os adultos (Glanville e Kaplan 1964; James e col. 1997). 
Liem e col. (2004) comentam a possibilidade na imaturidade do sistema gustativo para processar informações da mistura de gostos. Citaram que a utilização do suco de laranja despertaria a atenção da criança para várias características além da intensidade de doçura, por exemplo, incluindo a sensação do flavour.

Segundo Liem e col. (2004) e Oram e col. (2001) há a hipótese das crianças de 5 anos terem uma menor capacidade discriminatória do que adultos devido 'a diferente forma com que avaliam a mistura dos gostos, porém isso não se aplicaria aos testes de água deionizada com uma solução específica, método utilizado nesta pesquisa.

De Graaf e Zandstra (1999) sugeriram que as crianças apresentam menor capacidade discriminatória das concentrações de sacarose em água do que os adultos, entretanto usou o teste de magnitude, o que impede comparações com o teste de estímulo constante.

A afirmativa de James e col. (1997) de que os meninos apresentavam geralmente limiares de deteç̧ão dos gostos básicos superiores ao das meninas apenas foi evidenciado para o gosto ácido na presente pesquisa.

Stevens (1996) comenta que algumas variações individuais são óbvias, como por exemplo a característica idade e sexo, mas há outros aspectos que devem ser controlados e ainda não se sabe quais, e enfatiza que novos estudos devem tentar identificá-los.

A presente pesquisa inseriu a análise dos limiares de detecção considerando o estado nutricional da criança. A sensibilidade das crianças 
para a detecção dos gostos básicos não diferiu com o incremento do IMC nesse estudo, mesmo para o gosto ácido quando controlado outras variáveis de interesse e, destaca-se que Cox e col. (1999) e Nasser (2001) não obtiveram diferenças nas análises dos limiares de deteç̧ão do gosto doce salgado e amargo para o grupo de indivíduos eutróficos e obesos.

Bartoshuk (1978) comentou que o limiar de detecção variava no mesmo indivíduo de acordo com a área da língua estimulada, ou seja, quanto menor a área estimulada maior o limiar de detecção. Tal aspecto não foi motivo de preocupação deste estudo, pois a criança recebia a solução a ser colocada na cavidade oral e não apenas um papel filtro umedecido com a solução ou gotas da mesma.

Ressalva-se que estudos dos limiares de detecção dos gostos apresentaram diferentes resultados, provavelmente pela dificuldade de eliminar a influência das variáveis de caracter cognitivo nesses procedimentos (Guinard 2001). A importância da validade deste estudo na determinação dos limiares de detecção para crianças foi destacada quando se compararam os seus limiares médios e medianos com os encontrados na literatura, mostrando que houve uma otimização do procedimento interferindo positivamente nos resultados, com exceção do gosto salgado. 


\section{CONCLUSÃO E CONSIDERAÇÕES FINAIS}

Foi possivel investigar a detecção dos gostos básicos em préescolares e escolares, considerando as características globais dessas faixas etárias e incentivando a participação das crianças.

A variação entre as respostas das crianças no primeiro e segundo teste sensorial para cada gosto básico foi pequena. Contudo, deve se procurar novos meios para propiciar a medição dos limiares de detecção em largos periodos de tempo, sem a perda da estabilidade na resposta individual e para possibilitar o oferecimento de um maior número de soluçōes a ser degustada por crianças.

Os escolares são mais sensíveis ao gosto ácido (ácido cítrico) do que os pré-escolares. Destaca-se ainda que as escolares apresentaram os menores limiares de detecção.

Os pré-escolares são mais sensiveis que os escolares ao gosto amargo (cafeina) independentemente do sexo.

Nota-se que apesar de não ter sido observado uma relação de idade e limiar de detecção do gosto doce, ao selecionar-se um ponto da escala $(23,37 \mathrm{mmol} / \mathrm{L})$ os escolares apresentaram uma chance maior de detectar a solução. 
Nenhum dos fatores estudados, idade, sexo e estado nutricional influenciaram os limiares de detecção do gosto salgado.

Evidenciou-se um panorama da detecção dos gostos básicos em crianças de 4 a 10 anos, o qual independe do estado de eutrofia e excesso de peso. Porém, existe a necessidade de novas pesquisas que visem contribuir com o esclarecimento científico desta questão, em outras faixas etárias, associando aos hábitos alimentares e preferências alimentares, incluindo a análise da intensidade dos gostos básicos nos alimentos, além das respostas sensoriais na presença de diferentes doenças. 


\section{REFERÊNCIA:}

1. [ABNT] Associação Brasileira de Normas Técnicas. Teste de sensibilidade em análise sensorial. NBR 13172. São Paulo, 1994.

2. [ACTIA] Association de coordination technique pour l'industrie agroalimentaire. Sensory Evaluation Guide of good practice. Paris, 2001.

3. American Academy of Pediatrics. Policy Statement. Prevention of pediatric overweight and obesity. Pediatrics. 2003;112:424-30.

4. Anliker JA, Bartoshuk L, Ferris AM, Hooks LD. Children's food preferences and genetic sensitivity to the bitter taste of 6-npropylthiouracil (PROP). Am J Clin Nutr. 1991; 54: 316-320.

5. Arbisi PA, Billington $\mathrm{CJ}$, Levine AS. The effect of naltrexone on taste detection and recognition threshold. Appetite. 1999 Apr;32(2):241-9.

6. Baker KA et al. Efecct of age, Sex and illness on salt taste detection thresholds. Age aging 1983 May; 12 (2): 159-65.

7. Baldo MVC. Gustação e Olfação. In: Aires MM. Fisiologia. $2^{a}$ ed. Rio de Janeiro: Guanabara-Koogan; 1999. p. 247-250.

8. Barros FC, Victora CG. Epidemiologia da saúde infantil: um manual para diagnósticos comunitários. São Paulo: Ed. Hucitec; 1991.

9. Bartoshuk LM. The psychophysics of taste. Am J Clin Nutr. 1978 Jun;31(6):1068-77.

10. Bartoshuk LM. Comparing sensory experiences acroos individuals: recent psychophysical advances illuminate genetic variation in taste perception. Chem. Senses. 2000; 25: 447-460.

11. Beauchamp GK, Cowart BJ. Preference for high salt concentrations among children. Developmental Psycholoqv. 1990: 26(4): 539-545. 
12. Bellizi MC, Dietz WH. Workshop on childhood obesity: summary of the discussion. American Journal of clinical nutrition. 1999; 70: 173S$5 S$.

13. Berman S, Friedman D. The development of selective attention as reflected by event-related brain potentials. J. Exp. Child Psychol. $1995 ; 59,1-31$.

14. Birch LL, Sullivan AS. Measuring children's food preferences. Journal of School Health. 1991; 61(5): 212-214.

15. Bland JM, Altman DG. Measurement: statistical methods for assessing agreement between two methods of clinical measurement. The Lancet. 1986; 8: 307-311.

16. Bradley RM, Sterm IB, The development of the human test bud during the foetal period. J. Anat. 101, 743-747 (1967).

17. Brasil. Ministério da Saúde, Instituto Nacional de Alimentação e Nutrição. Pesquisa Nacional sobre Saúde e Nutrição. Condições nutricionais da população brasileira. Brasília: INAN; 1991.

18. Butter CM, Butchel HA, Santucci R. Spatial attentional shifts: further evidence for the role of polysensory mechanisms using visual and tactile stimuli. Neuropsychologia. 1989; 27: 1231-1240.

19. Caratin CVS. Análise dos limiares de detecção dos gostos básicos e sensibilidade ao 6 n-propiltiouracil em crianças de 7 a 10 anos. São Paulo. 2004. [Tese apresentada ao Departamento de Nutrição da Faculdade de Saúde Pública da Universidade de São Paulo para obtenção do Grau de Mestre].

20. Chaves JBP, Sproesser RL. Práticas de laboratório de análise sensorial de alimentos e bebidas. Universidade Federal de Viçosa. Minas Gerais: Imprensa universitária, 1993.

21. Coelho HDS, Pinto e Silva MEM. Estudo da detecção dos gostos básicos em crianças. Nutrição Brasil. 2003; 2(1): 13-18. 
22. Coelho HDS. Avaliação dos limiares de deteç̧ão dos gostos básicos em crianças. São Paulo. 2002. [Tese apresentada ao Departamento de Nutrição da Faculdade de Saúde Pública da Universidade de São Paulo para obtenção do Grau de Mestre].

23. Cole TJ. The use and construction of antropometric growth reference standars. Nutrition Research Reviews. 1993; 6:19-50.

24. Cole TJ; Bellizzi MC; Flegal KM; Dietz WH. Establishing a standard definition for child overweight and obesity worldwide: international survey BMJ. 2000; May 6 320(7244):1240-3.

25. Conde WL. Desenvolvimento e Aplicação de sistema classificatório para avaliação do estado nutricional de crianças e adolescentes brasileiros baseado no indice de massa corporal. São Paulo. 2004. [Tese apresentada ao Departamento de Nutrição da Faculdade de Saúde Pública da Universidade de São Paulo para obtenção do Grau de Doutor]

26. Cooper RM, Bilash I, Zubek JP. The effect of age on taste sensitivity. J. Gerontol. 1959; 14: 56-58.

27. Coutinho W. Consenso Latino-Americano de Obesidade. Arqu Bras Endocrinol Metab. 1999;43:21-67.

28. Cowart BJ. Development of taste perception in humans: sensitivity and preference throughout the life span. Psychol Bull. 1981 Jul;90(1):4373.

29. Cowart BJ. Relationships between taste and smell across the adult life span. Ann N Y Acad Sci. 1989;561:39-55.

30. Cox DN, Perry L, Moore PB, Vallis L, Mela DJ. Sensory and hedonic associations with macronutrient and energy intakes of lean and obese consumers. Int. Obes. Relat. Metab. Disord. 1999; 23: 403-410.

31. Davidson HI, Pattison RM, Richardson RA. Clinical undernutrition states and their influence on taste. Proc Nutr Soc. 1998 Nov;57(4):633-8. 
32. De Graaf C, Zandstra EH. Sweetness intensity and pleasantness in children, adolescents, and adults. Physiol Behav. 1999 Oct;67(4):51320.

33. Desor JA, Beauchamp GK. Longitudinal changes in sweet preferences in humans. Physiol Behav. 1987;39(5):639-41.

34. Desor JA, Greene LS, Maller O. Preferences for sweet and salty in 9to 15 -year-old and adult humans.Science. 1975 Nov 14;190(4215):6867.

35. Dietz WH. Childhood weight affects adult morbidity and mortality. J Nutr. 1998;128(2 Suppl):S4

36. Douglas RC. Fisiologia da Gustação.Tratado de Fisiologia aplicado à Nutrição. $1^{\text {a }}$. ed. São Paulo. Robe Editorial. 2002;p 247-61.

37. Drewnowski A. Taste preferences and food intake. Annu Rev Nutr $1997 ; 17: 237-53$.

38. Durán, Costell. Review: Perception of taste. Physiochemical and psychophysical aspects. Food Sci Tech Int. 1999; 5(4):299-309.

39. Dzuik-O'donnell, C. (1999). "Kids put flavor science to the test" in prepared foods $168,40-42$.

40. Ebbeling CB, Pawlak DB, Ludwig DS. Childhood obesity: public-health crisis, common sense cure. Lancet. 2002;360:473-82.

41. El-Chaar GM, Mardy G, Wehlou K, Rubin LG. Randomized, double blind comparison of brand and generic antibiotic suspensions: II. A study of taste and compliance in children. Pediatr Infect Dis J. 1996 Jan;15(1):18-22.

42. Escrivão MAMS, Oliveira FLC, Taddei JAAC, Lopez FA. Obesidade exógena na infância e na adolescência. Jornal de Pediatria. 2000; 76 (Suppl 3): S305-10. 
43. Essick GK, Chopra A, Guest S, McGlone F. Lingual tactile acuity, taste perception, and the density and diameter of fungiform papillae in female subjects. Physiology \& Behavior. 2003;80: 289-302.

44. Flegal KM. The obesity in children and adults: current evidences and research issues. Medicine \& Science in Sports \&Exercise. 1999; 31 (11); pS509-14.

45. Freedman DS, Dietz WH, Srinivasan SR, Berenson GS. The relation of overweight to cardiovascular risk factors among children and adolescents: The Bogalusa Heart Study. Pediatrics 1999; 103(6):117582

46. Freedman DS, Khan LK, Serdula MK, Dietz WH, Srinivasan SR, Berenson GS. Inter-relationships among childhood BMI, childhood heigth, and adult obesity: the Bogalusa Heart Study. Int J Obesity. 2004;28:10-16. a

47. Freedman DS, Thornton JC, Mei Z, Waang J, Dietz WH, et al. Heigth and adiposity among children. Obesity Research. 2004;12(5):846-53.b

48. Gallagher P, Tweedle DE. Taste threshold and acceptability of commercial diets in cancer patients. J Parenter Enteral Nutr. 1983 JulAug; $7(4): 361-3$.

49. Giugliano R, Melo ALP. Diagnóstico de sobrepeso e obesidade em escolares: utilização do indice de massa corporal segundo padrão internacional. J Pediatr. 2004;80(2):129-34.

50. Giugliano R, Carneiro EC. Fatores associados à obesidade em escolares. J Pediatr. 2004;80(1):17-22.

51. Glanville EV, Kaplan AR, Fischer R. Age, sex and taste sensitivity. J Gerontol. 1964; 19: 474-8.

52. Guinard JX. Sensory and consumer testing with children. Trends in Food Science \& Tecnology. 2001; 11: 273-283. 
53. Hahn H. Die adaptation des Geschmacksinnes Zeitschritft fur Sinnesphysiologie. 1934. 65, 105-47.

54. Hambridge KM, Hambridge C, Jacobs M, Baum JD. Low levels of zinc in hair, anorexia, poor growth and hypogeusia in children. Pediatric. 1972; 6: 868-874.

55. Hardy SL, Brennand CP, Wyse BW. Taste thresholds of individuals with diabetes mellitus and of control subjects. J Am Diet Assoc. 1981 Sep;79(3):286-9.

56. Hermel J, Schonwetter SV, Samueloff S. Taste sensation and age in man. J. Oral Med. 1970; 25:39-42.

57. Hess MA.Taste: the neglected nutritional factor. J Am Diet Assoc. 1997 Oct;97(10 Suppl 2):S205-7.

58. Hetherington MM. Taste and appetite regulation in the elderly. Proc Nutr Soc. 1998 Nov;57(4):625-31.

59. Hyde RJ, Feller RP. Age and sex effects on taste of sucrose, $\mathrm{NaCl}$, citric acid and caffeine. Neurobiol. Aging. 1981; 2; 315-8.

60. IBGE (Instituto Brasileiro de Geografia e Estatística) /UNICEF (United Nations Children's Fund). Perfil estatístico de crianças e mães no Brasil: Aspectos de Saúde e Nutrição de Crianças no Brasil. Rio de Janeiro: IBGE; 1992.

61. International Organization for Standartization. Sensory analysis methodology - flavour profile methods. ISSO 6564. Switzerland, 1985.

62. James CE, Laing DG e Oram N. A comparasion of the ability of 8-9years-old childen and adults to detect taste stimuli. Physiol-Behav 1997; 62(1): 193-7.

63. James CE, Laing DG, Oram N, Hutchinson I. Preception of sweetness in simple and complex taste stimuli by adults and children. Chem. Senses. 1999; 24, 281-7. 
64. Jefferson FC, Erdman AM. Taste sensitivity and food aversions of teenagers. J. Home Econ. 1970; 62:605-608.

65. Kamath S, Booth P, Lad TE, Kohrs MB, McGuire WP. Taste thresholds of patients with cancer of the esophagus. Cancer. 1983 Jul 15;52(2):386-9.

66. Kiess W, Galler A, Reich A, Müller G, Kapellen T, Deutscher J, et al. Clinical aspects of obesity in childhood and adolescence. Obesity reviews $2001 ; 2: 29-36$

67. Kim WY, Hur M, Cho MS, Lee HS. Effect of olfactory function on nutritional status of Korean elderly womem. Nutrition Research. 2003; 23: 723-734.

68. Kimmel, SA.; Sigman-Grant M.; Guinard, JX. Sensory testing with young children. Food Technol 1994; 92-99.

69. Koivisto UK, Sjoden PO. Food and general neophobia in Swedish families: parent-child comparisons and relationships with serving specific foods. Appetite. 1996 Apr;26(2):107-18.

70. Koops H. Effect of chemotherapy on taste sensation in patients with disseminated malignant melanoma. Oncology. 1983;40(1):36-8.

71. Korslund MK, Eppright ES. Taste sensitivity and eating behavior of preschool children. J. Home Econ. 1967; 168-170.

72. Kroll BJ. Evaluating rating scales for sensory testing with children. Food Tecnology. Nov 1990: 80-6.

73. Kugino K, Kaneko M, Akiyoshi T, Mizunuma T. [Studies on the taste perceptive threshold for 4 basic taste qualities at various sites of lingual surface] Fukuoka Igaku Zasshi. 1997 Oct;88(10):331-6.

74. Landis JR, Koch GG. The measurement of observer agreement for categorial data. Biometrics. 1977; 33: 159-174. 
75. Lauritsen JM, Bruus M. EpiData (version 1.5). A comprehensive tool for validated entry and documentation of data. The EpiData Association, Odense Denmark, 2001.

76. Lawless H. Sensory development in children: research in taste and olfaction. J Am Diet Assoc. 1985 May;85(5):577-82, 585.

77. Liem DG, Menella JA. Heightened sour preferences during childhood. Chem. Senses. 2003; 20: 451-159.

78. Liem DG, Mars M, De Graaf C. Consitency of sensory testing with 4 and 5 -year-old children. Food Quality and Preference. 2004;15:541-548.

79. Lin LI-K. A concordance correlation coefficient to evaluate reprodutibility. Biometrics. 1989; 45; 2-8.

80. Lohman TG, Roche AF, Matorell R. Anthropometric standardization reference manual. 1988. llinois: Human Kinetics Publishers.

81. Lopez JD. Dieta consumida por pré-escolares em centros infantis: avaliação em dois Cl's da Prefeitura do Município de Campinas. São Paulo; 1996. [Dissertação de Mestrado- Faculdade de Saúde Pública/Universidade de São Paulo]

82. Macfie HJ, Bratchell N. Designs to balance the effect of order of presentation and first-order carry-over effects in hall tests. J. of sensory Studies (4). 1989. August; 129-148.

83. Maga JA. Flavor Potentiators. In: Maga JA, Tu AT. Food additive toxicology. New York: Marcel Dekker; 1994. p 379-412.

84. Marks LE, Wheeler ME. Attention and detectability o weak taste stimuli. Chem. Senses. 1998; 23: 19-29.

85. Mc Burney DH and Shick TR. Taste and water taste of twenty six compounds for man. Percept Psychophys. 1971; 10: 249.

86. Meilgaard M, Civille GV, Carr T. Sensory Evaluation Techiniques 2".ed. Ed. Florida: CRC Press; 1991. 
87. Mello ED. de, Luft VC., Meyer F.. Childhood obesity: towards effectiveness. J. Pediatr. (Rio de J.), May/June 2004, vol.80 (3), p.173182.

88. Menella JA, Beauchamp GK. Early Flavor experiences: research update. Nutr Rev. 1998; 56(7):205-11.

89. Minohara M, Yakura N, Kasagi T. A study of taste-sensivity in preschool children with special reference to its time-course according to their growth. Nippon Koshu Eisei Zasshi. Apr 1991; 38(4):272-7

90. Mojet J, Christ-Hazelhof E, Heidema J. Taste perception with age: generic or specific losses in threshold sensitivity to the five basic tastes? Chem Senses. 2001 Sep;26(7):845-60.

91. Monteiro C.A. Saúde e Nutrição das crianças de São Paulo. Ed. Hucitec, São Paulo, 1988.

92. Monteiro CA, Benicio M H D'Aquino. Estudo das condições de saúde das crianças do Municipio de São Paulo, SP (Brasil), 1984/1985: VI. Doença respiratória. Rev. Saúde Pública. 1987 out; 21(5),380-386.

93. Monteiro CA, Conde WL, Popkin BM. Trends in under and over nutrition in Brazil. In: Caballero B, Popkin BM (org). The Nutrition Transition. London: Academic Press, 2002.

94. Monteiro CA, Mondini L, Souza ALM, Popkin BM. Da desnutrição para a obesidade: A transição nutricional no Brasil. In: Monteiro CA. (Org) Velhos e novos males da saúde no Brasil: A evolução do país e de suas doenças. São Paulo.1995, Hucitec. p. 247-55.

95. Monteiro CA, Conde WL. Tendência secular da obesidade segundo estratos sociais: nordeste e sudeste do Brasil. Arq Bras Endocrinol Metab. 1999;43:186-94.

96. Monteiro, CA e Conde, WL. Tendência secular da desnutrição e da obesidade na infância na cidade de São Paulo (1974-1996). Rev. Saúde Pública. [online]. dez. 2000, vol.34, no.6, supl. [citado 03 Abril 2005], 
$<$ http://www.scielo.br/scielo.php?script=sci_arttext\&pid=S0034$89102000000700008 \&$ Ing=pt\&nrm=iso $>$. ISSN 0034-8910.

97. Moraes MAC. Métodos para a avaliação sensorial de alimentos. $8^{\circ}$ ed. Campinas, Editora da UNICAMP, 1993.

98. Mulder NH, Smit JM, Kreumer WM, Bouman J, Sleijfer DT, Veeger W, Schraffordt $\mathrm{KH}$. Effect of chemotherapy on taste sensation in patients with disseminated malignant melanoma. Oncology. 1983; 40(1):36-8.

99. Nasser J. Taste, food intake and obesity. Obes Rev. 2001 Nov; 2(4): 213-8.

100. National Center for Health Statistics (NCHS). Advance Data from vital and Health Statisitcs of the Centers for Disease Control and Prevention. December 2000. 1-27.

101. Neto ASC, Saito MI Obesidade. In Marcondes E, Costa Vaz FC, Ramos JLA, Okay Y. Pediatria Básica: Pediatria Geral e Neonatal. $9^{a} e d$. São Paulo. Savier. 2002. Tomo I p 682-86

102. Obrebowski A, Obrebowska-Karsznia Z, Gawlinski M. Smell and taste in children with simple obesity. Int J Pediatr Otorhinolaryngol. 2000 Oct 16;55(3):191-6.

103. Ohara I, Tabuchi R, Kimura M, Itokawa Y. Decline of taste sensitivity in protein deficient adult rats. Physiol Behav. 1995, 57: 921-6.

104. Okoro EO, Uroghide GE, Jolayemi ET, George OO, Enobakhare CO. Studies on taste thresholds in rural Nigeria. Food Quality and Preference. 1998; 9:205-210.

105. Oliveira ZM. et al. Creches: crianças, faz de conta \& cia. $4^{a}$. ed. 1995. São Paulo, Ed. Petrópolis.

106. Oram N, Laing DG, Freeman MH, Hutchinson I. Analysis of taste mixtures by adults and children. Developmental Psychobiology. 38. 67-77. 
107. Ovesen L, Sorensen M, Hannibal J, Allingstrup L. Electrical taste detection thresholds and chemical smell detection thresholds in patients with cancer. Cancer. 1991 Nov 15;68(10):2260-5.

108. Palisin $\mathrm{H}$. Preschool temperament and performance on achievement tests. Dev. Psychology. 1986. 22,766-70.

109. Pfaffmann C, Bartoshuk LM, and McBurney DH. Taste psychophysics. In: L.M. Beidler (ed.),Handbook of Sensory Physiology. Vol. 4, Pt 2. Gustation. Springer Verlag, New York, pp. 87-88, 1971.

110. Phillips JO, Fuchs AF. Gestacion and olfaction. In: Textbook of physiology: excitable cells and neurophysiology. $2^{\circ}$ ed. Saunders, 475-503, 1989.

111. Pipes P. Nutrition in infancy and chidhood 4 th edition. St Louis: Times Mirror /Mosby College Publishing. 1989.

112. Plattig KH, The sense of taste in: Sensory Analysis of Foods. Piggot, JR. p 1-22. ed Elsevier Applied Science Publishers, London. 1984.

113. Radil T, Wysocki CJ. Anosmic Olfaction: unconscious olfactory perception in health and disease. Homeastasis in health and Disease. $1997 ; 38,134-135$.

114. Richter CP, Campbell K. Sucrose taste thresholds of rat and humans. AM. J. Physiol. 1940; 128:291-7.

115. Schiffman SS. Taste and smell in disease. N Engl J Med. 1983; 308:1275-9, 1337-43.

116. Schiffman SS., Erickson RP. A psychophysical model for gustatory quality. Physiol Behav 1971; 7: 617-33.

117. Schmitiz BA, Heyde ME, Cintra IP, Franceschini SC, Taddei JÁ, Sigulem DM. Políticas e programas governamentais de alimentação e nutrição no Brasil e sua involução. Cad Nutr 1997; 13:39-54.

118. Scott TR. The role of taste in feeding. Appetite. 2001 Oct;37(2):111-3. 
119. Seidell JC. Obesity in Europe: scalling an epidemic. International Journal of Obesity. 1995; 19 (3); S1-4.

120. Serdulla MK, Ivery D, Coates RJ, Freedman DS, Willianson DF, Byers T. Do obese children obese adults? A review of the literature. Preventive Medicine. 1993; 22; 167-177.

121. Shinha R, Fisch G, Teague B, Tamborlane WV, Banyas B, Allen K, et al. Prevalence of impaired glucose tolerance among children and adolescents with marked obesity. N Engl J Med. 2002; 346(11):802-10.

122. Siegel S. Estatística não paramétrica. Editora MC Graw Hill do Brasil, São Paulo, 1981.

123. Simonds JF, Simonds MP. Nursery school children's temperament related to sex, birth position, and socioeconomic status. J Pediatr Psychol. 1982 Mar;7(1):49-59.

124. Smith DV, Margolskee RF. Making sense of taste. Sci Am. 2001 Mar;284(3):32-9.

125. Souza MSF, Cardoso AL. Obesidade In: Marcondes E, Vaz FAC, Ramos JLA, Okay Y. Pediatria Básica: pediatria clínica geral. $9^{\mathrm{a}}$ ed. São Paulo: Sarvier; Tomo II. p.359-64. 2003.

126. SPSS Inc. SPSS for windows: versão 13.0. llinois: SPSS incorporation, 2003.

127. Statacorp. Stata statistical software: release 6.0. College Station, TX: Stata Corporation, 1999.

128. Stevens DA. Individual differences in taste perception. Food Chem. 1996; 56 (3): 303-11.

129. Stevens JC, Cain WS, Demarque A, Ruthruff AM. On the discrimination of missing ingredients: aging and salt flavor. Appetite. 1991 Apr;16(2):129-40. 
130. Strauss RS, Childhood obesity and self-steem. Pediatrics 2000;105(1):e15 (online) Available from: http://www.pediatrics.org/cgi/content/full/105/1/e15 [2003 Set 01].

131. Theunissen MJM, Polet IA, Kroeze JHA, Schifferstein HNJ. Taste adaptation during the eating of sweetened yogurt. Appetite 2000; 34, 21-27.

132. Tzuriel D, Klein PS. The assessment of analogical thinking modifiability among regular, special education, disadvantaged, and mentally retarded children. J Abnorm Child Psychol. 1985 Dec;13(4):539-52.

133. Velle W. Sex differences in sensory functions. Perspect. Biol. Med. $1987 ; 34 ; 490-522$.

134. Visser J, Kroese JHA, Kamps WA, Bijleved CMA. Testing taste sensitivity and aversion in very young children: development of a procedure. Appetite. 2000; 34: 169-176.

135. Wang Y, Monteiro CA, Popkin BM. Trends of obesity and underweight in older children and adolescents in the United States, Brazil, China, and Russia. Am J Clin Nutr. 2002;75:971-77.

136. Weiffenbach JM, Baum BJ, Burghauser R. Taste thresholds: quality specific variation with human aging. J Gerontol. 1982 May;37(3):372-7.

137. Who - World Health Organization. Physical Status: the use and interpretation of antropometry. Geneve: Who; 1995. (WHO Techinical Report Series, 854).

138. Woods MP. Taste and Flavour perception. Proc Nutr Soc 1998; 57:603-7.

139. Yasaki T. Study on sucrose taste thresholds in children and adults. Jpn Dental Health. 1976; 26: 20-25.

140. Zahar. Psicologia Sensorial. Tradução Álvaro Cabral. $2^{a}$ ed. Rio de Janeiro. 1977. Prentice Hall Inc. New Jersey. 
ANEXO 1

Parecer do Comitê de Ética FSP/USP 


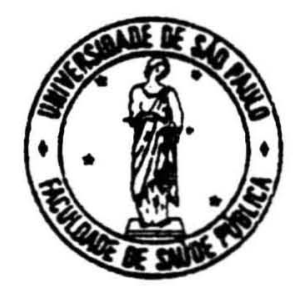

\section{UNIVERSIDADE DE SÃO PAULO \\ FACULDADE DE SAÚDE PÚBLICA \\ COMITÉ DE ÉTICA EM PESQUISA-COEP}

Av. Dr. Arnaldo, 715 - sala 18 - sub-solo - Cerqueira César

São Paulo-SP CEP: 01246-904

Telefone (OXX11) 3066-7776 - e-ma11: mogracaseusp.br

\section{Of.COEP/063/00}

24 de abril de 2000

Pelo presente, informo que o Comitê de Ética em Pesquisa da Faculdade de Saúde Pública da Universidade de São Paulo, em sua 2.\%00 Sessão Ordinária realizada em 18.04.2000, analisou e aprovou com recomendações, de acordo com os requisitos da Resolução CNS/196/96, o protocolo de pesquisa n. ${ }^{\circ} 282$, intitulado: "TESTE DE LIMITE: ANÁLISE DE PERCEPÇÃO DE SABORES BÁSICOS EM CRIANÇAS”, apresentado pela pesquisadora Hellen Daniela de Souza Coelho.

Recomendando que, no Termo de Consentimento Livre e Esclarecido, seja acrescentado "caso não concorde em participar da pesquisa. não haverá nenhum impedimento ou alterações nas relações entre seu filho e a creche".

Atenciosamente,

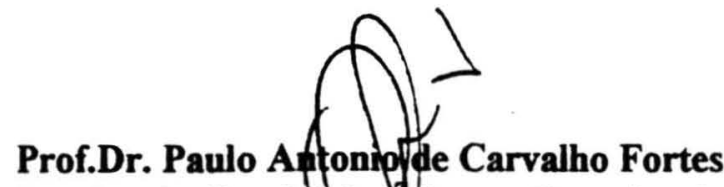

Vice-Coordenador do Comite de de em Pesquisa da FSP-COEP 


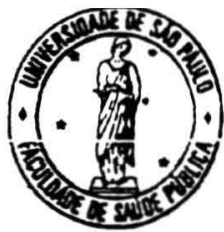

\section{Universidade de São Paulo}

Faculdade de Saúde Pública

COMITÊ DE ÉTICA-COEP

Av. Dr. Arnaldo, 715 - CEP 01246-904 - São Paulo - Brasil

Telefones: (55-11) 3066- 7734 - fone/fax (55-11) 3064 -7314 - e-mail: mdgracas@usp.br

Of.COEP/267/02

13 de novembro de 2002

Pelo presente, informo que o Comitê de Ética em Pesquisa da Faculdade de Saúde Pública da Universidade de São Paulo-COEP, analisou e aprovou, em sua 9. $\% 02$ Sessão Ordinária realizada em 12.11.02, de acordo com os requisitos da Resolução CNSi196/96, o Protocolo de Pesquisa n. ${ }^{\circ} 871$, intitulado: “ANÁLISE DOS LIMIARES DE DETECÇÃO DOS GOSTOS BÁSICOS E SENSIBILIDADE AO 6-N PROPILTIOURACIL EM CRIANÇAS DE 7 A 10 ANOS", apresentado pela pesquisadora Carla Vanessa de Sousa Caratin.

Atenciosamente,

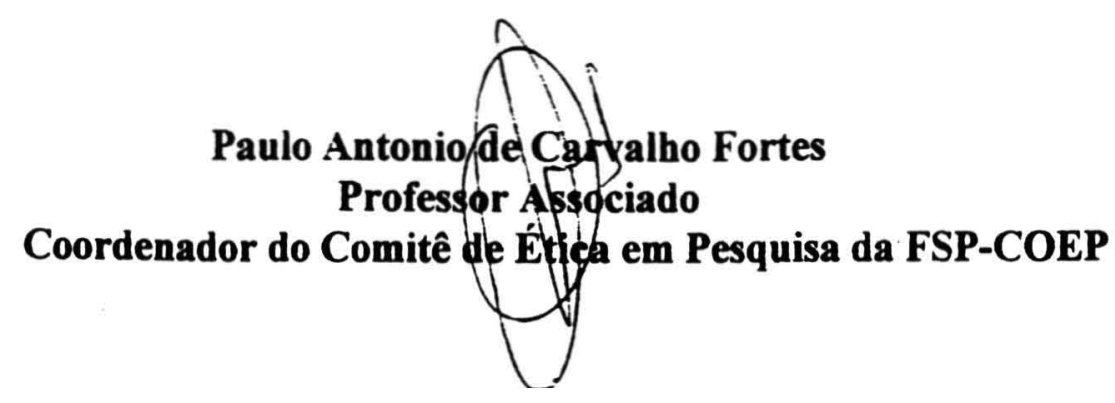




\section{ANEXO 2}

\section{Termo de consentimento esclarecido -Instituições}


Termo de Consentimento Esclarecido - Resoluçăo $n^{\circ} 196$, de 10 de outubro de 1996, segundo o Conselho Nacional da Saúde (CNS)

A Divisão de Creches da Coordenaria de Assistência Social da Universidade de São Paulo aceita livremente participar do estudo "Teste de limite: Análise de percepção de sabores básicos em crianças" sob responsabilidade dos seguintes pesquisadores, Maria Elisabeth Machado Pinto e Silva, docente da Faculdade de Saúde Pública da Universidade de São Paulo e Hellen Daniela de Sousa Coelho, mestranda do curso de Pós graduação em Saúde Pública, área de concentração Nutrição, da Universidade de Săo Paulo.

Este estudo será realizado pela experimentação de soluçōes com água e sacarose, ou com cloreto de sódio anidro, ou cafeína cristalizada, ou ácido cítrico cristalizado em concentraçōes diferentes e pela coleta das medidas antropométricas.

Objetivo: Identificar e associar o limiar de percepção dos 4 sabores básicos: ácido (azedo), doce, salgado e amargo por crianças de 4 a 7 anos com estado nutricional, sexo e idade.

Risco: 0 presente estudo năo trará nenhum risco à integridade física (saúde) e moral da criança, porém poderá ocasionar sabor desagradável por poucos segundos à criança.

Beneficios: A classificação do limiar de percepção dos sabores por crianças, pode contribuir na adequação de receitas e desenvolvimentos de produtos alimentícios específicos para essa faixa etária, considerando o estado nutricional e sexo.

Privacidade: As informaçōes obtidas neste estudo poderão ser divulgadas em congressos e publicaçōes, entretanto não identificará os participantes. A participação da instituição é voluntária, podendo retirar seu consentimento e deixar de participar da pesquisa em qualquer período sem maiores consequências.

Questões éticas: Cada creche terá acesso a um número de telefone, endereço para correspondência e eletrônico (a baixo), o qual poderá ser utilizado para esclarecimentos de dúvidas ou reclamaçōes.

Entrar em contato com: Hellen Daniela de Sousa Coelho Telefone: 30667771

Endereço: Departamento de Nutrição da Faculdade de Saúde PúblicalUSP

Av Dr. Amaldo $n^{0}$ 715. Cerqueira César CEP 01246-904 São Paulo-SP

Endereço eletrônico: hellencoelho@hotmail.com

Ciente do compromisso assumido na colaboração desta pesquisa, e pela importância da mesma, subscrevo-me a seguir:

Nome completo do responsável:

Assinatura:

Assinatura do pesquisador: 
Termo de Consentimento Esclarecido

Resolução no 196, de 10 de outubro de 1996, do Conselho Nacional da Saúde (CNS)

A Escola aceita livremente participar do estudo "Análise dos limiares de detecção dos gostos básicos e sensibilidade ao 6-n-propylthiouracil em crianças de 7 a 10 anos" que será realizado pela pesquisadora Carla Vanessa de Sousa Caratin, aluna de pós-graduação (mestrado) sob responsabilidade da Profe. Dra. Maria Elizabeth Machado Pinto e Silva, docente do Departamento de Nutrição da Faculdade de Saúde Pública da Universidade de Sảo Paulo.

Este estudo será realizado pela experimentação de soluções com água e sacarose, cloreto de sódio anidro, cafeina cristalizada e ácido cítrico cristalizado e de uma substância denominada 6n-propylthiouracil (PROP). Também serăo coletadas as medidas antropométricas das crianças participantes do estudo.

Objetivo: Identificar o limiar de detecção dos quatro gostos básicos: amargo, azedo, doce e salgado e a capacidade de detectar ou não o 6-n-propylthiouracil (PROP) de crianças de 7 a 10 anos e associar ao estado nutricional, sexo e idade destas.

Procedimento: As crianças terão seu peso e sua altura medidos, além de experimentar alguns alimentos/bebidas.

Beneficios: Estas informações contribuirão na adequaçăo de receitas e desenvolvimento de produtos alimentícios específicos para esta faixa etária.

Risco: Não haverá nenhum risco à integridade física e moral da criança, podendo apenas ocasionar sabor desagradável por alguns segundos.

Privacidade: As informações obtidas neste estudo poderão ser divulgadas em congressos e publicaçōes cientificas, sem nunca identificar os nomes dos participantes.

A participação da instituição é voluntária, podendo inclusive retirar seu consentimento e deixar de participar da pesquisa a qualquer momento sem maiores consequêencias.

Caso deseje maiores esclarecimentos sobre a pesquisa ou reclamações, entrar em contato com:

Carla Vanessa de Sousa Caratin

Telefone: 3066-7771_Correio eletrônico: cacaratin@uol.com.br

Endereço: Departamento de Nutrição da Faculdade de Saúde Pública - USP

Av. Dr. Arnaldo n 715 - Cerqueira César - São Paulo/SP CEP: 01246-904

Ciente do compromisso assumido na colaboração desta pesquisa, e pela importância da mesma, subscrevo-me a seguir:

Nome completo do responsável pela instituição:

Assinatura:

Assinatura do pesquisador: 
ANEXO 3

- Termo de consentimento esclarecido- Responsável pela criança 
Termo de Consentimento Esclarecido (pais) - Resolução n 196, de 10 de outubro de 1996, segundo Conselho Nacional da Saúde (CNS)

Caro pai ou responsável de

$$
\text { (nome da criança) }
$$

O projeto "Teste de limite: Análise sensorial de sabores básicos em crianças" será realizado pelas pesquisadoras Maria Elizabeth Machado Pinto e Silva (docente) e Hellen Daniela de Sousa Coelho (mestranda) da Faculdade de Saúde Pública da Universidade de São Paulo.

Objetivo: Conhecermos como as crianças percebem os diferentes sabores: doce, amargo, azedo e salgado.

Procedimento: Mediremos o peso e altura das crianças. Elas experimentarão diferentes alimentos/bebidas.

Benefícios: Contribuiremos na adequação de receitas e desenvolvimentos de produtos especificos para essa faixa etária.

Risco: Não haverá nenhum risco à integridade física (saúde) e moral da criança, entretanto poderá ocasionar sabor desagradável por poucos segundos à criança.

Privacidade: As informaçōes obtidas neste estudo poderăo ser divuigadas em congressos e publicações, porém não identificará os participantes.

A sua participação, assim como a de seu filho é voluntária, caso não concorde em participar da pesquisa, não haverá nenhum impedimento ou alteraçōes nas relações entre seu filho e a creche, podendo retirar seu consentimento e deixar de participar da pesquisa em qualquer período sem maiores conseqüências.

Caso necessite de maiores esclarecimentos sobre a pesquisa, entrar em contato com:

Hellen Daniela de Sousa Coelho Telefone: 30667771

Email:

hellencoelho@hotmail.com

Endereço: Departamento de Nutrição da Faculdade de Saúde PúblicalUSP

Av Dr. Amaldo n ${ }^{\circ}$ 715. Cerqueira César CEP 01246-904 São Paulo-SP

Ciente do compromisso assumido na colaboração desta pesquisa, e pela importância da mesma, subscrevo-me a seguir:

Nome (completo do responsável)

Assinatura

Assinatura do pesquisador 
Termo de Consentimento Esclarecido Resolução no 196, de 10 de outubro de 1996, do Conselho Nacional da Saúde (CNS)

Caro pai ou responsável de

O projeto "Análise dos limiares de detecção dos gostos básicos e sensibilidade ao 6-npropylthiouracil em crianças de 7 a 10 anos" será realizado pela pesquisadora Carla Vanessa de Sousa Caratin (mestranda) sob responsabilidade da Prof. Dra. Maria Elizabeth Machado Pinto e Silva, docente do Departamento de Nutrição da Faculdade de Saúde Pública da Universidade de São Paulo.

Objetivo: Conhecer como as crianças percebem os diferentes gostos: amargo, azedo, doce e salgado e se elas detectam ou não uma substância denominada 6-n-propylthiouracil (PROP).

Procedimento: As crianças terão seu peso e sua altura medidos, além de experimentar alguns alimentos/bebidas.

Beneficios: Estas informações contribuirão na adequação de receitas e desenvolvimento de produtos alimenticios específicos para esta faixa etária.

Risco: Não haverá nenhum risco à integridade física e moral da criança, podendo apenas ocasionar sabor desagradável por alguns segundos.

Privacidade: As informações obtidas neste estudo poderão ser divulgadas em congressos e publicações científicas, sem nunca identificar os nomes dos participantes.

A sua participação, assim como a do seu filho, é voluntária. Caso não concorde em participar da pesquisa não haverá nenhum impedimento ou alteração na relação entre seu filho e a escola, podendo inclusive retirar seu consentimento e deixar de participar da pesquisa a qualquer momento sem maiores conseqüências.

Caso deseje maiores esclarecimentos sobre a pesquisa, entrar em contato com:

Carla Vanessa de Sousa Caratin

Telefone: 3066-7771 Correio eletrônico: cacaratin@uol.com.br

Endereço: Departamento de Nutrição da Faculdade de Saúde Pública - USP

Av. Dr. Amaldo n 715 - Cerqueira César - São Paulo/SP CEP: 01246-904

Ciente do compromisso assumido na colaboração desta pesquisa, e pela importância da mesma, subscrevo-me a seguir:

Nome completo do responsável:

Assinatura:

Assinatura do pesquisador: 
ANEXO 4

Formulário de saúde e antropometria -Pré-escola/Creche 


\section{Dados antropométricos:}

Creche:

Código da creche:

Turma:

Número da criança:

Data da entrevista:

Nome da criança:

01 - Comprimento do braço: $\mathrm{cm}$.

$2 \mathrm{~A}$ - Perímetro braquial (1) : _ $\mathrm{Cm}$.

2B - Perímetro braquial (2) : __ $\mathrm{cm}$.

Código da criança:

$3 A$ - Prega cutânea triciptal (1) $\mathrm{mm}$.

3B - Prega cutânea triciptal (2) $\mathrm{mm}$.

1. Em que ano e mês sua criança foi matriculada nesta creche pela primeira vez? $\overline{\text { mês }}^{\prime} \overline{\text { ano }}$ $4 A$ - Altura (1) $\mathrm{cm}$.

4B - Altura (2) _ $\mathrm{cm}$.

$5 A$ - Peso (1) __ kg.

2. Data de nascimento da criança:

- ' I -

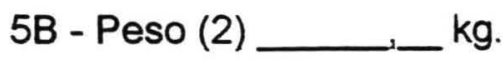

3. Sexo da criança: $\square$
1-Masculino
2-Feminino

\section{Observações:}

4. Naturalidade da criança :

cidade estado

5. Esta criança está com:

1. anemia

2. tosse elou gripe

3. febre

4. outros

6. Esta criança está consumindo algum medicamento/suplemento? $\square$

1-Sim 2-Não

Qual? 
ANEXO 5

- Formulário de antropometria e análise sensorial - Escola 


\section{Código da criança:}

Nome da criança:

Série:

Turma:

\section{ANTROPOMETRIA}

Dia:

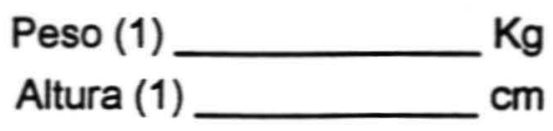

Peso (2) $\mathrm{Kg}$

Altura (2) $\mathrm{cm}$

\section{ANÁLISE SENSORIAL}

Indique para cada amostra se você percebe a presença de algum estimulo (gosto) (diferente $=1$ ) ou não (igual $=0$ ).

Gosto Doce

Dia:

\begin{tabular}{|c|c|c|c|c|c|c|c|c|c|c|c|}
\hline \multicolumn{2}{|c|}{$0,5 \mathrm{~g} / \mathrm{l}$} & \multicolumn{2}{|c|}{$1,0 \mathrm{~g} / \mathrm{l}$} & \multicolumn{2}{c|}{$2,0 \mathrm{~g} / \mathrm{l}$} & \multicolumn{2}{c|}{$4,0 \mathrm{~g} / \mathrm{l}$} & \multicolumn{3}{c|}{$8,0 \mathrm{~g} / \mathrm{l}$} & \multicolumn{3}{|c|}{$16,0 \mathrm{~g} / \mathrm{l}$} \\
\hline 0 & 1 & 0 & 1 & 0 & 1 & 0 & 1 & 0 & 1 & 0 & 1 \\
\hline 0 & 1 & 0 & 1 & 0 & 1 & 0 & 1 & 0 & 1 & 0 & 1 \\
\hline
\end{tabular}

Comentários:

Gosto Salgado

Dia:

\begin{tabular}{|c|c|c|c|c|c|c|c|c|c|c|c|}
\hline \multicolumn{2}{|c|}{$0,09 \mathrm{~g} / \mathrm{l}$} & \multicolumn{2}{|c|}{$0,18 \mathrm{~g} / \mathrm{l}$} & \multicolumn{3}{c|}{$0,37 \mathrm{~g} / \mathrm{l}$} & \multicolumn{3}{c|}{$0,75 \mathrm{~g} / \mathrm{l}$} & \multicolumn{3}{|c|}{$1,5 \mathrm{~g} / \mathrm{l}$} & \multicolumn{3}{|c|}{$3,0 \mathrm{~g} / \mathrm{l}$} \\
\hline 0 & 1 & 0 & 1 & 0 & 1 & 0 & 1 & 0 & 1 & 0 & 1 \\
\hline 0 & 1 & 0 & 1 & 0 & 1 & 0 & 1 & 0 & 1 & 0 & 1 \\
\hline
\end{tabular}

Gosto Azedo

\begin{tabular}{|c|c|c|c|c|c|c|c|c|c|c|c|}
\hline \multicolumn{2}{|c|}{$0,004 \mathrm{~g} / \mathrm{l}$} & \multicolumn{2}{|c|}{$0,008 \mathrm{~g} / \mathrm{l}$} & \multicolumn{3}{|c|}{$0,015 \mathrm{~g} / \mathrm{l}$} & \multicolumn{3}{|c|}{$0,030 \mathrm{~g} / \mathrm{l}$} & \multicolumn{3}{|c|}{$0,062 \mathrm{~g} / \mathrm{l}$} & \multicolumn{3}{c|}{$0,125 \mathrm{~g} / \mathrm{l}$} \\
\hline 0 & 1 & 0 & 1 & 0 & 1 & 0 & 1 & 0 & 1 & 0 & 1 \\
\hline 0 & 1 & 0 & 1 & 0 & 1 & 0 & 1 & 0 & 1 & 0 & 1 \\
\hline
\end{tabular}


Gosto Amargo

Dia:

\begin{tabular}{|c|c|c|c|c|c|c|c|c|c|c|c|}
\hline \multicolumn{2}{|c|}{$0,025 \mathrm{~g} / \mathrm{l}$} & \multicolumn{2}{|c|}{$0,050 \mathrm{~g} / \mathrm{l}$} & \multicolumn{2}{|c|}{$0,100 \mathrm{~g} / /$} & \multicolumn{2}{|c|}{$0,200 \mathrm{~g} / \mathrm{l}$} & \multicolumn{2}{|c|}{$0,400 \mathrm{~g} / \mathrm{l}$} & \multicolumn{2}{|c|}{$0,800 \mathrm{~g} / \mathrm{l}$} \\
\hline 0 & 1 & 0 & 1 & 0 & 1 & 0 & 1 & 0 & 1 & 0 & 1 \\
\hline$\overline{0}$ & 1 & 0 & 1 & 0 & 1 & 0 & 1 & 0 & 1 & 0 & 1 \\
\hline
\end{tabular}

Comentários:

\section{6-n-propiltiouracil (PROP)}

$0,0032 \mathrm{mmol} / \mathrm{l}$

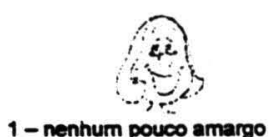

$0,0100 \mathrm{mmol} / \mathrm{l}$

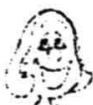

1 - nenhum pouco amargo

$0,0320 \mathrm{mmol} / \mathrm{l}$

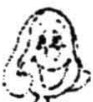

1 - nenhum pouco amargo

$0,1000 \mathrm{mmol} / \mathrm{l}$

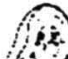

(a)

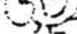

1 - nenhum pouco amargo

$0,3200 \mathrm{mmol} / \mathrm{l}$

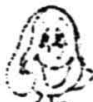

1 - nenhum pouco amargo

$1,0000 \mathrm{mmol} / \mathrm{l}$

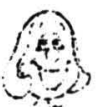

(m):

1 - nenhum pouco amargo

$3,2000 \mathrm{mmol} / \mathrm{l}$

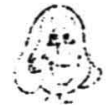

1 - nenhum pouco amargo
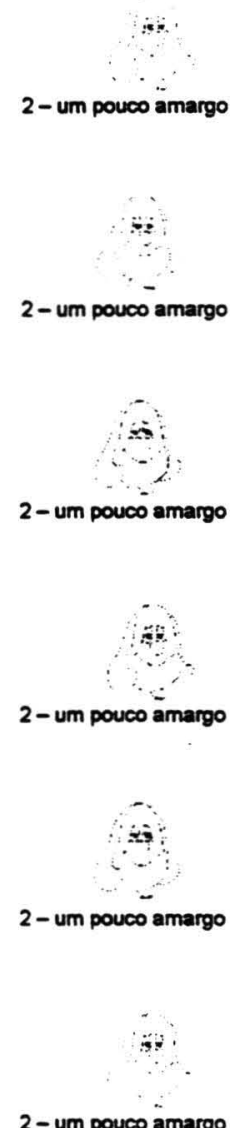

- um pouco amargo

2 - um pouco amargo

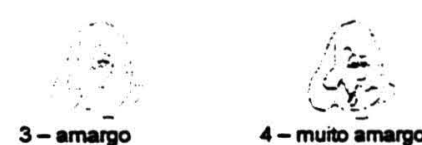

4-muito amargo

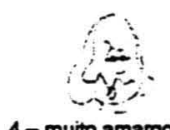

4- muito amargo

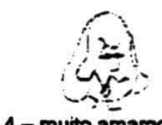

4- muito amargo

3- amargo

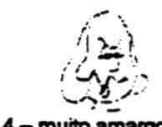

4- muito amargo

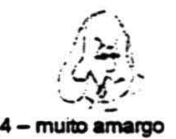

3-amargo

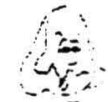

4-muito amargo

3- amargo

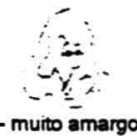

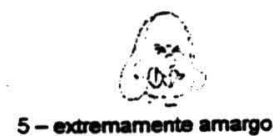
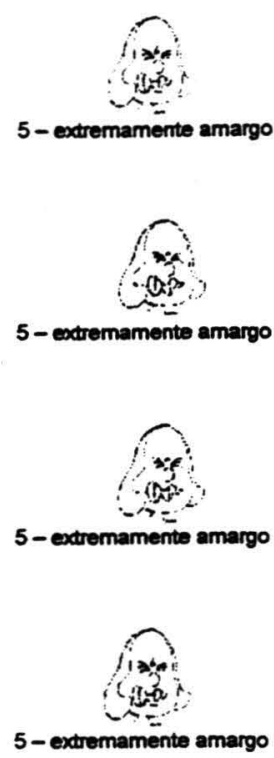

$\rightarrow$

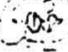

5 - extremamente amargo

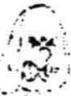

5 - extremamente amargo 


\section{Código da criança:}

Nome da criança:

Sexo da criança: MASCULINO

Série:

Turma:

\section{ANTROPOMETRIA}

Dia:

Peso (1)

Altura (1)
$\mathrm{Kg}$

$\mathrm{cm}$
Peso (2)

Altura (2)
$\mathrm{Kg}$

$\mathrm{cm}$

\section{ANÁLISE SENSORIAL}

Indique para cada amostra se você percebe a presença de algum estímulo (gosto) (diferente $=1$ ) ou não (igual $=0$ ).

Gosto Doce

\begin{tabular}{|c|c|c|c|c|c|c|c|c|c|c|c|}
\hline \multicolumn{2}{|c|}{$0,5 \mathrm{~g} / \mathrm{l}$} & \multicolumn{2}{|c|}{$1,0 \mathrm{~g} / \mathrm{l}$} & \multicolumn{2}{|c|}{$2,0 \mathrm{~g} / \mathrm{l}$} & \multicolumn{2}{|c|}{$4,0 \mathrm{~g} / \mathrm{l}$} & \multicolumn{2}{|c|}{$8,0 \mathrm{~g} / \mathrm{l}$} & \multicolumn{2}{|c|}{$16,0 \mathrm{~g} / \mathrm{l}$} \\
\hline 0 & 1 & 0 & 1 & 0 & 1 & 0 & 1 & 0 & 1 & 0 & 1 \\
\hline 0 & 1 & 0 & 1 & 0 & 1 & 0 & 1 & 0 & 1 & 0 & 1 \\
\hline
\end{tabular}

Gosto Salgado

\begin{tabular}{|c|c|c|c|c|c|c|c|c|c|c|c|}
\hline \multicolumn{2}{|c|}{$0,09 \mathrm{~g} / \mathrm{l}$} & \multicolumn{2}{|c|}{$0,18 \mathrm{~g} / \mathrm{l}$} & \multicolumn{2}{|c|}{$0,37 \mathrm{~g} / \mathrm{l}$} & \multicolumn{2}{|c|}{$0,75 \mathrm{~g} / \mathrm{l}$} & \multicolumn{2}{|c|}{$1,5 \mathrm{~g} / \mathrm{l}$} & \multicolumn{2}{|c|}{$3,0 \mathrm{~g} / \mathrm{l}$} \\
\hline 0 & 1 & 0 & 1 & 0 & 1 & 0 & 1 & 0 & 1 & 0 & 1 \\
\hline 0 & 1 & 0 & 1 & 0 & 1 & 0 & 1 & 0 & 1 & 0 & 1 \\
\hline
\end{tabular}

Gosto Azedo

\begin{tabular}{|c|c|c|c|c|c|c|c|c|c|c|c|}
\hline \multicolumn{2}{|c|}{$0,004 \mathrm{~g} / \mathrm{l}$} & \multicolumn{2}{|c|}{$0,008 \mathrm{~g} / \mathrm{l}$} & \multicolumn{2}{|c|}{$0,015 \mathrm{~g} / \mathrm{l}$} & \multicolumn{2}{|c|}{$0,030 \mathrm{~g} / \mathrm{l}$} & \multicolumn{2}{|c|}{$0,062 \mathrm{~g} / \mathrm{l}$} & \multicolumn{2}{|c|}{$0,125 \mathrm{~g} / 1$} \\
\hline 0 & 1 & 0 & 1 & 0 & 1 & 0 & 1 & 0 & 1 & 0 & 1 \\
\hline 0 & 1 & 0 & 1 & 0 & 1 & 0 & 1 & 0 & 1 & 0 & 1 \\
\hline
\end{tabular}

Comentários: 
Gosto Amargo

Dia:

\begin{tabular}{|c|c|c|c|c|c|c|c|c|c|c|c|}
\hline \multicolumn{2}{|c|}{$0,025 \mathrm{~g} / \mathrm{l}$} & \multicolumn{2}{|c|}{$0,050 \mathrm{~g} / \mathrm{l}$} & \multicolumn{2}{c|}{$0,100 \mathrm{~g} / \mathrm{l}$} & \multicolumn{2}{c|}{$0,200 \mathrm{~g} / \mathrm{c}$} & \multicolumn{2}{|c|}{$0,400 \mathrm{~g} / \mathrm{l}$} & \multicolumn{3}{c|}{$0,800 \mathrm{~g} / \mathrm{l}$} \\
\hline 0 & 1 & 0 & 1 & 0 & 1 & 0 & 1 & 0 & 1 & 0 & 1 \\
\hline 0 & 1 & 0 & 1 & 0 & 1 & 0 & 1 & 0 & 1 & 0 & 1 \\
\hline
\end{tabular}

Comentários:

\section{6-n-propiltiouracil (PROP)}

$0,0032 \mathrm{mmol} / \mathrm{l}$
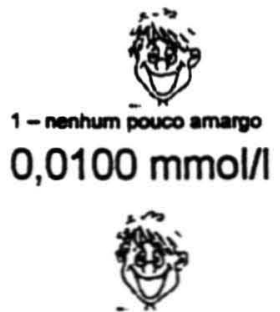

1 - nenhum pouco amargo $0,0320 \mathrm{mmol} / \mathrm{l}$

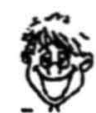

1- nenhum pouco amargo $0,1000 \mathrm{mmol} / \mathrm{I}$

1 - nenhum pouco amargo $0,3200 \mathrm{mmol} / \mathrm{l}$

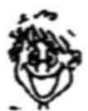

1 - nenhum pouco amargo $1,0000 \mathrm{mmol} / \mathrm{l}$

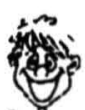

1 - nenhum pouco amargo $3,2000 \mathrm{mmol} / \mathrm{l}$

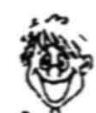

1 - nenhum pouco amargo
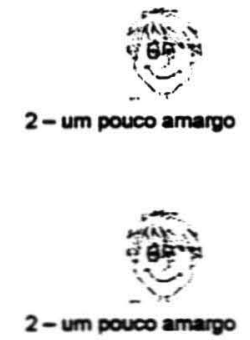

2 - um pouco amargo
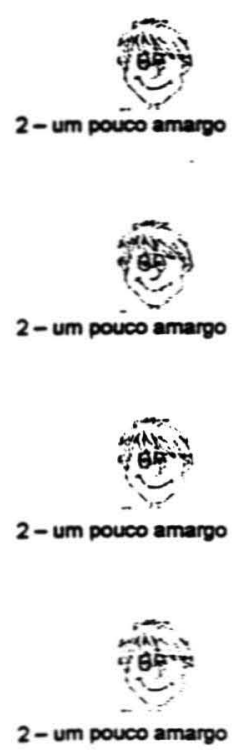

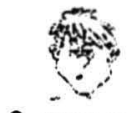

3-amargo

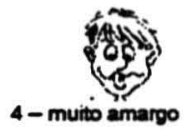

5- extremamente amargo

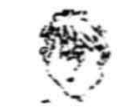

3-amargo
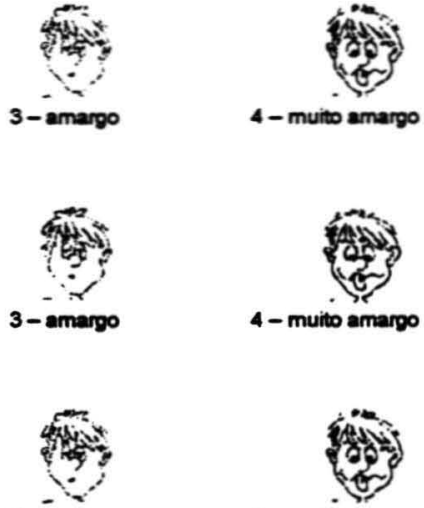

3-amargo
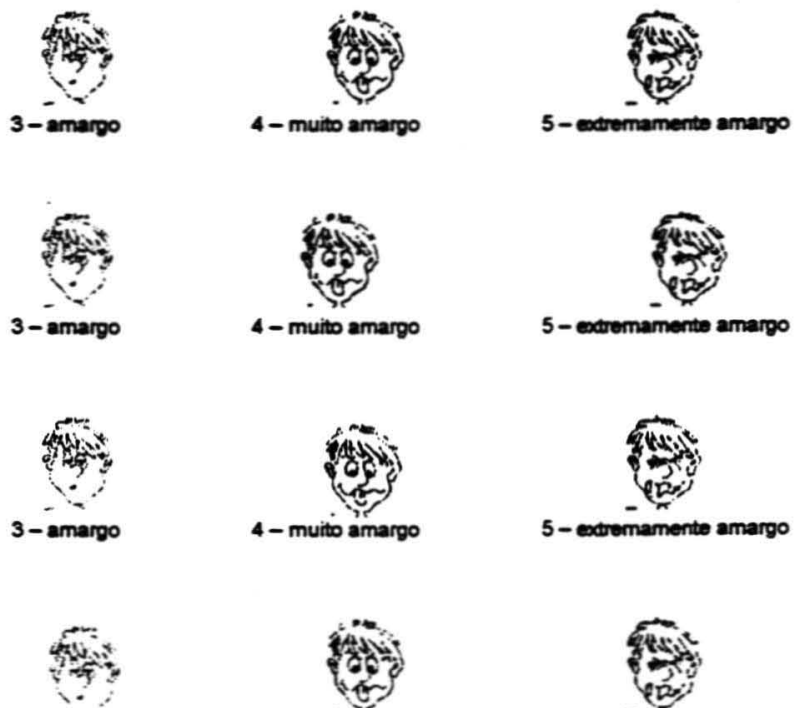

3- amargo
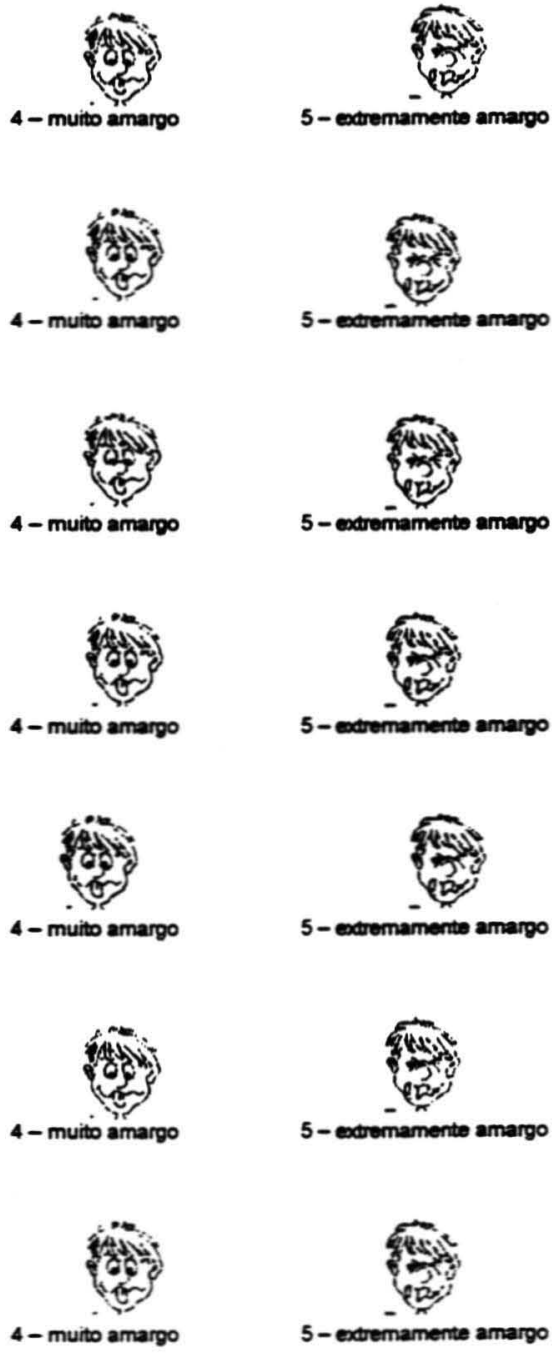
ANEXO 6

Formulário de saúde da criança-

Escola 
Nome da criança:

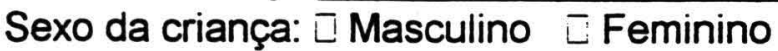
Naturalidade:

cidade $\frac{1}{\text { estado }}$

Data de nascimento: Descendência:

A criança está tomando algum medicamento ou suplemento?

(ex.: japonesa, italiana, índia, ...)

$\square$ Não $\square$ Sim. Qual?

A criança está com:

$\begin{array}{llllll}\text { Febre? } & \square \text { Não } & \square \text { Sim. } & \text { Tosse/gripe? } & \square \text { Não } & \square \text { Sim. } \\ \text { Amigdalite? } & \square \text { Não } & \square \text { Sim. } & \text { Alergia/Rinite? } & \square \text { Não } & \square \text { Sim. } \\ \text { Anemia? } & \square \text { Não } & \square \text { Sim. } & \text { Outra doença? } & \square \text { Não } & \square \text { Sim. }\end{array}$

Anemia? $\square$ Não $\square$ Sim. Outra doença? $\square$ Não $\square$ Sim.

Qual?

A criança pratica algum tipo de atividade física? $\square$ Não $\square$ Sim.

Quantas horas por semana?

Quantas horas por semana a criança passa assistindo televisāo?

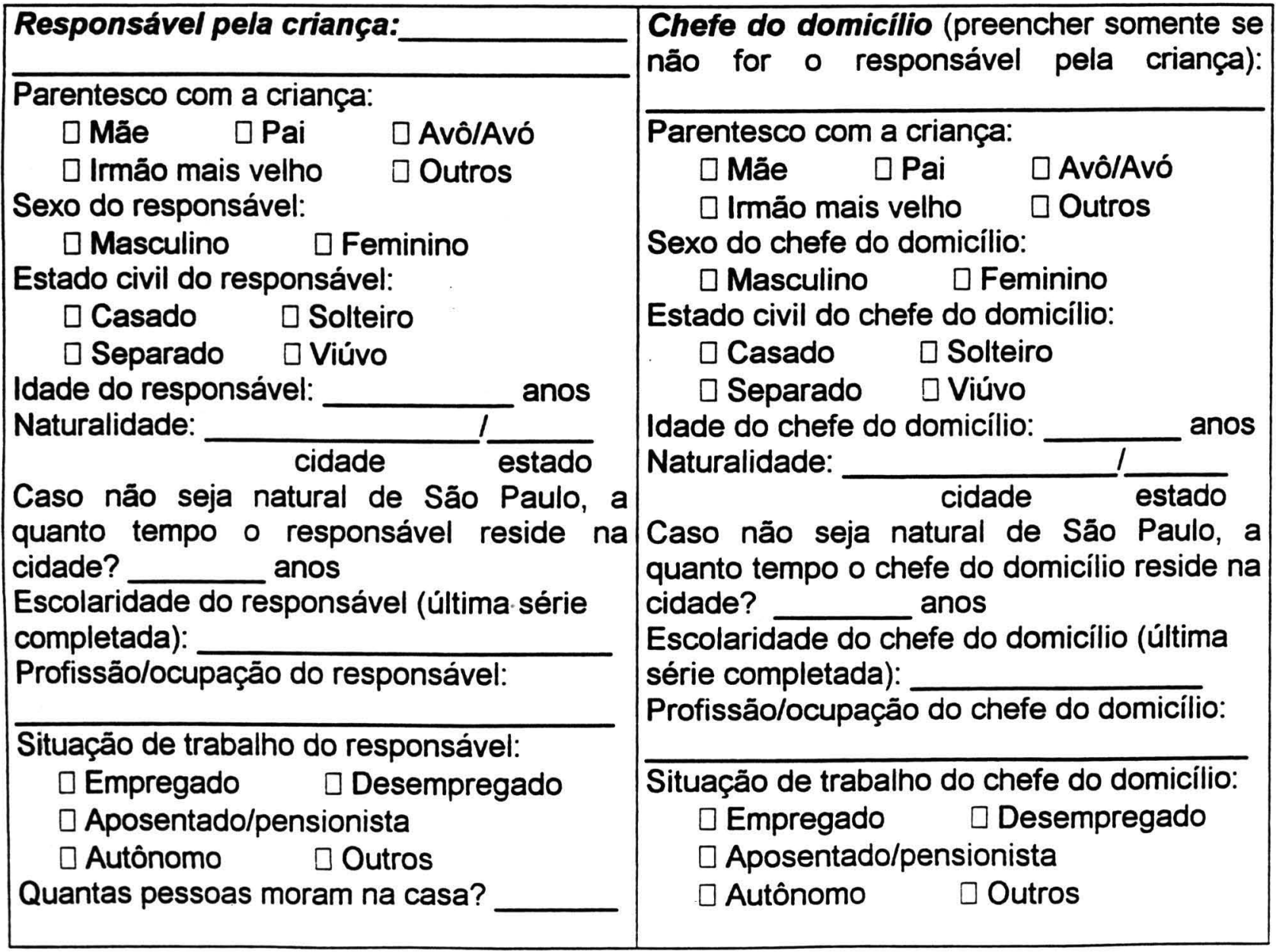


ANEXO 7

Formulário de análise sensorial -Creche 
Ficha de Análise Sensorial

\begin{tabular}{|ll|l|}
\hline & $\begin{array}{c}\text { Teste Sensorial } \\
\text { CRECHE }\end{array}$ & Ficha $\mathrm{n}^{\circ}$ \\
\hline Nome: & Data de nasc:_'___ \\
\hline
\end{tabular}

\begin{tabular}{|c|c|c|c|c|c|c|c|c|c|c|c|}
\hline & & & & & & & & Dia & 1 & & \\
\hline $\begin{array}{l}\text { Indio } \\
\text { estim }\end{array}$ & gos & an & se & $\hat{\mathrm{e}} \mathrm{F}$ & e & & & (Igu & $a$ & nça & \\
\hline & & & & & & & & & & & \\
\hline 0 & 1 & 0 & 1 & 0 & 1 & 0 & 1 & 0 & 1 & 0 & 1 \\
\hline 0 & 1 & 0 & 1 & 0 & 1 & 0 & 1 & 0 & 1 & 0 & 1 \\
\hline
\end{tabular}

\begin{tabular}{|c|c|c|c|c|c|c|c|c|c|c|c|}
\hline \multicolumn{8}{|c|}{ Salgado } & \multicolumn{4}{|c|}{ Dia _L_ I_ } \\
\hline \multicolumn{12}{|c|}{$\begin{array}{l}\text { Indique, para cada amostra, se você percebe (Diferente=1) ou não (Igual=0) a presença de algum } \\
\text { estímulo (gosto) }\end{array}$} \\
\hline \multicolumn{2}{|c|}{0.09} & \multicolumn{2}{|c|}{0.18} & \multicolumn{2}{|c|}{0.37} & \multicolumn{2}{|c|}{0.75} & \multicolumn{2}{|c|}{1.5} & \multicolumn{2}{|c|}{3} \\
\hline 0 & $\overline{1}$ & $\overline{0}$ & 1 & 0 & 1 & 0 & 1 & 0 & 1 & 0 & 1 \\
\hline 0 & 1 & 0 & 1 & 0 & 1 & 0 & 1 & 0 & 1 & 0 & 1 \\
\hline
\end{tabular}

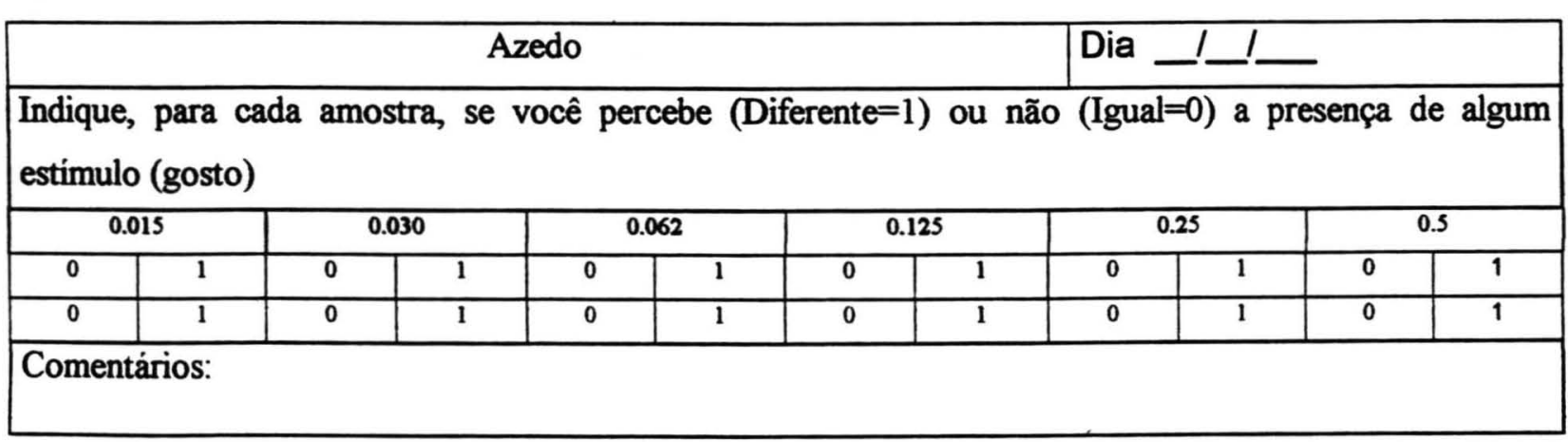

\begin{tabular}{l|l} 
Amargo & Dia _L_- -
\end{tabular}

Indique, para cada amostra, se você percebe (Diferente=1) ou não (Igual=0) a presença de algum estimulo (gosto)

\begin{tabular}{|c|c|c|c|c|c|c|c|c|c|c|c|}
\hline \multicolumn{2}{|c|}{0.012} & \multicolumn{2}{|c|}{0.025} & \multicolumn{2}{|c|}{0.05} & \multicolumn{2}{|c|}{0.1} & \multicolumn{2}{|c|}{0.2} & \multicolumn{2}{|c|}{0.4} \\
\hline 0 & 1 & 0 & 1 & 0 & 1 & 0 & 1 & 0 & 1 & 0 & 1 \\
\hline 0 & 1 & 0 & 1 & 0 & 1 & 0 & 1 & 0 & 1 & 0 & 1 \\
\hline
\end{tabular}

Comentários: 